\title{
Über primäre Beckenknochensarkome (mit einer Zusammenstellung von 178 Beckensarkomfälle aus der Literatur und einem selbst beobachteten Fall).
}

Von Max Schmidseder, Medizinalpraktikant aus Baumgarten (Niederbayern).

Unter den im allgemeinen selten zur klinischen Beobachtung kommenden Geschwülsten des knöchernen Beckenringes nimmt das Sarkom sowohl nach Häufigkeit als hinsichtlich seiner Bösartigkeit die erste Stelle ein. Es kann wie alle vom Knochen ausgehenden Sarkome als periostale und als myelogene Neubildung auftreten.

Die periostalen Sarkome, die im Gegensatz zum Fibrom von der inneren Schicht des Periostes ausgehen, wobei dessen ïußere Lage noch längere Zeit als fibröser Überzug der Neubildung, diese in ihrem Wachstum hemmend, erhalten bleiben kann, sind meist harte, feste Tumoren. Manchmal sind es Mischgeschwülste, wie Fibro-, Myxo-, Lipo-, Chondro-, Osteo- und Osteoidsarkome. Nicht selten enthalten sie Partien, die fast rein den Charakter des Fibroms, Chondroms, namentlich des Osteoidchondroms oder des Osteoms an sich haben und von denen aus man dic allmählichen Übergänge zum Sarkom verfolgen kann.

Der unter solchen periostalen Sarkomen liegende Knochen erhält sich in der Regel wenigstens teilweise, ja er wird sogar oft sklerotisch. Nur da, wo unter der dünneren Corticalis sich Spongiosa befindet, wie das bei den Beckenknochen der Fall ist, vermag dic Geschwulstmasse in den Knochen hineinzuwuchern und so den Unterschied zwischen periostalem und myelogenem Ursprung zu verwischen. Auch der Knorpel ist sehr resistent gegen dic periostalen Sarkome.

Wird die oben genannte fibröse Kapsel durchbrochen, so beginnt cin rapides Durchwuchern der Lmgebung, Gefäße und Nerven werden umwachsen, zuweilen Venenwandungen durchbrochen und Thrombosen, Embolien, Metastasen, diese besonders in den Lungen, sind die Folge.

Der Durchschnitt durch cin periostales Sarkom bietet eine weißlich-gelbe, oft graulich durchscheinende Fläche; durch Hämorrhagien kann diese ein geflecktes, rötlich-braun bis braungelb marmoriertes Aussehen bekommen. Die Konsistenz ist fest, zuweilen speckig. An 
der Basis einer solchen Geschwulst, wo sich häufig cin dichtes, feinbalkiges Skelett von Knochennadeln findet, das sowohl als Umwandlungsprodukt der spezifischen Sarkomelemente, sowic auch als rein periostische Bildung gedeutet werden kann, kann die ganze Partie Aussehen und Konsistenz der Spongiosa crhalten.

Mikroskopisch erweisen sich dic periostalen Sarkome vorwiegend als Spindelzellensarkome; in den jüngsten, oberflächlichsten Partien sind auch Rundzellen vorhanden. Auch reine Rundzellensarkome kommen zur Beobachtung. Riesenzellen finden sich in den periostalen Sarkomen der Beckenknochen fast nie. In seltenen Ausnahmefällen können periostale Sarkome auch markzcllenhaltiges Gcwebe enthalten (v. H a n s e m a n $n$ ). Die Interzeliularsubstanz ist im allgemeinen sehr spärlich vorhanden; doch kann sie bei festeren Formen durch eine reichlichere Entwicklung und ausgesprochenen fibrillären Charakter dem Gewebe einen alveolären Bau verleihen.

Die zweite Gruppe der Knochensarkome entsteht entweder von den Endost-Zellen oder von den Markzellen aus. R i b b e rt teilt die Sarkome des Knochensystems ein in periphere und zentrale, da nach ihm die sogenannten periostalen Sarkome von den peripheren Teilen der Spongiosa, die myelogenen im Innern des Knochens entstehen und bei den letzteren die Abstammung des Tumors von Elementen des Markes erst jedesmal bewiesen werden muß. Meist liegt der Ursprung der sogenannten myelogenen Sarkome nicht in der eigentlichen Markhöhle; es sind spongiöse Knochen, die von dieser Art der Neubildung befallen werden. Die Diploë der Beckenknochen bildet so einen geeigneten Boden für dic Entwicklung von myclogenen Sarkomen.

Es sind dicse zentralen oder myelogenen Sarkome im weiteren Sinne meist weiche Geschwülste von markähnlicher, durch Überreste von Knochengewebe zuweilen sandiger Konsistenz und mit weißlicher bis grau-rötlicher Schnittfläche. Unter ihrem Wachstum gelangt innen der Knochen zur Resorption, außen aber wird oft Knochen gebildet und es entsteht dann eine Knochenschale, die oft nur mit zerfallenem Geschwulstgewebe und Blutgerinnscln erfült ist. In anderen Fällen hält diese ossifizierende Tätigkeit des P'eriostes auf die Dauer nicht stand. Es bilden sich auf der Schale dünne, nachgiebige Partien, welche dem Fingerdruck unter dem charakteristischen Pergamentknistern nachgeben. Dicse Partien dehnen sich mehr und mehr aus und perforieren schließlich. Unregclmäßige iiber dic Geschwulstoberfläche inselartig verbreitete Knochenblättchen verraten zuletzt noch dic früher vorhanden gewescne Knochenschale. So kann es kommen, daß cin myelogenes Sarkom sich als ein fluktuierender Tumor präsentiert. Frei von jenem Panzer aber wächst nun die Geschwulst in beschleunigtem Tempo weiter nach außen.

Manchmal findet sich auch im Innern eincs myelogenen Sarkoms 
Knochengewebe, man spricht dann von einem myclogenen Osteosarkom oder es ist bloß osteoides Gewebe vorhanden und es wird dann als Osteoidsarkon bezeichnet.

Zuwcilen findet sich in den myelogenen Sarkomen eine enorme Gefäßentwicklung in Form von weiten und sinuösen Kapillaren, so daB man nach $Z$ iegler von einem teleangiektatischen Gewebe sprechen kann. In den blutrcichen Gefäßen kommt es zu Stauungen und eine geringe äußere Veranlassung führt zu Blutungen. Es entstchen so durch zahlreiche größere und kleinere Extravasationen bedingte hämorrhagische Herde und Infiltrationen, welche sich oft durch das ganze Geschwulstparenchym ausbreiten. Die dabei entstehenden hämorrhagischen Erweichungsherde sind keine wahren Cysten, denn es fehlt ihnen eine sie auskleidende, mit Epithel überzogene Membran. Durch diesen großen Blutreichtum mancher myelogener Sarkome kommt es oft zu Pulsation, welche cin Aneurysma vortäuschen kann.

Kommen Konsistenzveränderungen durch regressive Metamorphosen schon bei den periostalen Sarkomen vor, so sind diese Erscheinungen bei den weichen, blutreichen myelogenen ungemein häufig. Durch Verfettungen, Erweichungen, Blutungen ,geht unter Umständen der größte Teil der Geschwulst verloren und es bleiben nur die knöcherne Schale sowie cine spärliche Menge (ieschwulstgewebe übrig, welch letzteres teils der Innenwand der Schale anhängt, tcils anastomosierende Balken und Scheidewände bildet, welche trübe oder geklärte, weißlich oder hämorrhagisch gefärbte, mit Zerfallsmassen untermischtc Flüssigkeit cinschließen" (Zi $\circ \mathrm{gl}$ ler).

Was dic Zellformen der myelogenen Sarkome anlangt, so sind es meist Rundzcllensarkome, auch Spindelzellensarkome und polymorphzellige Sarkome kommen vor. Relativ am unschädlichsten unter den myelogenen Sarkomen sind die Ricsenzellensarkome oder Tumeurs à myćloplaxes (Nélaton). Wie bei den periostalen, so gibt es auch bei den myelogenen Sarkomen sogenannte Alveolärsarkome, die dann entstehen, wenn ein alveolär gebautes Bindegewebsstruma gebildet wird.

Es ist hier noch eine besondere Geschwulstform zu erwähnen, nämlich das Myclom, eine sehr verschieden aufgefaßte, von manchen Autoren zu den myelogenen Rundzellensarkomen gerechnete Erkrankung des roten Knochenmarks. Es besteht in Bildung multipler Herde von pulpöser oder festerer Konsistenz und dunkelroter, sraurötlicher bis graugelber Farbe. Geht dic erste Entwicklung dicser Herde lediglich mit einer kariösen Zerstörung der Spongiosa einher ohne äußere Veränderung, so kann der weitere Verlauf ganz wie der oben bei den myelogenen Sarkomen geschilderte sein: Es tritt Auftreibung des Knochens ein, es kann cine Schale gebildet und dann durchbrochen werden, so daß schließlich das weiche Gewebe frei zutage tritt. Nach Borst unterscheidet sich das Myclom vom myelogenen 
Rundzellensarkom durch die Abwesenheit der Mycloplaxen, durch das primär gleichzeitig multiple Befallenwerden des Markes, durch das Beschränktbleiben auf den Knochen und die fehlende Metastasenbildung. Nach ihm werden die typischen, reinen Fälle von multiplem Myelom am besten der aleukämischen Lymphombildung (Pseudoleukämie) zugerechnet und als besondere Form derselben aufgefaßt.

Die Zellen in den Myelomen tragen noch den Charakter der im Knochenmark vorhandenen Zellen; es sind im wesentlichen Rundzellen, meist gleichmäßig verteilt, seltener gruppenweise vereinigt in einem retikulären Stützgewebe.

Es ist beim Myelom meist die Blutzusammensetzung nicht ganz normal; vor allem machen solche Neubildungen eine auffallende Anämie. Von pathognomonischer Wichtigkeit ist nach $\mathrm{Vig} n$ a rd und Gallavardin das Vorkommen des B ence-Jones schen Körpers im Harn, einer Albumose, welche sich beim Kochen löst und bei Abkühlung auf 50-60 Grad ausfällt.

Einige Male wurden auch Melanosarkome der Beckenknochen beobachtet. Es sind dies rasch wachsende, meist mit reichlicher Gefäßbildung ausgezeichnete Geschwülste von bräunlichcr oder schwarzer, ja sepiaartiger Farbe mit hochgradiger Neigung zu örtlicher Destruktion und Metastasenbildung. Sie enthalten ncben gewöhnlichen Sarkomzellen - es können Rund- und Spindelzellen sein, groß und klein. manchmal in alveolärer Anordnung - zahlreiche Pigmentzellen. Auch Wanderzellen, junge Gewebszellen, ferner Endothelien der Kapillaren und Lymphgefäße können pigmenticrt sein. Das intrazcllulär gelegene Pigment durchtränkt anfangs die Zellen diffus, später bildet es in derselben feinere oder gröbere Körnchen. Es findet sich jedoch Pigment auch frei im Gewebe. Der Herkunft nach ist alles Pigment in Melanosarkomen wahrscheinlich hämatogen.

Die genannten verschiedenen Sarkomarten verteilen sich auf die einzelnen Beckenknochen nach früheren Statistiken folgendermaßen: Die periostalen Sarkome, namentlich auch in Form von Chondrosarkomen, kommen besonders häufig am Darmbein vor, aber auch myelogene Riesenzellensarkome haben dort manchmal ihren Ursprung. Der Lieblingssitz dieser letzteren ist jedoch das Kreuzbein. Aber auch hier hat man kleinzellige, pulsierende, periostale Sarkome gefunden. Mischgeschwülste, wie Fibro-, Myxo-, Fibromyxosarkome, finden sich mit Vorliebe in der Gegend des Kreuzbeins, lateralwärts von der Synchondrosis sacroiliaca und der Linea innominata.

Was nun die Häufigkeit der sarkomatösen Erkrankung der einzelnen Knochen des Beckenringes betrifft, so findet sich 
eine auffallende Prädilektionsstelle für die Sarkome in der Fossa iliaca interna und externa, besonders im mittleren Teil der Darmbeingrube, das heißt in der Gegend nach außen von den Gefäßen und Nerven. Das rechte Darmbein scheint nach manchen Statistiken etwas häufiger befallen zu sein als das linke. Verhältnismäßig ziemlich häufig ist dann die Gegend der Articulatio sacroiliaca, seltener das Kreuzbein oder das Schambein oder vollends das Sitzbein Ausgangspunkt einer derartigen Neubildung. Tillmanns (Deutsche Chir., Liefg. 62a) fand unter I Io Fällen 53 Sarkome des Darmbeins, 22 des Kreuzbeins, 4 des Schambeins. Unter den Fällen, die Viktor Freymadl zusammenstellte, fanden sich 5 Sarkome des Os ilium dextr., 5 des Os ilium sin., I des Os pub., o des Os ischii, I des Os coccygis, 7 des Os sacrum. Neben diesen Fällen, wo nur ein einziger Knochen erkrankt war, waren in 6 Fällen der Statistik Freymadls mehrere Beckenknochen ergriffen, ohne daß der Ausgangspunkt zu bestimmen war.

Ti $11 \mathrm{~m}$ an $\mathrm{ns}$ fand in seinen 166 Sarkomen der Beckenknochen keinen Fall, der auf das Sitzbein allein beschränkt war. Nach ihm gehen die hier entstehenden Sarkome rasch auf das Schambein über. Zwei oder mehrere Knochen waren in 20 Fällen befallen.

Unter den 60 Fällen Braunsteins finden sich nur 4 reine Sarkome des Kreuzbeins und 3, bei denen dasselbe mitergriffen war.

Wenn wir das Alter der Patienten in Betracht ziehen, so ist, abgesehen von den relativ häufig zwischen dem I6. und 20. Jahr vorkommenden Sarkomen der Sexualdrüsen und der Epiphysen der langen Röhrenknochen, das Sarkom bekanntlich eine Erkrankung des mittleren Lebensalters. Doch wird das Beckensarkom in allen Altersstufen vom Neugeborenen angefangen beobachtet. Weitaus die meisten Fälle allerdings fallen in das jugendliche und mittlere Lebensalter. Bei den Fällen Tillmanns schwankt das Alter zwischen 6 Monaten und 68 Jahren.

Was das Geschlecht betriff, so werden ebenso viele Frauen wie Männer von Sarkomen der Beckenknochen befallen im Gegensatz zu den Sarkomen an allen anderen Körperstellen, wo die Disposition der Männer eine größere ist. In der geschlechtsreifen Zeit jedoch, also vom I 5.--50. Lebensjahr, sind die Frauen für die Beckensarkome mehr disponiert als die Männer. 
Karl Güldn e r fand bei 89 Fällen folgendes: Es waren 47 Männer und 42 Weiber betroffen. Von Männern nach dem 50. Jahr fanden sich I6, von Frauen nur 2 Fällc; bei Männern unter I 5 Jahren kein Fall, bei Frauen 3 Fälle.

Die Symptomatologie der Beckenknochensarkome zeichnet sich durch eine große Mannigfaltigkeit aus. Es ist dies leicht erklärlich, wenn man bedenkt, daß diese unaufhaltsam in die Nachbarschaft fortschreitenden Geschwülste an einem Knochenring sitzen, der eine große Zahl wichtiger Organe umschließt, der den Halt für wichtige Ausfuhrkanäle aus dem Körper bildet, durch und um den eine Unmenge großer und kleiner Gefäße und Nerven ziehen.

Drei Umstände sind es vor allem, welche die verschiedenen Symptome der Beckenknochensarkome bedingen, nämlich deren Sitz, deren Ausdehnung sowohl im Knochen als auch über dessen Niveau hinaus, endlich ihr histologischer Aufbau. Außen am Beckenring sitzende Sarkome machen andere Erscheinungen als solche, die an der Innenwand lokalisiert sind. Von größter Wichtigkeit ist es, ob ein Beckenknochensarkom in der Nähe von größeren Gefäßen oder Nerven sitzt. Auch darauf kommt es an, ob ein Sarkom bloß im Knochen seine zerstörende Tätigkeit ausübt, wieviel es von dem Knochen zugrunde richtet, ob es als ein großer Höcker in das Becken vorspringt. Ein Knochen oder Knorpel enthaltendes Sarkom ferner wird andere Symptome machen als eines, das sich aus teleangiektatischem Gewebe aufbaut.

Wohl immer und charakteristischerweise fast ausnahmslos als erstes Symptom stellen sich Schmerzen ein, sei es lokal, sei es an dem der erkrankten Beckenhälfte zugehörigen Bein, Knie oder Fuß, in seltenen Fällen an beiden Beinen. Überaus häufig treten die Schmerzen in Form einer manchmal geradezu unerträglichen Neuralgie des Nervus obturatorius und besonders des Nervus ischiadicus auf, die ganz plötzlich, ohne eine erkennbare Ursache einsetzt und im Gegensatz zur eigentlichen Ischias intermittierend ist. Sehr oft sind an der entsprechenden Extremität Parästhesien vorhanden, manchmal Hyperästhesie, seltener Anästhesie. Einzelne nervöse Bezirke der Beckengegend können gefühllos werden. Es kann sich ein Gefühl der Müdigkeit und 
Schwere sowie Fremdkörpergefühl im Becken einstellen. Sitzen, Stehen, Gehen oder Liegen können nahezu unmöglich sein. Bei etwas beweglichen Tumoren können die Störungen sich ändern mit einer Änderung der Körperlage. In den Muskeln, deren Nerven komprimiert oder von der Geschwulst umwachsen sind, treten manchmal Zuckungen und Zittern, Kontraktionen ein, sogar Lähmungen der entsprechenden unteren Extremität im Bereich des Nervus ischiadicus, femoralis werden hier und da beobachtet. Sehr oft sieht man ein Nachschleppen des Beines beim Gehen.

Sitzt das Sarkom in der Nähe des Hüftgelenks, so kann es je nach der Lage und Größe die Funktionen desselben in hohem Grade becinträchtigen, es kann Flexions-, Abduktionsstellung bewirken. Hat es das Gelenk selbst ergriffen, so werden natürlich koxitische Symptome, scharf lokalisierter Schmerz, weitgehende Funktionsstörungen, oft Luxation, Frakturen, Verkürzung des Beines dic Folge sein.

Durch Kompression der Venen von außen, andererseits aber auch durch Wucherung des Sarkoms in das Venenlumen hinein bilden sich übcraus häufig und manchmal bereits sehr frühzcitig starke Ödeme der unteren Extremität, nicht selten doppelseitig. Auch kommt es dadurch oft zur Bildung von Varicen, durch deren Platzen mehrfach hochgradige Blutungen gesehen wurden. Wird, was seltener der Fall ist, eine Arterie zum Verschluß gebracht, so zeigt sich dies durch Anämie, Kühle, Müdigkeit und Abmagerung des betreffenden Beines an, sowie durch die verspätete und niedrige Pulswelle im Vergleich zu der in der entsprechenden Arterie der anderen Extremität. Wird eine Arterie arrodiert, so kann eine lebensgefährliche Blutung eintreten.

Ungemein häufig bewirken Sarkome der Beckenknochen, namentlich wenn sie in das Beckeninnere selbst vordringen und einen erheblicheren Umfang erreicht haben, cine Verlagerung und Kompression der Beckenorgane, vor allem des unteren Teiles des Dickdarms, seltener des Anus. Hochgradige Verstopfung ist meist die Folge, wenn nicht durch die venöse Stauung Diarrhöen verursacht werden. Die Obstipation wieder führt zu Allgemeinerkrankungen, Appetitlosigkeit, psychischer Depression; Meteorismus, Koliken, Ileus und seine Folgen können sich 
einstellen. Sehr oft treten auch Störungen in den Funktionen des Harnapparates auf und manchmal stehen diese Symptome sehr im Vordergrund des Krankheitsbildes. Es kann nämlich die Urethra komprimiert werden, der Blasenhals kann, während der Fundus vesicae selbst ohne wesentliche Beeinträchtigung dem Druck auszuweichen vermag, so verschoben werden, daß eine Knickung der Urethra an der im Beckenbindegewebe festsitzenden Pars membranacea zustande kommt oder aber „die Urethra tangential zur Blase gestellt wird und es so zu einem ventilartigen Verschluß kommt". Wird das Lumen der Harnröhre nicht vollständig verschlossen, so können die Kranken meist in gewissen Stellungen Urin entleeren, z. B. beim Stehen mit stark vornüber gebeugtem Körper. Cystitis, Pyelitis, Pyelonephritis sind natürlich fast immer mit diesen Störungen der Blasenentleerung verknüpft. Auch die Ureteren können, besonders an ihren Mündungen, komprimiert, sie können geknickt werden; in seltenen Fällen findet eine vollständige Obliteration derselben statt. Unter dumpfen Schmerzen entwickelt sich Hydronephrose. Die Anurie verläuft allerdings in diesen Fällen meist nicht unter akuten Erscheinungen, sondern es wechseln Exacerbationen ab mit kürzer oder länger dauernden Zeiten relativen Wohlbefindens, doch kann es gelegentlich auch zu Urämie kommen. Beim weiblichen Geschlecht ist noch besonders Verlagerung und Kompression der Vagina und des Uterus durch Sarkome der Beckenknochen zu erwähnen. Es können diese hochgradige Dystokien verursachen, ja eine Geburt auf natürlichem Wege vollständig unmöglich machen. Es sind in der Literatur verhältnismäßig viele Fälle beschrieben, wo infolge eines Beckenknochensarkoms bei der Geburt Mutter und Kind zugrunde gingen oder wo die Mutter nur durch Tötung des Kindes gerettet werden konnte.

Als bösartige Neubildungen machen dann die Sarkome der Beckenknochen, namentlich wenn sie eine gewisse Größe erreicht haben, allerdings nicht in allen Fällen, allgemeine von der tiefgreifenden Störung im Haúshalte des Organismus zeigende Symptome: Schon von Anfang an ist merkwürdigerweise oft leichtes Fieber vorhanden. Nach und nach aber entwickelt sich das Bild der fortschreitenden Kachexie, nach Borst und Rib- 
bert hauptsächlich infolge der Autointoxikation durch Resorption von Stoffen, welche durch Gewebszellen oder durch die spezifische Tätigkeit der Geschwulstzellen selbst geliefert werden.

Für das Myelom speziell gibt $T$. v. Verebély folgende allgemeine Symptome an:

a) Veränderung des Blutes, die meist eine einfache Anämie ist;

b) Fieber, zum Teil als Folge von Komplikationen, zum Teil als primäres Symptom des Knochenmarkschwundes (Nothnagel, $\mathrm{Kammer}$; in letzterem Falle hat es einen intermittierenden Charakter;

c) Albumosurie, beziehungsweise Auftreten der Bence-Jonesschen Mischung im Harn. - Dieser Bence-Jonessche Eiwcißkörper, der von $\mathrm{K}$ ü h ne als Albumose crkannt wurdc, ist übrigens auch für alle anderen myclogenen Tumoren pathognomonisch. ElIinger hat diesen Körper auch im Blut und in der Ascitesflüssigkeit nachgewiesen.

Die Diagnose der Sarkome der Beckenknochen kann in manchen Fällen überaus leicht sein, kann aber unter Umständen auch nahezu unüberwindliche Schwierigkeiten bieten, besonders in den allerersten Stadien ihrer Entwicklung. Es wird natürlich ein außen am knöchernen Beckenring sitzendes Sarkom in der Regel leichter zu diagnostizieren sein als ein in der Beckenhöhle verborgenes, einmal schon deswegen, weil es der Untersuchung besser zugänglich ist, ganz besonders aber, weil der differentialdiagnostische Kreis für dasselbe ungleich enger gezogen ist.

Wichtige Anhaltspunkte wird in beiden Fällen sehr oft dic Anamnese über Ätiologie, Wachstum der Geschwulst liefern. Ein außen am Knochen lokalisiertes Sarkom bietet sich natülich schon sehr oft der bloßen Adspektion, besonders aber der Palpation frühzeitig als kleinerer oder größerer Tumor dar. Auch ein von der Innenseite des knöchernen Beckenringes entspringendes Sarkom wird unter Umständen die Bauchdecken sichtbar vorwölben. Diese sind, wenn nicht von der Geschwulst mitergriffen, uiber dieser verschieblich und fallen an der Circumferenz der Vorwölbung steil ab. In der Mehrzahl der Fälle wird ein solches im Innern des Beckens gelegenes Knochensarkom durch genauestc bimanuelle Untersuchung per rectum bzw. bei Frauen per vaginam ebenfalls gefühlt werden können. In späteren Stadien ist natürlich die Diagnose Sarkom sehr oft aus Metastasen- 
bildungen, sei es in benachbarten Lymphdrüsen, sei es in entfernteren Organen des Körpers, zu stellen.

Eine große Erleichterung in der Diagnose bietet uns heute das Röntgenverfahren, das eine selbst ganz unscheinbare Veränderung an Knochen uns erkennen läßt. Kümmel (Hamburg) sagt: „Von den Geschwülsten geben die den Knochen breit aufsitzenden, sowie die zentralen Osteosarkome ein deutliches Bild und beseitigen diagnostische Zweifel." Es ist durch dieses Hilfsmittel möglich, eine am Knochen oder in diesem sitzende Geschwulst bereits zu einer Zeit zu erkennen, wo höchstens Schmerzen auf einen KrankheitsprozeB hindeuten. Nach Bircher (Jahresbericht über die Fortschritte in der Chirurgie 19I0) liegt die Bedeutung der Röntgenographie der Knochentumoren überhaupt in folgenden Punkten:

I. sic setzt uns in den Stand, mit ziemlicher Sicherheit zu entscheiden, ob ein vom Knochen ausgchender Tumor oder einc andere Krankheit vorhanden ist: sie klärt dic I)iagnose;

2. sie läßt uns den Umfang der Erkrankung im Knochen erkennen, wie weit das Wachstum im Knochen fortgeschritten ist, wie der Tumor sich ausgebreitet hat. Dadurch ebnet sie uns den Weg, den wir bei der Operation einzuschlagen gedenken, ob wir mit konservativer oder radikaler Opcration vorgehen müssen: sie gibt uns scharfe Operationsindikationen;

3. in vielen Fällen läßt sie uns den Ausgangspunkt des Tumors erkennen und auch seine Wachstumsrichtung. Sie klärt uns oft über Verhältnisse auf, die uns makroskopisch dunkel bleiben: sie unterstützt daher auch die pathologisch-anatomische Untersuchung.

Dem möchte ich speziell für die Sarkome noch einen weiteren Punkt anfügen, nämlich' sie ermöglicht uns durch wiederholte Anwendung das rasche Wachstum eines Tumors zu erkennen: sie gibt uns frühzeitig Aufschluß über die Malignität einer Geschwulst.

Hier sei auch erwähnt, was Carl Beck (New York) über den Unterschied der röntgenographischen Bilder eines myelogenen Sarkoms und einer diesem im klinischen Verlauf manchmal sehr ähnlichen Knochencyste sagt:

„Der Schwund einzelner Cortexteile sowie abnorme und unregelmäßige Grenzlinien wcrden als charakteristisch für Sarkom angesprochen. Im Gegensatz dazu soll die regelmäßige Anordnung der Cortcx, welche wie ein scharf definierter Ring die elliptische oder 
runde Form der Höhle umgibt, für Knochencyste sprechen; ferner wirft der flüssige Inhalt der Cyste einen viel helleren Schatten als ein durch sarkomatösen Zerfall durchsichtig gewordener Knochenteil.

Ein weiteres diagnostisches Hilfsmittel bietet sich vielleicht auch in der Blutuntersuchung. Es wurde $j a$ in neuester Zeit von Ascoli eine Reaktion des Blutes bei bösartigen Geschwülsten beschrieben, die Meiostagminreaktion.

A scoli prüfte das Verhalten der Oberflächenspannung bei der Reaktion zwischen Immunscris und Antigenen und fand zunächst beim Typhus, daß bei dem Zusammenbringen von Serum eines Kranken mit Typhusbazillenextrakt eine Herabsetzung der Oberflächenspannung eintritt. Ascoli und I zar fanden bei 93 Proz. der bösartigen Geschwülste positive Meiostagminrcaktion. Sie berichten auch, daß die 7 Proz. negativen Fälle mit den verschiedensten Antigenen konstant dasselbe Resultat ergaben, während die 93 Proz. der positiven Fälle mit allen Antigencn mehr oder minder ausgesprochen reagierten. F. M icheli und F. Cattorett i schreiben: „Die Seren der an bösartigen Tumoren crkrankten Individuen weisen in bezug auf die Meiostagminreaktion eine breitcre Reaktionszone auf als die normalen oder die den verschiedensten Erkrankungen entstammenden Scren, was mit der nötigen Vorsicht zu diagnostischen Zwecken verwendet werden kann." 'Tillmanns crwähnt ferner für Tumoren, namentlich für bösartige Geschwiilste verschiedene Veränderungen des Blutes: Verminderung des Kohlensäuregehaltes bis zu einem Drittel der Norm, Verminderung des spezifischen Gewichts, des Eiweiß- und Hämoglobingehalts, der Erythrocyten und der Färbekraft. Vermehrung der Leukocyten haben Girawitz und andere Autoren hervorgehoben. Nach Rommclairc und R a ncicr nimmt auch dic Harnstoffausscheidung $\mathrm{ab}$ und geht schließlich unter $12 \mathrm{~g}$ pro die herab.

Endlich stehen uns zur Diagnose eines Beckenknochensarkoms auch noch zur Verfügung die Probepunktion und Probeincision bzw. Probeexcision sowie die mikroskopische Untersuchung der dadurch gewonnenen Geschwulstteile.

Damit komme ich zugleich zur Differentialdiagnose, die gerade bei Sarkomen der Beckenknochen manchmal ungemein schwierig sein kann, wie so viele in der Literatur beschriebene Fälle zeigen.

Die verschiedenartigsten Krankheitsprozesse können zu Verwechslungen mit Sarkomen der Beckenknochen oder doch zu schweren diagnostischen Zweifeln Veranlassung geben. Es ist dies um so mehr erklärlich, als die Beckenknochensarkome die 
verschiedensten Bilder darbieten können: Bald machen sie eine blasenartige Auftreibung des Knochens, bald sitzen sie diesem als scharf umschriebene Höcker, bald ganz diffus mit unbestimmbaren Grenzen auf, sie können sich nach allen Richtungen hin ausbreiten, ihre Oberfläche kann glatt oder auch flachhöckerig, ihre Konsistenz sehr wechselnd sein, sie können Fluktuation oder Pulsation zeigen.

So kann es denn sehr große Schwierigkeiten machen sowohl außen als ganz besonders auch innen am Becken ein Sarkom der Knochen zu unterscheiden von anderen von diesen ausgehenden Tumoren, nämlich von Osteomen oder Exostosen, Fibromen, Enchondromen.

Für Exostosen, die übrigens sehr oft multipel sind, und für die Fibrome ist differentialdiagnostisch vor allem ihre Gutartigkeit zu betonen, so daß sie also Symptome, welche von Störungen im Haushalte des Körpers herrühren, nicht machen.

Auch die Enchondrome, diese Übergangsform zum Sarkom, machen im Beginn ihrer Entwicklung keine solchen Erscheinungen, wenn sie jedoch einmal einen größeren Umfang erreicht haben, dann allerdings können auch sie wie die Sarkome in die Nachbarschaft einbrechen, manchmal sogar Metastasen machen. Das Sarkom dagegen ist vom ersten Anfang an durch seine Bösartigkeit, durch sein schnelles, unaufhaltsames Wachstum charakterisiert. Ein guter Fingerzeig können dann besonders auch Schmerzen sein, die gerade beim Sarkom im Gegensatz zum Enchondrom gewöhnlich schon zu einer Zeit auftreten, wo wir noch gar keinen Tumor palpieren können; in vielen Fällen von Beckenknochensarkom treten außerdem die Schmerzen zum ersten Male ganz plötzlich und zugleich oft so intensiv auf, daß sie zu einer Ohnmacht des Kranken führen können.

Sehr wichtig für die Differentialdiagnose der genannten Tumoren und der Sarkome der Beckenknochen ist dann aber der Sitz. Die Fibrome, die von der äußeren Schicht des Periostes ihren Ursprung nehmen, gehen ziemlich konstant von der Spina anterior superior aus. Allerdings sind auch Fibrome beobachtet worden, die primär im Musculus iliacus (Diegner) oder Musculus psoas (Jakobsthal) entstanden waren. Der Lieblingssitz der Osteome ist die Gegend der Articulatio sacro-iliaca. Die 
Enchondrome künnen vom Os pubis, Os ischii, Os sacrum und Os ilium ausgehen, und zwar sitzen sie an letzterem gewöhnlich in oder nahe der Kreuzdarmbeinfuge, selten im Gegensatz zum Sarkom in der Fossa iliaca interna, fast nie an der Außenfläche der Darmbeinschaufel.

Auch Form und Konsistenz ist vielfach für diese einzelnen Tumorarten charakteristisch. So bietet sich das Fibrom als ein glatter, derber, scharf umschriebener, schmerzloser Tumor dar. Frauen, die geboren haben, neigen besonders zu dieser Neubildung, welche gern im mittleren Lebensalter auftritt. Die Exostosen sind gleichmäßig harte, mit kleinen Höckern versehene Geschwülste, die nur durch ihre Größe zu Störungen führen. Infolge ihres sehr langsamen Wachstums machen sie erst ganz spät Kompressionserscheinungen und im allgemeinen überhaupt nur lokale Symptome.

Das Enchondrom, das unter allen Beckengeschwülsten die bedeutendste Größe erreichen kann, hat eine sehr unregelmäßige Oberfläche; deutliche, bald größere, bald kleinere Hervorragungen, denen wieder kleinere Höckerchen und Knospen aufsitzen, wechseln mit Verticfungen ab. Die Konsistenz ist anfänglich gleichmäßig hart, kann aber auch weich, ja schleimig sein. Später tritt dann gewöhnlich an manchen Stellen Erweichung ein. Die dadurch entstehende Fluktuation ist demnach nicht wie beim Sarkom über dem ganzen Tumor vorhanden, sondern nur über einzelnen Teilen, während andere Gebiete hart sind. Die weicheren Enchondrome entarten übrigens gerne sarkomatös und gehen in Rund- oder Spindelsarkome über. Das Enchondrom kommt fast ausschließlich bei jugendlichen Individuen unter 20 Jahren vor. Eine von C. O. Weber aufgestellte Statistik über 94 Fälle von Enchondromen zeigt uns, daß über die Hälfte derselben vor dem 20., ja ein Drittel vor dem Io. Lebensjahr begonnen hat. Da überdies die Enchondrome weder spontan Schmerzen zu machen pflegen, noch auch auf Druck empfindlich sind, da sie ferner erst sehr spät und da nur selten Metastasen machen, so ist es meistens nur die Größe der Geschwülste und die dadurch bedingten Störungen, was die Kranken belästigt.

Genaue Anamnese und Beachtung der beschriebenen Charakteristika wird wohl in den meisten Fällen eine Differential- 
diagnose zwischen Sarkom der Beckenknochen und cinem der genannten Tumoren möglich machen. Ein Röntgenbild kann auch in diesem Punkte unter Umständen gute Dienste tun.

Noch andere an den Beckenknochen sich abspielende Prozesse können differentialdiagnostisch beim Sarkom in Frage kommen, so besonders bei jugendlichen Individuen die Osteomyelitis. Es ist dies eine seltene Erkrankung der Beckenknochen und kommt nur ausnahmsweise am Kreuzbein, etwas häufiger am Darmbein vor. Eine Osteomyelitis am vorderen Beckenring gehört zu den allergrößten Seltenheiten. Eine genaue Untersuchung des Knochens wird immer zur Erkennung einer Entzündung führen. Es wird zudem darauf hingewiesen, daß man beim Sarkom unterhalb der fluktuierenden Masse meist den verdickten Knochen und eine feine Krepitation fühlt. Auch eine genaue Temperaturkurve wird den Weg weisen, wenngleich das Vorhandensein oder Fehlen von Fieber kein untrügliches Merkmal ist. Es gibt nach Garrè Osteomyelitiden mit sehr schleichendem und subakutem Verlauf, bei denen es nur sehr langsam zu Abszeßbildung kommt. Sarkom wie Osteomyelitis können plötzlich mit heftigen Schmerzen beginnen. Tritt Fieber gleich zu Anfang der Erkrankung ein, so spricht das für eine Entzündung; bei dieser setzen auch gewöhnlich die Störungen des Allgemeinbefindens viel stürmischer ein. Wichtig ist dann die Blutuntersuchung auf Mikroorganismen. Kurt Krüger hat in seiner Dissertation die Frage aufgeworfen, ob vielleicht die Zählung der weißen Blutkörperchen zu einer Differentialdiagnose zwischen Sarkom und Osteomyelitis führen könnte.

Verhältnismäßig oft findet man bei den in der Literatur beschriebenen Fällen von Beckenknochensarkomen, daß die Diagnose fälschlicherweise auf tuberkulöse Ostitis gestellt wurde. Eine solche kommt am Becken vor am Darmbein, und zwar am dickeren Teil hinter der Pfanne, am Schambein, an der Symphyse, am Sitzbein und nach König zuweilen am Mittelstück des Kreuzbeins. Wichtig ist eigentlich hier nur die tuberkulöse Entzündung des Iliosakralgelenks, die vorwiegend bei männlichen Individuen zwischen dem 20 . und 35. Lebensjahr vorkommt. Das erste und einzige Symptom sind hier wie beim beginnenden Sarkom Schmerzen, und zwar ischiatische. Nach kürzerem oder 
längerem Verlauf der Ostitis tuberculosa bildet sich jedoch ein kalter AbszeB, sei es in Form einer teigigen Schwellung entlang der Gelenklinie, welche bei stärkerer Eiterung in der Richtung der Gesäßmuskel nach außen wandert, sei es an der Vorderfläche des Kreuzbeins. Eine Probepunktion wird dann Aufklärung geben, wenn nicht vorher schon durch die Anamnese, durch genaue Untersuchung des ganzen Körpers, durch die typische tuberkulöse Fieberbewegung oder ev. auch durch die nicht sehr wertvolle Tuberkulinprobe die Diagnose sicher gestellt wurde.

Schr schwer kann manchmal die Differentialdiagnose zwischen Sarkom und Lues eines Beckenknochens sein, besonders auch der tertiären syphilitischen Ostitis, die sowohl am Larmbein wic auch am Kreuzbein beobachtet wird. v. Esmarch hat wiederholt darauf hingewiesen, wie leicht eine Verwechslung zwischen Knochensarkom und Knochengumma möglich ist. Die fast stets intermittierenden Schmerzen beim Sarkom, die mitunter äußerst heftig werden, können ganz den für Lues charakteristischen Dolores osteocopi nocturni gleichen. Es kann eine durch Sarkom bedingte diffuse Auftreibung des Knochens vollkommen aussehen wie durch Lues hervorgerufen. Nach v. Esmarch gibt sogar die mikroskopische Untersuchung nicht immer ein sicheres Resultat; denn es ist nach ihm nicht immer möglich, ein kleinzelliges Sarkom von jungem Bindegewebe zu unterscheiden. Heute allerdings ist das anders geworden. Einmal kennen wir jetzt den Erreger der Syphilis und können ihn ev. durch die mikroskopische Untersuchung eines excidicrten Stückes auffinden. Dann aber wird in vielen Fällen die Wassermannsche Reaktion und besonders eine antiluetische Kur, vor allem in Form einer Salvarsaninjektion, in kürzester Zeit Aufklärung bringen. Im übrigen sind Gummata gewöhnlich multipel und zerfallen frühzeitig im Zentrum. Unter Umständen gibt auch die Anamnese Aufschluß über eine stattgehabte luetische Infektion.

Durch scharf lokalisierte Schmerzen, Funktionsstörungen im Hüftgelenk, scheinbare Verkürzung oder Verlängerung des betreffenden Beines kann ein Beckenknochensarkom eine verhältnismäßig unschuldige Arthritis vortäuschen. Eine genaue Untersuchung des Gelenks wie des Beckens in Narkose und besonders eine Röntgenphotographie wird jedoch vor Verwechslungen schützen. 
Auch der Echinococcus des Beckens kann, besonders wenn Pseudofluktuation vorhanden ist, differentialdiagnostisch in Frage kommen, namentlich in echinokokkenreicher Gegend. Der häufigste Sitz dieses Parasiten am Becken ist das Darmbein und die Pfannengegend, seltener das Os ischii oder das Os pubis. Er kann sich jedoch auch unter der Haut und unter der Muskulatur einnisten. Gerne tritt er durch das Foramen ischiadicum aus dem Inneren des kleinen Beckens nach außen unter die Muskulatur. Eine Probepunktion der Cyste und eine chemische und mikroskopische Untersuchung der erhaltenen Flüssigkeit, ev. das charakteristische Hydatidenschwirren werden alle $Z_{w e i f e l}$ beseitigen. Außerdem wachsen die Echinococcuscysten im allgemeinen sehr langsam und machen daher anfänglich nur allgemeine Symptome; wenn keine Vereiterung der Cysten eintritt, so ist es auch später meist nur die Größe der Geschwulst und die durch diese bedingten Druckerscheinungen, was dem Kranken Beschwerden macht.

Das Carcinom der Beckenknochen kommt bei der Differentialdiagnose kaum in Betracht; denn einmal ist es so gut wie immer sekundär, andererseits aber ist die Prognose und Therapie, wenn es gelegentlich als primäre Neubildung in Frage käme, dieselbe wie beim Sarkom.

Neben diesen Erkrankungen der Beckenknochen können auch die verschiedensten Prozesse der Weichteile sowohl innerhalb als auch außerhalb des Beckens einem Sarkom eines der Knochen ungemein ähnlich sein. Es sind da einmal Lipome, die sehr seltenen Myxome und von den Weichteilen ausgehende Sarkome zu nennen. Nach Steinthal ist es verhältnismäßig einfach, die Lipome und die periostalen Sarkome voneinander zu unterscheiden; denn es sind die letzteren im Gegensatz zu den gestielten Lipomen weniger gelappt und von gleichmäßiger Konsistenz. Die Lipome treten zudem oft multipel auf, sind gutartig und machen gewöhnlich keine Beschwerden.

Sehr schwierig kann es besonders sein, Geschwülste der Bauchdecken und bei Frauen solche des Ligamentum rotundum und des Ligamentum latum mit Sicherheit auszuschließen. Unter den ersteren möchte ich hier besonders die Desmoide erwähnen, also Fibrome von äußerst harter und zäher Konsistenz und 
sehnig-glänzender Schnittfläche. Lassen sich kleinere dieser Geschwülste, die hügelig den Bauchdecken aufsitzen und deren Bewegungen mitmachen, leicht crkennen, so kann es ungemein schwer sein, wenn eine große Geschwulst vorliegt, die Differentialdiagnose zwischen einem Bauchdeckenfibrom und einem Sarkom des vorderen Teiles des knöchernen Beckenringes zu stellen. Können doch diese Desmoide „Hemdenknopfform" haben und mit einer Seite tief in die Bauchhöhle hineinragen. Sie können mit dem Bauchfell verwachsen und völlig unbeweglich werden, ja mehr als die Hälfte des Bauches einnehmen. Fs haben solche Fibrome der Bauchdecken anfänglich meist die Gestalt eines Ovoids mit der Längsachse in der Faserrichtung der Muskulatur, später nehmen sie oft Kugel- oder Kegelform an. Die Oberfläche ist glatt oder nur wenig uneben, knollig. Sie verdrängen die Muskeln und bringen sie durch Druck zur Atrophie. Auch ein großes Knochensarkom kann Ähnliches bedingen. Es kann infolge der Größe der Geschwulst unter Umständen selbst mittels des Röntgenbildes der Ausgangspunkt derselben nicht festgestellt werden. Allerdings wird in den meisten Fällen die Verschieblichkeit der Bauchlecken, die übrigens auch bei einem großen Sarkom fehlen kann, die Verschieblichkeit der Geschwulst zum Knochen für dlas eine oder andere mehr sprechen. Doch es können alle diese Charakteristika versagen und schließlich bleibt, namentlich wenn auch Wachstumsgeschwindigkeit der Geschwulst und das Allgemeinbefinden des Patienten nicht nach einer bestimmten Richtung hin zu verwerten sind, nur die Probelaparotomie übrig.

Daß ein Osteosarcoma pelvis mit einem Tumor des Ligamentum rotundum verwechselt werden kann, geht bereits aus der tabellarischen Zusammenstellung Sängers hervor, die dieser von den zahlreichen Affektionen gemacht hat, welche intra vitam differentialdiagnostisch bei Geschwülsten des runden Mutterbandes in Betracht kommen.

Auch Cysten der Ligamenta lata und Tumoren aus Resten des Wolffschen Körpers sollen hier nicht unerwähnt bleiben. Ein Fall ist in der Literatur beschrieben, wo ein Myom des Uterus ein vom Promontorium ausgehendes Osteosarkom vortäuschte. 
Ferner kann unter Umständen die Differentialdiagnose zwischen Knochensarkom und Dermoid bzw. Teratom schwer sein. Es ist freilich der Sitz dieser Geschwülste entsprechend ihrer Entstchungsgeschichte meist ein so charakteristischer, daß sie wohl nicht allzu häufig in Frage kommen können. Sie sitzen nämlich entweder genau in der Mittellinie des Kreuzbeins oder doch in deren Nähe entsprechend den drei letzten Kreuzbeinwirbeln oder auch über dem Steißbein. Besonders schwierig kann es aber sein, ein vom Beckenbindegewebe ausgehendes, also im Becken gelegenes Dermoid mit Sicherheit auszuschließen. Als ein wichtiges Symptom der Dermoide gilt ihre Formbarkeit durch Kneten des teigigen Inhalts; auch wird betont, daß man nicht selten bei Druck auf ein Dermoid ein charakteristisches Knistern fühlt infolge des Reibens der in diesen Geschwülsten oft vorhandenen Haare.

Endlich kann ein Knochensarkom sich gelegentlich auch einmal präsentieren wie irgendein mehr oberflächlich sitzender ganz harmloser cystischer Tumor, z. B. wie ein Hygrom des Schleimbeutels des Tuber ischii, das übrigens sehr selten ist, oder wie eine Atheromcyste, wie sie zwischen Sitzknorren und Afterrand gerne vorkommen.

In weitaus den meisten Fällen, wo eine solche von den Weichteilen ausgehende Geschwulst in Frage kommt, wird ja wohl die Beweglichkeit des Tumors einen Anhaltspunkt für die Diagnose geben, es wird das Röntgenbild das Verhalten der Geschwulst zum Knochen und dessen Unversehrtheit bzw. Erkrankung erkennen lassen, es wird bei einem cystischen Tumor die Punktion Klarheit bringen. In manchen Fällen aber, glaube ich, kann erst durch eine Probeincision bzw. Laparotomie eine sichere Diagnose gestellt werden.

Ähnlich verhält es sich mit den verschiedenen innen und außen am Becken vorkommenden Abszessen, deren Unterscheidung von einem Beckenknochensarkom, wie aus der Literatur ersichtlich ist, oft große Schwierigkeiten macht. Und in der Tat kann große Ähnlichkeit bestehen. Es kann cin Sarkom durch leichte Fieberbewegungen, durch Fluktuation, durch die starke Vaskularisierung der bedeckenden Haut einem Abszeß aufs Haar gleichen. Es sind Fälle beschrieben, wo die Differen- 
tialdiagnose schwankte zwischen Knochensarkom des Beckens und Senkungsabszeß, parametritischem, prävesikalem, perirektalem, retroperitonealem AbszeB, Abszedierung von Lymphdrüsen. Auch hier wird neben einer genauen Anamnese, einer sorgfältig angelegten Temperaturkurve und einer gründichen Untersuchung des ganzen Körpers, vor allem das Röntgenbild und die Probepunktion die Diagnose stets klären. Auch kann in solchen Fällen zweifellos die wiederholte Zählung der Leukocyten manchmal auf den richtigen Weg führen. Bei Verdacht auf Tuberkulose speziell wird man nach weiteren Zeichen dafür fahnden, ev. auch eine Tuberkulinreaktion zu Rate zichen.

Unstreitbar eine der schwierigsten Differentialdiagnosen bei einem Beckenknochensarkom kann die gegenüber einem Aneurysma sein und, wie die Fälle in der Literatur zeigen, ist sie auch eine der häufigsten. Wie ähnlich ein pulsierendes myelogenes Knochensarkom, das in der Nähe eines Gefäßes sitzt, einem Aneurysma sein kann, das geht schon daraus hervor, daß man früher diese I'ulsationssarkome gar nicht für maligne Neubildungen hielt, sondern sie als ,Knochenaneurysmen" ansprach. Es kommen hier in Betracht Aneurysmen der Arteria glutaca, die in der Regel am oberen Rande der Incisura ischiadica major sitzen, sich aber über einen großen Teil des Beckens ausbreiten können, dann Aneurysmen der Arteria ischiadica, welche mehr nach dem Tuber ischii zu liegen, und solche der lliakalarterien, die das ganze Scarpasche Dreicck einnehmen, bis zum Rippenbogen hinauf reichen und auch im Innern des Beckens verborgen liegen können. Wichtig zur Unterscheidung zwischen einem pulsierenden Sarkom und einem Ancurysma ist die Auskultation über dem Tumor und die Beachtung ev. vorhandener Geräusche. Bei Aneurysmen sind diese hauchend, schabend und immer, wenn nicht zufällig ein arterio-venöses Aneurysma vorliegt, intermittierend. Geräusche in einem pulsierenden Sarkom pflegen viel stärker $z u$ sein als aneurysmatische. Allerdings können Geräusche nicht bloß bei pulsierenden Sarkomen, sondern auch bei Aneurysmen fehlen. Forner kann die Art, wie sich der fragliche Tumor mit Blut füllt, differentialdiagnostisch verwertet werden. Das Sarkom nämlich füllt sich plötzlich, ohne daß die palpierende Hand eine stärkere Ausdehnung der Ge- 
schwulst merkt, während ein Aneurysma sich langsam füllt und im Verhältnis zu seiner Größe sich ziemlich erheblich ausdehnt, und zwar im Gegensatz zum Sarkom nach allen Richtungen, so daß die darauf liegenden Finger nicht bloß gehoben, sondern auch auseinandergedrängt werden. Die Verschiedenheit der Konsistenz des Tumors spricht nicht ohne weiteres für ein Sarkom, denn infolge von Fibrinablagerungen an verschiedenen Stellen auf der Innenseite eines Aneurysmas können auch bei einem solchen neben weichen festere Partien vorhanden sein. Ein myelogenes Sarkom wird sich in manchen Fällen durch das charakteristische Pergamentknistern verraten.

Bei einem pulsierenden periostalen Sarkom wird der Knochen im Röntgenbild wie „angefressen“ erscheinen. Allerdings kann dieser auch bei einem ihm anliegenden Aneurysma eine Aushöhlung erfahren, doch hat diese dann eine glatte Wandung. Ein sicherlich oft wertvolles diagnostisches Hilfsmittel bietet, wenn ausführbar, die Kompression des betreffenden Gefäßes, das als Ursprung des fraglichen Aneurysmas in Betracht kommt. Denn diese kann bei einem pulsierenden Sarkom, das von zahlreichen Gefäßen durchzogen ist, nicht wie bei einem Aneurysma die Pulsation zum Stillstand bringen. Ein an sich unsicheres Unterscheidungsmerkmal zwischen Aneurysma bzw, Abszeß und myelogenem Tumor hat ferner Ollier angegeben. Er schlägt vor, eine feine Nadel in die pulsierende oder fluktuierende Geschwulst einzustechen. Wenn jene den Knochen leicht durchdringt, so spricht das gegen AbszeB oder Aneurysma. Endlich kann die Anamnese manches zur Klärung der Diagnose beitragen; Allgemeinbefinden des Patienten, Schwellung benachbarter Lymphdrüsen können auf die richtige Fährte bringen. Die Probepunktion kann auch beim Sarkom Blut ergeben, doch werden dann in diesem durch eine mikroskopische Untersuchung wohl sicherlich immer Sarkomzellen aufgefunden werden.

Eine sehr häufige und oft ungemein schwierige Differentialdiagnose bei einem beginnenden Beckenknochensarkom ist, wie aus der Literatur ersichtlich ist, die gegenüber einer einfachen Ischias oder auch einem Rheumatismus. Für eine Neuralgie des Nervus ischiadicus ist charakteristisch, daß die Schmerzen mehr kontinuierlich, weniger remittierend oder intermittierend sind 
als die durch Tumoren des Beckens hervorgerufenen. Zudem ist die eigentliche Ischias sehr oft bedingt durch eine Stoffwechselstörung, vor allem durch Diabetes. Manchmal ist in der Familie Gicht; auch Syphilis und Arteriosklerose liegen nicht selten einer Ischias zugrunde. Für ein sehr wichtiges Symptom einer einigermaßen schweren richtigen Ischias hält Prof. Friedrich v. Vüller das Fehlen des Achillessehnenreflexes an dem betreffenden Bein. Ias I assèguesche Symptom -- heftige Schmerzen am Gesäß und in der Kniekehle durch passive Beugung des Beines in der Hüfte bei gestrecktem Unterschenkel — spricht wohl auch meistens zugunsten einer Ischiadicusneuralgie. Sehr verdächtig ist immer eine doppelseitige Ischias. Bei Beckentumoren ändern sich übrigens manchmal die Schmerzen mit der Lage des Patienten. Auch mag es richtig sein, was Kurt Krüger in seiner I)issertation betont, daß bei durch Geschwülste verursachter Ischias von den Druckpunkten des Nervus ischiadicus der an seiner Austrittstelle aus dem kleinen Becken am empfindlichsten ist. Vor einer Fehldiagnose in diesem Punkte aber kann mit Sicherheit nur schützen die Befolgung des Rates, den Tillmanns gibt: „Bei chronischer Ischias soll man bei Fehlen sonstiger Erscheinungen auch an die Möglichkeit einer den Ischiadicus komprimierenden Geschwulst denken." Ja, die vielen falschen Diagnosen, die in der Literatur sich finden, und der dadurch gestiftete Schaden lassen die Forderung berechtigt erscheinen, daß bei jedem Kranken mit Ischias eine genaue Untersuchung des Beckens und besonders auch der Wirbelsäule vorgenommen und ev. ein Röntgenbild angefertigt werden soll. Das gleiche gilt für Coxalgie und Coccygodynie, über deren Ursache man sich nicht klar ist.

Wohl in ganz seltenen Ausnahmefällen kann endlich auch noch eine Hernia ischiadica differentialdiagnostisch bei einem Beckenknochensarkom in Betracht kommen. Es treten diese Brüche durch das Foramen ischiadicum majus aus, und zwar meist am oberen, selten am unteren Rande des Musculus piriformis. Auch eine Hernie, welche durch die Incisura ischiadica minor unter den Musculus glutaeus maximus tritt, könnte gelegentlich durch ein Beckenknochensarkom vorgetäuscht werden. Es wird jedoch wohl auf jeden Fall heute durch eine Röntgen- 
photographie eine Hernie sich ausschließen lassen, wenn es nicht durch die Symptome und eine genaue Untersuchung möglich sein sollte.

Die wenig wichtige Differentialdiagnose zwischen einem periostalen und einem myelogenen Sarkom wird meist erst durch die Operation bzw. durch die Obduktion möglich sein. Doch kann unter Umständen ein myelogenes Sarkom an der beiderseitigen Auftreibung des Knochens erkannt werden.

So sehen wir denn, daß zwar auch heute noch die Differentialdiagnose bei Beckenknochensarkomen manchmal sehr erhebliche Schwierigkeiten machen kann, daß aber doch eine sichere Diagnose ungemein leichter und auch viel frühzeitiger möglich ist als noch vor ganz wenigen Jahren. Vor allem ist uns auch auf diesem Gebiete in dem Röntgenverfahren ein sehr wertvolles diagnostisches Hilfsmittel zuteil geworden. Dann aber kann auch heute, wo die operativen Eingriffe durch Asepsis und Antisepsis so viel an Gefährlichkeit verloren haben, ausgiebig Gebrauch gemacht werden von Probepunktion, Probeincision, Probeexcision und ganz besonders auch von der Probelaparotomie.

Die Therapie der Beckensarkome kann auch heute noch einzig und allein eine operative sein. Zwar hat man zu jeder Zeit versucht und wird es auch in Zukunft versuchen, die malignen Geschwülste auf nichtoperativem Wege zu bekämpfen, doch bis jetzt im großen und ganzen mit nicht sehr gutem Erfolg. Früher hat man, um das Blut zu verbessern, alle möglichen inneren Mittel probiert, so Merkurialien, arsenige Säure, Jod, Schwefel, Eisen, Mineralwässer; auch Hunger-, Schwitz- und Abführprozeduren wurden gegen diesen Feind aufgeboten. Wohl gibt man auch heutzutage bei einer bösartigen Geschwulst innerliche Mittel, aber nicht um einen dyskrassischen Zustand des Blutes zu beseitigen, sondern um möglichst lange den von der malignen Neubildung befallenen Organismus kräftig zu erhalten und ihm so den Kampf gegen diesen Todfeind zu erleichtern. Auch Jodkali, von Esmarch empfohlen, hat sicherlich keinen spezifischen Einfluß auf bösartige Tumoren, doch soll dieses wie auch Arsenik, das Esmarch sehr lobt, den Kranken nicht vorenthalten werden.

Vielfach aber sieht der Arzt bei den malignen Geschwülsten sich gezwungen, eine konservative lokale Therapie einzuschlagen, 
nämlich dann, wenn eine radikale Entfernung der Neubildung durch das Messer nicht mehr möglich ist. Man hat denn auch teils in dem Bestreben in solchen inoperablen Fällen noch Hilfe zu bringen, teils geleitet von dem bestechlichen Gedanken, dal3 es doch vermutlich etwas geben müsse, was diesen, ich möchte sagen, üppig gewordenen Zellen das Leben zu nehmen vermag, die mannigfachsten Mittel lokal gegen die malignen Tumoren angewendet: Ätzmittel, Injektionen von Liquor ferri sesquichlorati, von Arsen, von Pyoctanin, Erfrierung, Glühhitze, methodische Kompression, Unterbindung der zuführenden Arterien, galvanokaustische Ligatur. Doch alle diese Mittel haben, wenn überhaupt einen, so höchstens einen vorübergehenden Nutzen. Bisweilen machen sie große Schmerzen, ja stiften unter Umständen bloß Schaden. v. Winiwarter will durch parenchymatöse Injektionen von 4-IO Tropfen einer I proz. wässerigen Lösung von Acid. hyperosmic. inoperable Sarkome zum völligen Verschwinden gebracht haben. Die von Fehleisen unternommenen Injektionen von Erysipelkokken und die Einspritzungen deren Toxine, was durch die Beobachtung angeregt wurde, daß bei zufälligem Erysipel Sarkome sich zurückbildeten, stellten sich als vergeblich heraus, ja bisweilen trat bei diesen künstlichen Erysipclinfcktionen ein zentraler Zerfall ein, während an der Peripherie sich ein beschleunigtes Wachstum einstellte.

In neuester Zeit hat man einen ganz eigenartigen Weg betreten, den bösartigen Geschwülsten nahezukommen, ich meine den Versuch, dic malignen Tumoren durch Röntgen- und Radiumstrahlen zu vernichten. Vielleicht hat diese Therapic eine gute Zukunft. Czerny sagt in seiner Rede zur Eröffnung der II. internationalen Konferenz für Krebsforschung in Paris:

„Eine unerwartete Hilfe für clic Therapie der Krebse brachte uns dic Anwendung der Röntgen- und Radiumstrahlen. Sie wirken bis zu einem gewissen Grade elektiv zcrstörend für die Krebszelle, können manchmal im Beginn der Erkrankung das Messer crsetzen und bringen den armen Kranken selbst dann noch erheblichen Nutzen, wenn eine operative Hilfe nicht mehr möglich ist. Die ursprïnglichen Hoffnungen, welche man anfangs auf diese Mittel setzte, haben sich freilich nicht erfiillt."

R. Werner und A. $\operatorname{Caan}^{1}$ ) berichten über die Wirkung 1) Münchn. med. Wochenschr. Ig10. 
von Röntgenstrahlen auf 50 Sarkomfälle. Nach ihnen ist die Reaktionsfähigkeit auch bei den Sarkomen wie bei den Carcinomen davon abhängig, ob sie an einer geschützten Stelle liegen oder nicht. Von Sarkomen, die vom Oberarm, Unterarm und Unterkicfer ausgingen, wurde die Hälfte wesentlich gebessert. $\mathrm{Ob}$ eine wirkliche Heilung eintrat, konnten sie wegen der kurzen Beobachtungszeit nicht angeben. Rückbildungen und Erweichen der Tumoren, auch Abnahme der Schmerzen, abgesehen von zwei Fällen, wo diese sich steigerten, kamen auch bei den übrigen Gruppen vor. Fin Myxosarkom und eine Reihe von anderen Sarkomfällen fing sogar noch während der Behandlung an, rapid zu wachsen und Metastasen zu bilden. Werner und Caan glauben, daß bei Sarkomen noch mehr wie bei Carcinomen eine Röntgenbehandlung, die nicht imstande ist das Leiden zurückzudämmen, Schaden stiften kann und korrigieren die in der Literatur (u. a. von Bachem und neuerdings auch von Phaller) mehrfach ausgesprochene Meinung, daß die Sarkome für die Röntgenbestrahlung erheblich günstiger seien als die Carcinome, dahin, daß doch nur ein ganz verschwindend kleiner Prozentsatz sich den Röntgenstrahlen gegenüber nicht refraktär zeigt. Allerdings ist nach ihnen die Rückbildung derjenigen Sarkome, welche gut reagieren, eine auffallend rasche und glatte. Diese beiden Autoren empfehlen nach ihren Erfahrungen folgende Indikationen:

„Operable Tumoren sind unter allen Umständen chirurgisch zu entfernen, doch ist die Röntgentherapie als Nachbehandlung, selbst wenn andere Hilfsmethoden, z. B. Fulguration oder Thermopenetration verwendet wurden, durchaus zu empfehlen. Die Bestrahlung in eine offene Wunde scheint wirksamer zu sein als die perkutane Belichtung des Operationsfeldes. Die Röntgenisierung exstirpierbarer Geschwülste wird aber trotzdem vorgenommen werden müssen, wenn der chirurgische Eingriff aus besonderen Gründen unmöglich ist. Unter diesen Bedingungen wird die Röntgenbestrahlung mit rücksichtsloser Energie durchzuführen sein, wenn die chirurgische Kontraindikation eine absolute ist; sonst aber ist jedenfalls ein Verfahren, das zu, stärkerer Veränderung der Haut führt, zu vermeiden, da bei weiterer Progredienz des Tumors die Operation vom Kranken resp. vom Arzt doch bisweilen nochmals riskiert wird und dann der Wundverlauf durch eine vorausgegangene Cberexposition leicht gefährdet wird."

Das gleiche fordern sie für Tumoren, die an der Grenze der 
Operabilität stehen, zumal wenn sie auch durch große Dosen nicht beweglicher werden. Für inoperable Tumoren verlangen sie in jedem Falle Versuche mit Röntgentherapie, die aber kontraindiziert erscheinen, wenn nach der ersten Bestrahlungsserie $(5-6 \mathrm{X}$ auf jeden Punkt der Oberfläche) eine Verschlechterung eintrete. Mittlere Dosen von Röntgenstrahlen könnten eben doch wenigstens durch Linderung der Schmerzen, Eindämmung des Wachstums der Geschwulst, Hebung des körperlichen Zustandes und der Gemütsstimmung Nutzen stiften. Ich erwähne auch, was Mülle $\mathbf{r}^{\mathbf{1})}$ schreibt:

„Im allgemeinen muß man jedenfalls sagen, daß weit fortgeschrittene maligne Neubildungen - von ihnen am allermeisten die Spindelzellensarkome - eine günstige Aussicht auf Erfolg durch die Röntgentherapie nicht darbicten, daß dicsclben aber auch moist inoperabel sind und deshalb trotzdem ein genügend langer Versuch mit der Bestrahlung gerechtfertigt ist. Im Beginn stchende Neubildungen werden ganz entschieden gïnstig beeinflußt, weshalb in jedem Falle eine Beseitigung mit Röntgenstrahlen versucht werden darf. Bei nicht promptem Rückgang aber ist dieser Versuch nicht zu weit auszudehnen, sondern die allein zuständige Hilfe der Chirurgen in Anspruch zu nehmen."

Über den gegenwärtigen Stand der Strahlentherapie schreibt R. Werner-Heidelberg $\left.{ }^{2}\right)$ :

,Die Röntgenstrahlen finden ihre Verwendung bei der Vorbereitung zur Radikaloperation (Schrumpfung), bei der Nachbehandlung, nachdem opericrt worden (Rezidive), ausnahmswcise als Ersat\% der Opcration und clann als Palliativmittel zur Schmerzstillung und Förderung der Übcrhäutung von Ulcerationen. Die Strahlung mul3 eine harte (Filterbestrahlung) und genügende sein, sonst wird der in der Tiefe ungenügend bestrahlte Tumor zu schnellerem Wachstum angeregt. Radiosensible Geschwülste werden durch die Haut hin durch bestrahlt, resistentere Geschwiilste kann man operativ bloßlegen und direlet bestrahlen, daneben Bestrahlung von verschiedenen Seiten. Als Palliativmittel haben dic Röntgenstrahlen einen hohen Wert, be sonders in Hinsicht auf die Schmerzlindcrung und zur Überhäutung von Ulcerationen."

I) Aus der Röntgenabteilung des physikalisch-therapeutischen Instituts des Krankenhauses 1. d. I. in München. Münchn. med. Wochenschr. 1909, Nr. 5 .

2) Die Rolle der Strahlentherapie bei der Behandlung der malignen Tumoren. Strahlentherapie 1912, Bd. I, H. I u. 2, S. 100. Ref. im Arch. f. phỵsik. Med. u. med. Technik, Bd. 7, HI. 2. 
Neben der Behandlung mit Röntgenstrahlen möchte ich noch einige ncuere Versuche, die bösartigen Tumoren zu beeinflussen, nicht unerwähnt lassen: vor allem die Radiumbehandlung. Über diese schreibt A. $\operatorname{Caan}^{\mathbf{1}}$ ):

„Obwohl die Radiumtherapie zu den modernsten und jügsten Behandlungsmethoden gehört, so ist ihre Anwendung dennoch bereits eine vielseitige geworden. Insbesondere die Beeinflussung bösartiger Geschwülste wurde von verschiedenen Seiten versucht, und wenn auch die Erfolge in der Mehrzahl der Fälle noch nicht als Heilungen bezeichnet werden dürfen, so ist doch zweifelsohne festgestellt worden, daß die Einführung des Radiums als Heilfaktor auch für dieses schwicrige Gebiet der ärztlichen Tätigkeit eine nicht zu unterschätzende Bedeutung besitzt." über das Resultat der Radiumbehandlung von Sarkomen am Heidelberger Institut für Krebsforschung berichtet er: „Am auffallendsten waren die regressiven Veränderungen bei zwei Melanosarkomen: hier kam es zur Verflüssigung, Verklcincrung bzw. völligem Verschwinden der Tumoren bei Hebung des subjektiven Befindens. Die übrigen 7 Fälle reagierten mit einer Ausnahme wenig bzw. überhaupt nicht." „Im großen und ganzen," so schreibt $\mathrm{C}$ a a n weitcr, ,geben unsere Erfahrungen mit Radiumbchandlung der bösartige: Geschwülste trotz aller Skepsis begründete Hoffnung, da $B$ es gelingen wird, mit Hilfe des Radiums oder noch besser durch Kombination mit anderen Mitteln weitere Fortschritte zu erziclen." Nach R. W e r n e r sind die radioaktiven Substanzen (strahlende Elemente), Salze und Emanation von Radium, das Aktinium, das Mesothorium und das Thorium X, eine Unterstützung und Ergänzung der Röntgentherapie; sie sollen den Tumor lokal von innen her oder von der Oberfläche aus angreifen. Um ev. Metastasen zu treffen, werden auch intravenöse Injektionen gemacht. Nach Werner können die Erfolge, wenigstens für die erste Zcit, rccht gutc sein, obschon nicht alle Tumoren gleich günstig reagieren. Es kommt aber doch vor, daß die scheinbar glänzenden momentanen Erfolge sich später als trügcrisch erweisen.

Eine weitere moderne Waffe gegen bösartige Geschwülste ist die Elektrotherapie in Form der de Forestschen Nadel, der Thermopenetration und Fulguration.

Die Operation mit der de Forestschen Nadel hat nach Werner den Vorteil, daß man knapp am Krankheitsherde operieren kann, ohne Ausstrcuungen befürchten zu müssen. Mit der Thermopenetration lassen sich Operationswunden ,,sterilisicren“. Doch darf man sich nicht darauf verlassen, daß zurückgebliebene Keime damit sicher der

I) Münchn. med. Wochenschr. I909, Nr. 42. 
Vernichtung anheimfallen. Durch die Thermopenetration ist es nach ihm möglich, cine bösartige Neubildungr gewaltsam zu zerstören, indem man sukzessive tiefe Schorfe setzt, die sich durch Demarkation abstoßen oder durch Exkochleation entfernt werden. Keine besonderen Exfolge hat bis jetzt der Versuch eriseben, Tumoren durch Durchwärmung für dic Röntgenstrahlen zu sensibilisicren. Bei der Fulguration werden nach Werner kleine zirkumskripte Verbrennungen erzeugt, die eine primäre Anämie und dann eine sekundäre Hyperämie zur Folge haben. Nach de Keating $\mathrm{H}$ art werden dadurch Geschwulstreste zerstört, dic Umgebung wird zum Widerstand angereizt und zurückgebliebene Tumorzellen sollen mit Hilfe der intensiven Wundsekretion ausgeschwemmt werden. Dieses Verfahren ist erfolglos, wenn größre Reste bösartigen Gewebes vorhanden sind, es wird dagegen schr cmpfohlen zur C̈berhäutung ulcerierter Flächen inoperabler Tumoren. Nach v. C \% er n y wirkt der lange Blitzfunke bei der Fulguration nicht bloß durch die Hitze, sondern er zertrümmert auch das weiche Protoplasma junger Zellen und zerstört chemische Verbindungen.

Erfolglos war bis jetzt die Immunotherapie bei den Sarkomen, während dic (hemotherapic nicht zu unterschätzende Ergebnisse aufzuweisen hat. So wurden durch Atoxyl und Salvarsan bisher bei einigen Sarkomen nicht aber bei Carcinomen gute Resultate erzielt. Cholinlösungen wirken ähnlich wie radioaktive Substanzen oder Röntgenstrahlen und schienen nach $\mathrm{R}$. Werner geeignet zur Unterstützung oder auch zum Ersatze derselben. Injektionen von Fermenten haben geringe Erfolge, höchstens kann durch tryptische Fermente eine lokale Erweichung von Tumoren erziclt werden. Um bei inoperablen Tumoren Jauchung und Schmerzen erträglicher zu machen, leisten Ätzungen mit Chemikalien, wic Chlorzink, neben der Kauterisation, Elektrokauterisation und Elektrokoagulation gute Dienste.

Beachtung scheint mir das Resultat zu verdienen, das A. Sticker ${ }^{1}$ ) bei der Behandlung von Sarkomen und Carcinomen mit Pflanzenkohle erzielte: es kam das Wachstum des schnell wachsenden Rundzellensarkoms beim Hunde vollständig zum Stillstand, das langsam wachsende Rundzellensarkom wurde in seiner Auskeimung und in seinem Wachstum sehr gehemmt, auch das Wachstum des Alveolarcarcinoms der Maus wurde entschieden verringert.

1) Münchn. med. Wochenschr. I909, Nr. 50. 
F. Blumenthal') hat gefunden, daB eine einmalige Einspritzung eines dreitägigen Autolysats gleichartige Tumoren von Tauben- bis Hühnereigröße zum Rückgang bringt.

Doch selbst ein fanatischer Operationsgegner muß gestehen, $\mathrm{daB}$ wir trotz all der zahlreichen Versuche einer unblutigen Therapie der malignen Tumoren und trotz so manchen Hoffnungsstrahles heute nur eine zuverlässige Waffe gegen die bösartigen Neubildungen haben, das Messer. Und dieses soll gerade auch beim Beckensarkom so frühzeitig und so ausgiebig als nur möglich in sein Recht treten. Vorbedingung aber für seine erfolgreiche Anwendung ist, daß noch in sicher gesundem Gewebe operiert werden kann und daß noch keine Metastasen vorhanden sind. Besteht keine Aussicht, alles Sarkomatöse vollständig zu entfernen, dann verzichte man darauf, Teile abzutragen, denn dadurch wird, wie die Erfahrung lehrt, nur ein schnelleres Wachstum bewirkt. Ist aber eine Radikaloperation ausführbar, dann muß sie so gründlich als nur möglich sein; auch alle regionären Lymphdrüsen, selbst wenn sie noch gesund zu sein scheinen, sollen bis auf die letzte exstirpiert werden.

Ein radikales Vorgehen bei der durch die topographische Lage oft ungemein schwierigen Operation von Beckenknochensarkomen ist heute um so leichter möglich, als man gelernt hat, die gefürchtetste Komplikation zu vermeiden, nämlich die Blutung. Es wird diese auf die verschiedenste Weise verhütet. O. Zeller ${ }^{2}$ ) nennt als bestes Mittel die Blutung zu beherrschen, das Operieren im Gesunden, ,fern von der gefäßreichen Neubildung". Tillmanns ${ }^{3}$ ) gibt als Mittel zur Stillung der Blutung bei der Exstirpation von größeren Beckengeschwülsten die intraabdominale manuelle Kompression der Aorta oberhalb der Bifurkation an; die Kompression der Art. iliaca communis macht nur eine Beckenhälfte blutleer. Nach ihm kann man durch diese intraabdominelle Kompression, besonders der Aorta, die sonst so blutreiche Auslösung von Beckengeschwülsten nahezu blut-

1) Med. Klinik 19ro, VI, 50.

2) Deutsche Zeitschr. f. Chir. 1904.

3) Deutsche Chirurgie, Liefg. 62 a. 
leer gestalten. Dreist stellte im Jahre $1903^{1}$ ) Fälle von Communisunterbindung zusammen, darunter 8 als präliminare Operation bei Operationen am Becken und 5 von temporärer Ligatur, ferner 5 von intraperitonealer digitaler und 15 von instrumenteller Kompression. Nach ihm ist dic definitive Unterbindung der Art. iliaca communis trotz der Antisepsis wegen der drohenden Beingangrän eine sehr gefährliche Operation. Ihr ist, wenn irgendwie möglich, die temporäre Ligatur oder die Digitalkompression, welche am besten intraperitoneal vorgenommen wird, vorzuzichen. Madelung empfiehlt (ebendort) die intraperitoneale I igitalkompression, bei der nach vorausgegangener Beckenhochlagerung mit der ganzen Hand der Hauptstamm der Beckenarteric und Vene gegen den Knochen gedrückt wird, als ein sicheres Verfahren, um jede stärkere Blutung im Becken stillen zu können.

Hogarth Pringle ${ }^{2}$ ) empfiehlt die Art. iliaca communis erst im weiteren Verlauf der Operation zu unterbinden.

Nanu hält dic Unterbindung der Arteria und Vena iliaca externa und hypogastrica für besser als eine Ligatur der Arteria und Vena iliaca communis.

Kocher wiederum hält es für empfehlenswert, die Vasa iliaca interna temporär oder definitiv zu unterbinden. Tillmanns gibt den Rat, bei der Unterbindung der Iliacalgefäße subperitoneal zu diesen vorzudringen.

Was nun die Unterbindung cler Aorta anlangt, so ist in den I3 Fällen, von denen $\mathrm{König} \mathrm{und} \mathrm{Kast} \mathrm{berichten,} \mathrm{jedesmal} \mathrm{der}$ Tod eingetreten. Trotzdem glaubt Leser, daß man in verzweifelten Fällen die Aorta unterbinden müsse, da ja infolge der anatomischen Verhältnisse cine Unterbindung der Aorta zwischen dem Abgang der Art. mesenterica inferior und ihrer Teilung in die beiden Arteriae iliacae communes absolut nicht den Tod zufolge haben müsse. Und zwar sei sie am besten, wie Murray angegeben hat, extraperitoneal zu unterbinden.

Eine erhebliche Verbesserung der Resultate bei ausgedehnten Beckenoperationen ist $\mathrm{zu}$ erhoffen von der Momburgschen

I) Jahresbericht über dic Fortschritte der Chirurgie rgo3.

2) Lancet. Nr. 4460. 
Blutleere. Riese ${ }^{1}$ ) hat bei einer Beckenresektion bei cinem I 3 jähr. Mädchen dieses Hilfsmittel genau nach Vorschrift Momburgs angewendet und es war die Blutleere eine ideale. Doch führt er die schweren Durchfälle, welche das Kind nach der Operation bekam, als eine Folge und einen Nachteil der Momburgschen Blutleere an und glaubt sie auf Störungen im Bereich des Splanchnicus infolge des Druckes von seiten des Schlauches bei dem sehr mageren Kinde zurückführen zu müssen. Vielleicht rührte nach ihm auch der nach der Operation eingetretene Fluor albus von dieser Druckwirkung her. Leuten mit geschwächtem Herzen darf die Momburgsche Blutleere auf keinen Fall zugemutet werden (Rimann und Wolf).

Was die einzelnen Operationsmethoden zur Entfernung von Beckenknochensarkomen betrifft, so ist es nicht im Rahmen dieser Abhandlung, sie einzeln zu beschreiben. Sie sind natürlich sehr verschicden, je nach dem Sitze der Geschwulst.

Im Cavum pelvis sitzende Geschwülste können von den Bauchdecken aus, von der Lendengegend her durch einen Schnitt längs der Crista ilii (v. Bergmann), nach Hegar, O. Zuckerkandl und Sänger vom Damm aus exstirpiert werden. Auch vaginale und parasacrale Schnitte, letztere nötigenfalls verbunden mit temporärer Kreuzbeinresektion (Zeller), können den Wegr zu den Tumoren bilden. Teils um sich Zugang zu schaffen, teils aber auch, um radikal operieren zu können, ist es ferner bei den in der Literatur beschriebenen Fällen sehr oft notwendig geworden, große Teile des knöchernen Beckens zu opfern. Man hat das Kreuzbein, das Steißbein reseziert, große Stücke der Beckenschaufeln abgemeißelt. Sehr gut wird der Beckenraum zugänglich durch die osteoplastische Resektion des Os sacrum und Os coccygis nach Rydygier, welche Methode schon vor diesem von Rehn empfohlen wurde: es wird links ein parasacraler Schnitt und darauf ein Querschnitt in der Höhe des 4. Sacralwirbels gemacht mit anschließender querer Durchmeißlung und Seitwärtslagerung des Kreuz- und Steißbeins. Trendelenburg hat den ganzen vorderen Beckenring entfernt.

Dicses alles wurde mit gutem Erfolg ausgeführt. Speziell

I) Zentralbl. f. Chir. 1909, 40. 
über die funktionellen Erfolge bei Resektionen des vorderen Beckenringes finden sich in der Literatur wiederholt günstige Äußerungen (z. B. von Wilms). Kocher hat sogar dreimal die eine Beckenhälfte reseziert und dabei einen sehr guten Erfolg erzielt. Auch Roux hat nach Kocher einmal diese große Operation vorgenommen, und zwar ebenfalls mit günstigem Reusltat. Girard entfernte wegen Rezidiv mit gutem Ausgang das Os ilium, ischii und pubis unter Zurücklassung der Symphyse bei einem Patienten, bei dem I Jahr vorher der Femur exartikuliert worden war.

Als erste Voraussetzung für so tief eingreifende Operationen muß natürlich gefordert werden, daß keine Metastasen, ja daß nicht einmal begründete Verdachtsmomente für solche bestehen.

Eine geradezu heldenmütige Operation ist die nach Gayet und Ssalitscheff zuerst von Billroth (I889) gewagte Entfernung einer Beckenhälfte mit der zugehörigen unteren Extremität: die Exarticulatio interilio-abdominalis. Tillmanns berechnete im Jahre 1905 die Mortalität dieser Operation aus I7 Fällen auf 70,58 Proz. und bezeichnet sie als Ultimum refugiens, zu dem man nur dann seine Zuflucht nehmen wird, wenn der Tod des Patienten ohne diesen Eingriff sicher ist. Daß3 aber auch diese furchtbare Operation mit lirfolg ausgeführt und zum Heilmittel werden kann, das beweisen verschiedene Fälle in der Literatur (Jaboulay, Riese, Kocher, Ssalitschew usw., siehe meine Statistik).

Keen und $\mathrm{da} \operatorname{Costa}^{1}$ ) berichten, daB in den 19 Fällen von Exarticulatio interilio-abdominalis, die sie in der Literatur fanden, 6) Operierte den Eingriff für längere Zeit überstanden.

Die Indikation zu dieser so grausam verstümmelnden Operation ist nach $B$ ardenheuer und Girard bei Beckenknochensarkomen gegeben, wenn sie den Oberschenkel und die Beckenabteilung einer unteren Extremität einnehmen, ferner bei auf das Becken beschränkten Sarkomen, wenn die Kochersche Resektion der einen Beckenhälfte unausführbar ist, namentlich wenn die großen Gefäße und Nerven von der Geschwulst umwachsen sind.

I) Jahresbericht über die Fortschritte in der Chirurgic ı9०4, II. Teil. 
Tillmanns empfiehlt in geeigneten Fällen die Exarticulatio interilio-abdominalis zweizeitig zu machen, und zwar zuerst die Exarticulatio coxae und dann später die Exstirpation der zugehörigen Beckenhälfte ev. mit Erhaltung der Symphysis pubis und der Articulatio sacroiliaca. Czerny hat diese zweizeitige Operation zuerst gemacht. Das erste und wichtigste Erfordernis für ein Gelingen dieser Operation ist zweifellos die richtige Auswahl der Fälle. Natürlich ist auch hier selbst die leiseste Vermutung einer Metastase die strikteste Kontraindikation gegen den Eingriff, besonders aber ist auch der Kräfte- und Ernährungszustand und nicht am wenigsten das Alter zu berücksichtigen. Bei der Operation selbst ist dann neben einer sorgfältigen Blutstillung auch darauf zu sehen, daß dem Organismus durch den abgetrennten Körperteil nicht zuviel Blut entzogen wird, sondern daß dieser vorher durch richtige Lagerung (Beckenhochlagerung) und durch Einwicklungen vollständig blutleer gemacht wird. Subkutane und intravenöse Kochsalzinfusionen vor, während und nach der Operation, reichliche Fluissigkeitszufuhr per os und per rectum sind für einen günstigen Ausgang der blutigen Operation unerläßlich. Nach allem aber darf man sicherlich Oskar Zeller recht geben, wenn er glaubt, daß die Exarticulatio interilio-abdominalis bei häufiger Wiederholung und bei Ausführung an noch nicht allzu sehr heruntergekommenen Patienten wohl auch einiges von ihrer Gefährlichkeit verlieren wird. Und wenn Aussicht besteht, einen sonst unrettbar dem Tode Verfallenen durch dieses Mittel davor zu bewahren, so ist zweifellos seine Anwendung auch gerechtfertigt.

Sehr oft werden infolge ausgedehnter Verwachsungen bei den Operationen von Beckensarkomen durch Lösung derselben erhebliche Defekte im Peritoneum gesetzt, Ureteren und Mastdarm verletzt, welchen Schaden wieder gut zu machen, oft große Schwierigkeiten verursacht. Die Behandlung geschieht nach den allgemeinen Regeln der Chirurgie.

Kann ein Beckensarkom auf keine Weise mehr radikal entfernt werden, so ist es Aufgabe des Arztes, das trostlose Schicksal des armen Kranken durch s y m tomat is che Behandlung wenigstens so gut als möglich erträglich zu machen. Exulcerierte und jauchende Sarkome wird man mit den bereits erwähnten 
Mitteln behandeln, Ischiasschmerzen ev. mit perineuralen Injektionen von physiologischer Kochsalzlösung zu beseitigen suchen. Namentlich aber ist für Harn- und Stuhlentleerung zu sorgen, wenn nötig durch Anlegung einer Ureteren- oder Nierenfistel bzw. eines künstlichen Afters. Vor allem soll man ferner auch den Kranken Narkotika nicht vorenthalten, ja nach meiner Ansicht ihnen schließlich durch einen dauernden leichten Dämmerschlaf ihr trauriges Los nicht mehr zum Bewußtsein kommen lassen.

Oft werden die Sarkome der Beckenknochen am Ende einer Schwangerschaft bemerkt --- wahrscheinlich infolge des raschen Wachstums während der letzteren - und bilden dann manchmal ganz erhebliche Geburtshindernisse (siehe meine Statistik). Schon wegen des großen Blutreichtums der ganzen Beckengegend ist es in solchen Fällen wohl durchwegs unmöglich, vor oder auch bei der Geburt eine eingreifende Operation zur Entfernung der Geschwulst vorzunehmen. Hier gilt es dann die Dystokie auf irgendeine Weise zu bekämpfen und, wie aus der Literatur ersichtlich ist, wurden in derartigen Fällen die verschiedensten Versuche gemacht. Man kann ev. durch Punktion eine Verkleinerung der Geschwulst erreichen, etwas bewegliche Geschwülste können aus dem kleinen Becken gedrängt werden. Meist aber wird man zu Perforation, Zerstücklung des Kindes, abdominellem Kaiserschnitt und Totalexstirpation seine Zuflucht nehmen müssen.

Die Resultate der Therapie bei den Beckenknochensarkomen sind im ganzen bis jetzt als ziemlich ungünstige zu bezeichnen. Neben schon erwähnten Gründen und der starken Neigung der Sarkome zu Rezidiven trägt daran vor allem der Umstand die Schuld, daß das einzige Rettungsmittel, die Operation, in weitaus den meisten Fällen erst sehr spät zu seinem Rechte kommt, sei es infolge Gleichgültigkeit des Kranken, sei es durch falsche Diagnosen, sei es durch die Messerscheu des Patienten oder auch des Arztes. Hat doch jedes Sarkom nach dem Erfahrungssatz von Virchow eine mehr lokale und insofern unschuldige Periode und in dieser Zeit müßte eine Operation wohl fast immer gute Aussichten haben.

I 894 stellte Dorn II wegen Sarkom des Darmbeins operierte Fälle zusammen. Ein einziger ist von diesen I I Kranken geheilt 
worden, die anderen erlagen entweder der Operation oder starben bald an Rezidiven.

Resultat:

Karl Güldner fand 1895 bei 26 operierten Fällen folgendes

8 starben während oder kurz nach der Operation;

7 blieben ungeheilt und es trat Rezidiv und Tod ein;

2 Heilungen, abcr nach einigen Monaten Rezidiv und Tod;

I Heilung nach zweimaliger Operation, Rezidiv, Tod durch Erysipel;

I Fall zu kurz beobachtet;

6 völlige Heilungen, doch ist sehr wahrscheinlich, daß nach kürzerer oder längerer Zeit Rezidive eingetreten sein werden;

I Fall zweimal operiert, jedesmal Besserung.

A. G a s tp a r hat 1896 in seiner Dissertation 69 Fälle zusammengestellt, von denen ein größerer Tcil bereits in der Disscrtation von G üldner enthalten ist. Darunter gelangten 2I zur Operation. Es wurden aber nur 3 Patienten definitiv geheilt, was einen Prozentsatz von 14,29 Proz. crgibt, also eine Mortalität von 85,81 Proz.

Über die Prognose der Beckenresektion sowie der Exarticulatio interilio-abdominalis ist bereits das Wichtigste gesagt worden. Es sei nur noch erwähnt, daß im Anschluß an Exstirpationen von Beckensarkomen, besonders mit Resektionen von Beckenknochen, gewaltige Hernien, z. B. Sacral- und Iliacalhernien (Gussenbauer u. a.) auftreten können.

Mit der durch den Fortschritt in der Kultur abnehmenden Gleichgültigkeit der Masse gegenüber Krankheitssymptomen, mit der zunehmenden Aufklärung des Volkes über Gefährlichkeit und Heilbarkeit von Krankheiten, besonders auch der Geschwülste, andererseits mit der verbesserten Ausbildung der Ärzte, mit der Weiterentwicklung der Operationstechnik, vielleicht auch durch verschiedene neue therapeutische Mittel, besonders durch die Röntgen- und Radiumstrahlen, wird freilich zweifellos auch die Therapie der Beckensarkome allmählich bessere Erfolge erzielen; vorläufig aber müssen wir gestehen, daß die ärztliche Kunst auf diesem Gebiete zwar Großes, ja Heroisches versucht, aber infolge der ungünstigen Umstände bis jetzt verhältnismäßig sehr wenig gute Resultate zu verzeichnen hat.

Übrigens bieten die Beckenknochensarkome für die Lebensdauer des Trägers nicht alle die gleiche schlimme Prognose. Diese richtet sich einmal nach dem histologischen Aufbau der Geschwulst. Sie ist am relativ günstigsten bei den Riesenzellen- 
sarkomen. Je zellreicher und je ärmer an Interzellularsubstanz ein Sarkom ist, desto größer ist seine Malignität. Die periostalen Sarkome sind demnach viel gefürchteter als die myelogenen, welch letztere zudem durch ihre Knochenschale und ihre meist scharfe Umgrenzung einerseits langsamer wachsen, andererseits für dic Operation geeigneter sind. Dic melanotischen Sarkome haben eine durchaus schlechte Prognose, zumal nach Exstirpation cines solchen Tumors manchmal eine allgemeine Invasion auf dem Wege der Blutbahn stattfindet. Dann ist ferner für die Prognose wichtig der Sitz und die Ausdehnung des Tumors im Knochen und über diesen hinaus. Dazu kommt auch noch die Neigung zu Metastasen, welche bei weichen, blutreichen und kleinzelligen Sarkomen besonders groß ist. Ein Umstand, der bei den Beckensarkomen prognostisch, besonders in Rücksicht auf die Therapie, sehr in die Wagschale fällt, ist das allen Sarkomen im Gegensatz zu Carcinomen gemeinsame späte Übergreifen auf die regionären Lymphdrüsen.

Groß1) fand bei I43 Sarkomfällen nur iomal eine wirkliche Sarkominfektion von Lymphdrüsen. Andererseits sind allerdings oft bei Sarkomen in inneren Organen bereits zu einer Zeit Metastasierungen vorhanden, wo man solche noch kaum vermuten kann. $\Lambda \mathrm{m}$ häufigsten finden sich Depots in den Lungen. Stort ${ }^{2}$ ) fand bei Ioo Sarkomfällen 24 mal Metastasen in den Lungen, 16 mal in der Leber, 12 mal in der Pleura, 7 mal in den Nieren usw. Außcrdem begegnet man bei Sarkomen überaus oft ausgedehnten Geschwulsthrombosen der Blutgefäße, bei den Beckensarkomen vor allem der Iliacal- und Femoralgefäße sowie der Vena cava inferior.

Ich möchte nun dieser allgemeinen Abhandlung über dic Beckensarkome eine Zusammenstellung von 178 in der Literatur gefundenen Fällen von Beckensarkomen anreihen, die folgende Angaben enthalten soll: Autor, Alter, ev. Para, vorausgegangene Knochenerkrankungen, Trauma, Ausgangspunkt, pcriostal oder myelogen, Operation, Erfolg, Metastasen, Zeit zwischen Trauma und Erkrankung, Art des Sarkoms, Gesamtzeit des Verlaufes, falsche Diagnose und schlicßlich wichtigere Bemerkungen. Es seien dabei die an Beckensarkom er-

I) Amcrican Journal of med. sciences 1879.

2) Dissert. Berlin 1877 . 
krankten Männer, dann die Frauen und endlich diejenigen Fälle zusammengestellt, bei denen das Geschlecht nicht angegeben war.

Zuletzt soll dann ein sehr interessanter Fall von Beckensarkom krankten Männer, dann die Frauen und endlich diejenigen Fälle zusammengestellt, bei denen das Geschlecht nicht angegeben war.

\section{Männer.}

F al1 I. Société anat. 1827. Dissert. v. Braunste in 1888 . Dissert. v. Gü ld ne r 1895. - Alter: 45 Jahre. - Ausgangspunkt: Fossa iliaca sinistra. - Metastasen: Rechts glcicher Tumor. - Gesamtzeit des Verlaufs: I Jahr. - Falsche Diagnose: Anfangs rheumatische Schmerzen in den unteren Extremitäten. - Bemerkungen: Spontanfraktur beider Oberschenkel.

F a 112 wie I. Alter: 50 Jahre. - Ausgangspunkt: Linkes Os ilium. Gesamtzeit des Verlaufs: 6 Jahre. - Falsche Diagnose. - Ischias. Bemerkungen: Schmerzen in der Lendengegend. Verstopfung. Ödem. Degeneration der Muskeln und Nerven.

F all 3. Société anat. 1833. Dissert. v. B ra unstein i888. Dissert. v. Güldne r 1895. Alter: 45 Jahre. - Trauma: Fall auf linken Trochanter major. - Ausgangspunkt: Linkes Os ilium. - Periostal oder myelogen: Myelogen. - Metastasen: Niere. - Zeit zwischen Trauma und Erkrankung: Nach 3-4 Monaten Zeichen von Coxalgie. - - Art des Sarkoms: Fluktuierend. - Gesamtzeit des Verlaufs: 3 Jahre. - Falsche Diagnose: Coxalgic. - Bemerkungen: Das Sarkom war auf den Trochanter major übergegangen. Linkes Darmbein zerstört, teilweise auch Hals und Kopf des Femur. Ödem. Kachexie. Diarrhöe.

F a 11 4. Société anat. 1839 . Dissert. v. B raunste in 1888 . Dissert. v. Güldner 1895. Alter: 68 Jahre. - Ausgangspunkt: Rechtes Os ilium. - Gesamtzeit des Verlaufs: I Jahr. - Bemerkungen: Knorpel des Femurkopfes ergriffen. Kompression des Nerv. ischiadicus. Fast völlige Zerstörung des Lig. rot.

F a 11 5. S t a 1 l e y, Medico-chirurgical Transactions 1845 , A. 28, p. 3 I8. Dissert. v. G üld n e r 1895. Alter: 42 Jahre. - Vorausgegangene Knochenerkrankungen: Seit ıo Jahren ähnliche Geschwulst an den Weichteilen des Humerus. - Ausgangspunkt : Linkes Os ilium. - Operation: Ligat. der Iliaca communis. - Erfolg: Tod 3 Tage nach der Operation an Peritonitis. - Metastasen: Herz, Lunge, Bronchialdrüsen. - Art des Sarkoms: Pulsierend. Falsche Diagnose: Aneurysma. - Bemerkungen: Erst die Sektion ergab Sarkom.

Fall 6. Société anat. 1852. Dissert. v. Bra unstein I888. Dissert. v. Güldner I895. Alter: 5 I Jahre. - Vorausgegangene Knochenerkrankungen: Gleichzeitig ein Tumor des Femur der anderen Seite. - Ausgangs. punkt: Linkes Os ilium. - Gesamtzeit des Verlaufs: 2 Jahre. - Bemerkungen: Ödem. Kachexie.

Fall 7. John Adams, Lancet 1852, A. I, p. 9. Dissert. v. Güldner 1895. Alter: 18 Jahre. - Trauma: Kontusion. - Ausgangspunkt: 
Rechtes Os ilium. - Zeit zwischen Trauma und Erkrankung: 3 Monate nach dem Unfall Schmerzen an der gestoßenen Stelle. - Gesamtzeit des Verlaufs: 4 Jahre. - Bemerkungen: Kindskopfgroßer Tumor. Scrotum und rechtes Bein ödematös. Lymphgefäße hypertrophisch.

Fall 8. L a wrence, Lancet 1852 , A. II, p. Io. Dissert. v. Braun st e in 1888. Dissert. v. Güldner 1895. Alter: 23 Jahrc. - Ausgangspunkt: Sarkom, das wahrscheinlich vom Trochanter major ausgegangen und auf das Os ilium ïbergetreten war. - Periostal oder myelogen: Myelogen.

F all 9. A. H. Levings, Deutsche Chirurgie, Liefg. 62 a. Alter: 24 Jahre. - Trauma: Stoß gegen das rechte Darmbein. - Ausgangspunkt: Rechte Beckenschaufel. - Feriostal oder myelogen: Periostal. - Operation: Schnitt, der hinter der Mitte der Crista iliaca begann, letztcrer entlang bis zur Spina ant. sup. geführt wurde und dann am inneren Rand des M. sartor. 6 Zoll nach unten und rückwärts bis zur Kreuzung mit dem Femur unterhalb des Trochanter verlicf. Der Knochen wurde an der Ursprungsstelle nur mit scharfem Löffel ausgekratzt. - Erfolg: Vollständige Heilung nach 24 Tagen. - Art des Sarkoms: Cysto-osteochondrosarkom; kleine Rundzellen.

Fall Io. M. Th. Anger 1852. Dissert. v. Güldner I895. Alter: 28 Jahre. - Ausgangspunkt: Absteigender Schambeinast. - Operation: Exstirpation und Kauterisation mit dem Ferrum caudens. - Erfolg: Rezidive. - Bemerkungen: Sarkom war nach dem Oberschenkel hin gewachsen.

F all II. Lancet I852, A. I, p. I94. Dissert. v. Güldne I I 895 . Alter: 52 Jahre. - Ausgangspunkt: Fossa iliaca des linken Darmbeins. Periostal oder myelogen: Myclogen. - Operation: Ligatur der Art. iliaca externa. - Erfolg: Tod. - Art des Sarkoms: Pulsierend. - Falsche Diagnose: Aneurysma. - Bemerkungen: Schmerzen und ödem im Bein.

F a 11 12. Deutsche Chirurgie 1905. Fergus s on, Gaz. habdominad. I854. Alter: 54 Jahre. - Ausgangspunkt: Linkes Os ilium. - Metastasen : Lungen und Nieren. - Art des Sarkoms: Gefäßreich, pulsierend. - Gesantzeit des Verlaufs: ca. 2 Jahre. - Falsche Diagnose: Aneurysma. - Bemerkungen: Sektion crgab Sarkom. Spontanfraktur des Femur.

F a 11 13. Gaz. hebdomad. 1853, p. 460. Alter: 59 Jahre. - Aus. gangspunkt: Fossa iliaca dextra. - Operation: Ligatur der Art. iliaca dextra. - Erfolg: Tod. - Art des Sarkoms: Pulsierend. - Falsche Diagnose: Zuerst für Rheumatismus, dann für Knochenaneurysma gehalten. - Bemerkungen: Rechtes Bein scheinbar verkürzt, anormale Beweglichkeit, Krepitation.

F all 14. Société anatomique de Paris 1856. Alter: 25 Jahre. Trauma: Sturz vom I'ferd, dabei Kontusion der rechten Hüfte. - Ausgangspunkt: Rechtes Os ilium. - Zeit zwischen Trauma und Erkrankung: Nach 4 Monaten Schmerzen im rechten Knie. - Gesamtzeit des Verlaufs: 8 Monate. -- Bemerkungen: Der Tumor hatte auch den oberen Teil des Os sacrum, die beiden letzten Lendenwirbel und die Rückseite der Gelenkpfanne ergriffen. Ödeme.

Fall I5 wie I4. 1857. Alter: I9 Jahre. -- Ausgangspunkt: Linkes 
Os ilium. - Metastasen: In Wirbelsäule und Rippen.-- Gesamtzeit des Verlaufs: 3 Monate. - Bemerkungen : Kontin. Fieber mit Exacerbationen abends.

F a 11 I6 wie 14. I857. Alter: I8 Jahre. - Ausgangspunkt: Rechtes Os ilium und Os sacrum. - Metastasen: Sarkomatose der inneren Organe. Gesamtzeit des Verlaufs: 4 Monate. - Bemerkungen: Schmerzen in der rechten Hüfte beim Gehen.

Fall i7. Rokitansky, Wochenblatt der k. k. Gesellschaft der Ärzte zu Wien 1857, Nr. I. Alter: 45 Jahre. - Trauma: Fall auf die Hüfte vor Io Monaten. - Ausgangspunkt: Regio sacro-iliaca und im Bereich des Acetabulums. - Metastasen: Lungen und Bronchialdrüsen. - Zeit zwischen Trauma und Erkrankung: 2 Wochen. - Art des Sarkoms: Mannskopfgroßes Osteochondrosarkom. - Gesamtzeit des Verlaufs: Io Monate.

F a 11 I8 wie 14. I860. Alter: 52 Jahre. - Ausgangspunkt: Rechtes Os ilium. - Metastasen: Inguinaldrüsen mandelgroß. - Gesamtzeit des Verlaufs: I Jahr. - Bemerkungen: Adduktionsbewegung behindert durch einen 'Tumor, der sich in der Falte zwischen Femur und Scrotum zeigte. Unmöglichkeit, zu katheterisicren.

F all I9. S e nftleben, Langenbecks Archiv, Bd. I, S. I52 u. I 53. I 860 (?). Alter: 46 Jahre. - Operation: Unterbindung der Art. femor, dann der Art. iliaca externa. - Art des Sarkoms: Zellensarkom; wenig Interzellularsubstanz, einige Markzellen. - Falsche Diagnose: Abszeß, dann Ancurysma Pottii. - Bemerkungen: Die Geschwulstmasse füllte die rechte Gelenkkapsel ganz aus, Schenkelhals und Trochanteren resorbiert.

F a 1120 wie 14. I86r. Alter: 6I Jahre. - Ausgangspunkt: Linkes Os ilium. - Metastasen: Dieselben Tumoren am linken Oberschenkel, rechten Os ilium, an der Wirbelsäule und am Schädel. - Gesamtzeit des Verlaufs: I 8 Monate. - Bemerkungen: Unterschenkel sehr ödematös.

Fall 2I. Billroth, Langenbecks Archiv 186I, Bd. Io. Alter: 46 (oder 43?) Jahre. - Trauma: Heben einer Last. - Ausgangspunkt: Rechtes Os ilium. - Operation: Injektion von Liqu. ferri. - Erfolg: Keiner. - Metastasen: Lungen, Nieren, Pleura, Schilddrüse. - Art des Sarkoms: Pulsation. Sarc. teleangiektodes cysticum. - Gesamtzeit des Verlaufs: 4 Jahre und 8 Monate.

F a 11 22. Société des sciences méd. de Lyon. (Mém. et compt. rend.) 1865-66. Alter: ? -- Trauma: Sturz auf die Lendengegend. - Ausgangspunkt: Rechtes Os ilium. - Periostal oder myelogen: Myclogen. - Zeit zwischen Trauma und Erkrankung: 6 Monate. - Art des Sarkoms: Pulsation. - Falsche Diagnose: Ischias. - Bemerkungen: Odem am ganzen Bein.

F a 1123 wic 14. I866. Alter: I8 Jahre. - Ausgangspunkt: Fossa iliaca. - Gesamtzeit des Verlaufs: 6 Monate. - Bemerkungen: Anfang unter Erscheinungen der Coxalgie. Ödem der Beine.

Fall 24 wie I4. 1867. Alter: 30 Jahre. - Ausgangspunkt: Linkes Os ilium. -- Periostal oder myelogen: Myelogen. - Operation: Punktion. Erfolg: 8 Tage später Tod. - Metastasen: In den benachbarten Muskeln und inneren Organen. - Art des Sarkoms: Weich. - Gesamtzeit des Ver- 
laufs: I Jahr. - Falsche Diagnose: Wahrscheinlich AbszcB. - Bemerkungen: Beugung des Beines im Hüft- und Kniegelenk.

F a 1125 wie I4. 1867. Alter: 4I Jahre. - Ausgangspunkt: Linkes Os ilium. - Metastasen: Infarkt in der Milz. - Gesamtzeit des Verlaufs: x Jahr. - Bemerkungen: Coxalgie, Milzvergrößerung, Ödem des Beines, Kachexie, Diarrhöe.

Fall 26. Andrée, Arch. f, path. Anat. u. Physiol. Virchow 1874, 3d. 6I. Alter: 201/4 Jahre. - Trauma: (Früher mehrfach Gonorhöe); Anstrengung, Märsche dürten Einfluß auf das rasche Wachstum gehabt haben. - Ausgangspunkt: Rechte Darmbeinschaufel, Kreuzbein. - Metastasen: In Lunge, Leber, Milz. S.-Knoten in Beckenbindegewcbe, im Bereich des Uterus, des Blasenhalses und in den Leistendrüsen. Sarkomatöse Thromben der Beckenvenen. - Art des Sarkoms: Rundzellensarkom (wenig Spindelzellen). - Gesamtzeit des Verlaufs : ca. $9 \frac{1 / 2}{2}$ Monate. - Bemerkungen: Später Harnretention, ödem des rechten Beines, hochgradiges Fieber, blutige Sputa, Coma.

If a 1127 wie I4. 1874. Alter: 57 Jahre. - Ausgangspunkt: Linkes Os ilium. - Metastasen: Im Kreuzbein, einigen Lumbal- und Dorsalwirbeln. - Gesamtzeit des Verliufs: 4 Monate. -- Bemerkungen: Anfang mit Ischias, dann odem des linken Beines.

Fall 28. Nasse, Virchows Arch. 1878, Bd. 94, S. 461. Alter: ? Ausgangspunkt: Multiples primäres Sarkom der Beckenknochen; multiple "Tumoren am linken Schambein, auf den Darmbeinen, linker Spina sup. os ilei, Außenfläche der rechten Pfanne, hinteren Teil des Kreuzbeins und SteiBbeins. - Periostal oder myclogen: Periostal. -- Falsche Diagnose: Carcinoma recti. - Bemerkungen: Stuhlverstopfung und Urinretention.

Fall 29. The lancet, 7. Février 1880 , par le Dr. Fusscl. Alter: 33 Jahre. - Ausgangspunkt: Linkes Os ilium. - Metastasen: Lungen; es war Pleuritis und Pneumonic eingetreten. Verstopfung der Art. iliaca com. und ext. - Gesamtzeit des Verlaufs : 9 Monate. - Falsche Diagnose: Ischias. - Bemerkungen: Schüttelfröste; Bewegungsstörung und Ödem des linken Beines. Verstopfung, Erschwcrung des Urinierens. Pneumothorax.

F a 1 I 30 . Dissert. v. Kl o p f c r, ca. I880. Alter: 44 Jahre. - Trauma: Fall auf der Straße vor I Jahr. - Ausgangspunkt: Linkes Os ilium. -- Operation: Exstirpation der Geschwulst mittels Kreuzschnitt. Die von Sarkommassen durchsetzte Latm. int. sowie die Spina ant. sup. und inf. des linken Os ilium mit dem Meißcl entfernt. - Erfolg: Am 2. Tage l'eritonitis, die am 7. Tage den Tod herbeiführte. - Metastasen: Kcine Sektion. - Gesamtzeit des Verlaufs: I Jahr. -- Falsche Diagnose: Durch Probeincision die sarkomatöse Natur des Tumors festgestellt. - Bemerkungen: Seit dem Fall Schmerzen in der linken Hüftbeingegend; zunehmende Schwellung des linken vorderen Hüftbeins nach rechts bis fast zur Linea alba, nach hinten bis zur Mitte der Crista ilii reichend.

Fall 3I. Dissert. v. Li ebe, Straßburg i881. Alter: 45 Jahre. Trauma: Fall auf die rechte Hüfte vor I Monat. Sofort Beschwerden beim 
Gehen. - Ausgangspunkt: Rechtes Os ilium. - Metastasen: Lungen. - Zeit zwischen Trauma und Erkrankung: Unter Gehbeschwerden entsteht innerhalb eines Monats Schwellung in der Fossa il. dextr. Sark. I Mon. p. Tr. Gesamtzeit des Verlaufs: Exitus I I Mon. p. Tr. - Bemerkungen: Mannskopfgroßes Sarkom.

F a 1132 wie 31 . Alter: 20 Jahre. - Trauma: Überschüttung der linken Oberschenkelgegend mit Steinen. Sofort Schmerzen. - Ausgangspunkt: Os pubis. - Zeit zwischen Trauma und Erkrankung: Sarkom diagnost. 6 Mon. p. Tr. - Art des Sarkoms: Sacroma medullare.

Fall 33. Dr. S. Löwenstein, Beitr. z. klin. Chir. I906. Löwen th a l, Arch. f. klin. Chir. I895, Nr. 485. 1. c., I88 I, Nr. 626. Alter: 5 I Jahre. - Trauma: Fall auf das rechte Gesäß mit dem rechten Bein. Sofort Schmerzen im Gesäß, besonders beim Auftreten. - Operation: AgNO-Injektionen. - Zeit zwischen Trauma und Erkrankung: Bald nach dem Fall an der Hinterbacke immer mehr zunchmende Schwellung. Sark. diagn. Io Mon. p. Tr. - Gesamtzeit des Verlaufs: Tod I Jahr p. Tr.

Fall 34 wie 33. I88 (?). Alter: 25 Jahre. - Trauma: Fall von eincr Treppe auf das Steißbein. Sofort Schmerzen. - Ausgangspunkt: Os coccygis. - Operation: Enukleation. - Erfolg: Heilung. - Zeit zwischen Trauma und Erkrankung: Sark. diagnost. I 2 Mon. p. Tr. - Art des Sarkoms: Myxosarkom.

F a 11 35. L e is r u ek u. A l s b e r g, Langenbecks Archiv 1882, Bd. 28. Alter: 5I Jahre. - Trauma: Ausgleiten mit dem rechten Bein. - Ausgangspunkt: Rechtes Os ilium (?). -- Bemerkungen: Die Anschwellung setzte nach oben mit dem Darmbeinkamm ab und bildete hier einen stark erhöhten Wall; nach hinten ging sie bis zur Gesäßfalte. Nach vorn nahm sie das ganze Beckengebiet cin.

F a 11 36. Havag e, 1. c. 1882, S. I05. Alter: 34 Jahre. - Ausgangspunkt: Innenfläche des linken Os ilium in der Nähe der Art. sacro-iliaca. -Gesamtzeit des Verlaufs: 8 Monate. - Falsche Diagnose: Ischias; Intermittens; Rheumatismus. - Bemerkungen: Beginn plötzlich. Schmerzen in der linken Hüftgegend auf der Straße, daß or umfiel.

F a 11 37. L. Greger, Dissert. Greifswald 1884. Alter: 54 Jahre. Ausgangspunkt: Die ganze rechte Hälfte des 2. (?) Kreuzbeinwirbels war bis zum 4. herab von einer Geschwulst in einer Längsausdehnung von I I cm ersetzt. - Metastasen: Linkerseits findet sich seitlich von den Körpern des I. und 2. Kreuzbeinwirbels ein etwa walnußgroßer weicher Geschwulstknoten; in der Spongiosa der beiden Darmbeinschaufeln kleine Geschwulstherde. Art des Sarkoms: Spindelzellensarkom. - Gesamtzeit des Verlaufs: Vor Io Wochen plötzlich Reißen und Stechen in der rechten Hüfte und dem rechten Oberschenkel. - Bemerkungen: Die zunchmenden Schmerzen strahlten bis in die Wade aus. Hyperästhesie im Verlauf des N. ischiadicus. Pneumonie.

Fall 38. Ko cher, Chir. Operat.-Lehre I 884, 4. Aufl. Alter: 5 I Jahre. - Trauma: Ja; Art nicht angegeben. - Ausgangspunkt: Die Geschwulst nahm fast dic ganze rechte Darmbeinschaufel ein. - Operation: 9. XII. 
I884. Scham- und Sitzbein $2 \mathrm{~cm}$ medianwärts von der Pfanne durchsägt, Lösung hinten in der Synchondr. sacro-iliaca. Oberes Femurende reseziert. Erfolg: I9. I. 1885 Gehversuche, I6. III. mit Krücke und Stock entlassen. 3. VII. 1888: Scit der Operation gesund; er hat I Monat nach der Entlassung angefangen, leichte Arbeit zu verrichten. Jetzt ist er bei der Landarbeit behilflich. - Art des Sarkoms: Osteoidchondrosarkom; unregclmäßig, derb, höckerig; stellenweise eine dünne Knochenschalc. - Bemerkungen: 3. VII. I 888: Er kann eine Stunde weit gehen ohne Unterstützung, er hinkt wie ein Iuiftgelenk-Resezierter, geht auf der Fußspitze, setzt sein Bein in Schleuderbewegung vor.

I a 1139 wie 38 . I885 (?). Alter: 13 Jahre. - Operation: Exart. interilio-abdom. Schnitt von der Synchondr. sacro-iliaca entlang der Crista und dem l'oup. Bande. Abwärts werden erst unter dem Poup. Bande die Muskeln lateral von den großen Gefäßen abgelöst, dann stumpf dic Ansätze des Glut. med. und min. unter der Crista abgehoben bis zur Synch. Dann lliopsoas und Gelenkkapsel mit Lig. Bertini durchschnitten und medianwärts das Schamund Sitzbein durchschnitten. Jetzt Trennung der Synchondr. sacro-iliaca und Luxation der Beckenhälfte abwärts. Es bleibt noch der Rest der Rückfläche des Beckens frei zu machen und die Flexoren am Sitzknorren sowie die Lig. sacro-iliaca ab»utrennen. Keine größcren Gefäße verletzt. - Erfolg: Heilung per primam. - Art des Sarkoms: Pulsierendes Sarkom.

Ii a 11 40. Bergmann u. Bruns, Handb. d. prakt. Chir. I885 (?, 3. Aufl., Bd. 4. Alter: 36 Jahre. - Trauma: Quetschung der Kreuzbeingegend durch eine schwere Kistc. Sofort Schmerzen. - Ausgangspunkt: Kreuzbcin. - Zcit zwischen Trauma und Lirkrankung: 4 Wochen nach dem Unfall bettlïgeris. - Gesamtzeit des Verlaufs: 4 Monate nach dem Unfall Tod.

F a 11 4l. Köhler, Charité-Annalen, XIII. Jahrgang. Ber. pro 1886. Alter: 25 Jahre. - Trama: Fall beschleunigte wahrscheinlich nur das Wachstum, da schon vorher Schmerzen in der Iinken Hüftgegend. - Ausgangspunkt: Außenfläche der linken Darmbeinschaufel. - Operation: Bildung eines Lappens; aus cler Crista mußte ein Keil ausgesägt werden; vollständige Ausschälung des Tumors. Geringe Blutung (Paquel.). Von der Entfernung der Geschwulstmasse in Becken mußte abgesehen werden. Entfernung der Leistendrüsen. Gewicht der herausgenommenen Geschwulstteilchen $720 \mathrm{~g}$. Erfolg: Reaktionslose Heilung; Wohlbefinden bis I Monat nach der Operation. Rezidiv. Tod 2 Monate nach Operation. - Metastasen: Pulmonum, renum, gland. mesar. et retroperit. - Zcit zwischen Trauma und Erkrankung: Geschwulst nach 6 Wochen bemerkt. - Art des Sarkoms: Sarcoma medulare regionis coxae et femoral. sin. Fluktuierend. - Gesamtzeit des Verlaufs: ca. $1 / 2$ Jahr. - Bemerkungen: Im Becken Geschwulstmassen zu fühlen; durch Incis. isch. major ragte ein Zapfen hinein. Leistendrüsen faustgroB.

Fall 42. Gussenbauer, Prager Zeitschr. f. Heilk. I89o, Nr. 5 bis 6. I887. Alter: 25 Jahre. - Trauma: Fall. - Ausgangspunkt: Linke Darmbeinschaufel, inncre und äußcre Flächc. - Periostal oder myelogen: Myelogen. - Operation: Exstirpation mit Entfernung eines trapexförmigen 
Stückes aus dem Os ilium. - Erfolg: Heilung nach 7 Wochen. Rezidiv nach 3 Monaten. - Zeit zwischen Trauma und Erkrankung: ca. 3 Wochen. - Art des Sarkoms: Alveol. Rundzellensarkom. - Gesamtzeit des Verlaufs: ca. 1/2 Jahr. - Bemerkungen: Intermittierende Schmerzen an der Vorderseite des linken Oberschenkels.

Fall 43. B e a un e z, Virchow-Hirsch, Jahrg. I889, II. I888. Alter: 56 Jahre. - Ausgangspunkt: Steißbein. - Operation: Operation mit Resektion eines Teils des Kreuzbeins. - Erfolg: 3 Wochen nach Operation geheilt. Bemerkungen: Vor 8 Jahren zuerst bemerkt.

F a 11 44. Eugen Rüge, Dissert. Greifswald r888. Alter: 44 Jahre. - Trauma: Fall auf der Straße. - Ausgangspunkt: Linkes Hüftbein. Operation: Exstirpation; Entfernung der Lamina int. sowie der Spina ant. sup. und inf. des linken Hüftbeins. Bloßlegung des Periton. in großer Ausdehnung, aber ohne Verletzung desselben. - Erfolg: Exitus 7 Tagc p. operat. an Peritonitis (keine Sektion). - Gesamtzeit des Verlaufs: ca. I Jahr. --Falsche Diagnose: Probeincision ergibt Sarkom. - Bemerkungen: Dic Schwellung in der Gegend des linken Hüftbeins reichte nach vorn fast bis zur Linea alba, nach hinten bis zur Mitte der Crista ilei, nach oben und unten nicht deutlich abgrenzbar.

Fall 45 wie 44. I888. Alter: 45 Jahre. - Ausgangspunkt: Rechter horizontaler Schambeinast. - Operation: Bei Probeincision Herausdrücken möglichst großer Tumormassen. Keine weitere Operation, weil unmöglich alles entfernt werden konnte. - Erfolg: Tod unter Inanitionserscheinungen. - Metastasen: Leistendrüsen beiderseits etwas derb infiltriert. - Art des Sarjoms: Elastisch-weiches Myxosarkom und Rundzellen. Deutlich fluktuierend. - Falsche Diagnose: Bei Probeincision Entleerung von Myxomgewebe, gemischt mit derben Partien vom Ausschen von Sagokörnern. Bemerkungen: Der Tumor reichte nach links bis zur Linea alba, nach oben ca. $4 \mathrm{~cm}$ unter die Nabellinie und die große und kleine Beckenhälfte fast vollständig ausgefüllt. Später Blase und Mastdarm verdrängt. Decub., Ischurie, Ret. urinac. Ödem beider Beine.

Fall 46. Braunstein, Dissert. Bonn i888. Alter: 46 Jahre. Ausgangspunkt : Linke Darmbeinschaufel. - Operation: Exstirpation mit teilweiser Resektion des linken Darmbeins (W it z el). - Erfolg: 5 Tage später Exitus let. - Bemerkungen: Schmerzen im linken Bein.

Fall 47 wie 46. r888. Alter: 29 Jahre. - Ausgangspunkt: Linkes Os ilium, Fossa iliaca ext. und int. (Gegend der Art. sacro-iliaca sinistr.). Operation: Vollständige Entfernung des Tumors. MeiBelrescktion eines Stückes der Darmbeinschaufel und des Kreuzbeins (Trendelenburg). - Erfolg: Nach gut 3 Monaten Entlassung mit wenig sezernierender Wunde.-Art des Sarkoms: Chondrosarkom. - Bemerkungen: Heftige, nach dem linken Bein ausstrahlende Schmerzen.

F a 11 48. Langenbecks Archiv, Bd. I7, S. 92. Th. Jaffé. Alter: 25 Jahre. - Trauma: Keine bestimmte Schädlichkeit, wohl aber infolge stänständigen Rückwärtsgehens bei der Berufstätigkeit häufige Stöße an dem 
Körperteil, wo die Geschwulst saß. - Ausgangspunkt: Linkes Darmbein. Periostal oder myelogen: Periostal. - Operation: Innerhalb 8 Wochen 3 mal Elektropunktion nach $\mathrm{C}$ incinelli. Sehr blutige Operation (Simon); die Geschwulst konnte nicht vollständig entfernt werden. - Exfolg: Elektropunktion ohne jeden Erfolg. Tod am Tage der Operation. - Metastasen: In beiden Lungen. - Art des Sarkoms: Alveoläres Rundzellensarkom; pulsierend, blasende Geräusche. - Gesamtzeit des Verlaufs: I21/2 Monatc. Falsche Diagnose: Man schwankte zwischen Aneurysma der Art. glut. sup. und Sarkom. - Bemerkungen: Usur der linken Darmbeinschaufel im ganzen Durchmesser.

Fall 49. Roux, D uplay et Reclus, Revue de Chir., Paris 1889. Alter: ?. - Operation: Ausgiebige Resektion von Beckenknochen. Bei der 2. Operation wurde das Cöcum sehr weit bloßgelegt; es blieb kaum ein erbsengrobes Stück der Spina ischii zurück. - Erfolg: Wieder vollkommen arbeits. fähig. Rezidiv 4 Jahre später, wieder arbeitsfähig. Neues Rezidiv nach weiteren 2 Jahren. Tod nach künstlicher Infektion mit Erysipel. - Art des Sarkoms: Enchondroma malignum.

F all 50. Mersch, Virchow-Hirsch, Jahrg. 89, II, S. 395 u. 396. I889. Alter: 30 Jahre. - Trauma: Fall. - Ausgangspunkt: Darmbeinschaufel fast ganz verschwunden; Kreuzbein usuriert. - Art des Sarkoms: Gemischtes Sarkom. Gesamtzeit des Verlaufs: 2 Jahre. - Falsche Diagnose: Ischias und Aneurysma.

Fall 5r. Nierle, Iissert. München 1889. Alter: 44 Jahre. - Ausganspunkt: Darmbein. - Periostal oder myelogen: Myclogen. - Operation: Exstirpation und Wegnahme eines Teiles des oberen und äußeren Randes des Darmbeinkammes ( $\mathrm{N}$ u B b a u $\mathrm{m}$ ). - Zeit zwischen Trauma und Erkrankung: 4 Monate. - Art des Sarkoms: Spindelzellensarkom. - Gesamtzeit des Ver-

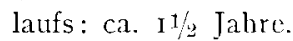

If a 11 52. Gussenbauer, I'rager Zeitschr. f. Heilk. э 890, Nr. 5 bis 6. Alter: 47 Jahre. - Trauma: 2mal Fall; der 2. Fall 4 Wochen später. - Ausgangspunkt: Os silcrum. - Operation: Os sacrum im r. Wirbel durchmeißelt und der 1. Stcißbcinwirbcl mitentfernt. - Erfolg: Ieilung unter Eiterung und Bildung einer Hernia sacralis. Wiederholte Rezidive nach Io Monaten. 'Tod 21/1 Jahre nach der Operation. - Zeit zwischen Trauma und Erkrankung: 2-3 Monate. - Art des Sarkoms: Myxosarkom. - Gesantzeit des Verlaufs: 4 Jahre. - Bemerkungen: Lungentuberkulose.

Fall 53. Tilluanns, Lehrb. f. Chir, 1892. Alter: 66 Jahre. Trauma: Fall mit dem Rücken auf einen Stuhl; später Heben ciner großen Last. - Ausgangspunkt: Rechte Darmbeinschaufel. - Periostal oder myelogen: Periostal. - Metastasen: Vorhanden. Halswirbelsäule? Halsdreieck. - Zeit zwischen Trauma und Erkrankung: ca. 3 Jahre. - Art des Sarkoms: Fibrosarkom. - Gesamtzeit des Verlaufs: 8 Jahre. - Falsche Diagnose: Ischias. - Bemerkungen: Fast kindskopfgroB.

Fall 54. Dissert. v. H. Dorn. Alter: 5I Jahre. - Ausgangspunkt: Rechtes Darmbein (Crista ilei). - Periostal oder myelogen: Periostal. - 
Operation: Durch 2 ovale sich unter spitzen Winkeln kreuzende Schnitte, welche von der Wirbelsäule aus nach rechts zwischen I2. Rippe und Darmbeinkamm geführt werden, wird ein Keil aus dem Tumor mit Haut entfernt. Erkranktc Bündel des M. sacrolumb. mit weggenommen. Riß in das Bauchfell; Einriß in die Pleura. Der ganze Darmbeinkamm wird in einer Ausdehnung von to $\mathrm{cm}$ Länge und $3 \mathrm{~cm}$ Höhe entfernt. N. cruralis wurde in ciner Ausdehnung von $3 \mathrm{~cm}$ reseziert und genäht. - Erfolg: Nach Operation Atemnot infolge Pneumothorax. Nach 9 Tagen Stuhlverhaltung, Appetitlosigkeit. Nach II Tagen Atemnot, leichte Cyanose. Über rechter Lunge h. Dämpfung, leises Bronchialatmen; Fieber. Subperiostale Rescktion der 7. Rippe; es entleert sich ca. $1000 \mathrm{ccm}$ eitrigen Exsudats. Delirien und Tod nach nicht ganz 4 Wochen. - Metastasen: I Lymphdrüse der rechten, Leistengegend. - Art des Sarkoms: Straffes, bindegewebiges Stroma und spindelförmige langgestreckte Zellen; auch kleine Rundzellen, die wohl lymphoiden Elementen angehören dürften; alveolärer Charakter. - Gesamtzeit des Verlaufs: Vom Beginn der Schmerzen bis zur Operation ca. $\mathrm{I}^{1 / 2} \mathrm{Jahr}$. - Falsche Diagnose: Zweifel, ob nicht I2. Rippe Ausgangspunkt sei. - Bemerkungen: Die Anschwcllung erstreckte sich von der Gegend der Crista ossis il. nach aufwärts bis zur letzten Rippe, nach vorn zu bis in die Gegend der Spina ant. sup. Der Tumor konnte weder gegen dic I2. Rippe, noch vom Darmbein, noch auch von der Wirbelsäule abgegrenzt werden. - Seit $I_{1 / 2}$ Jahren Schmerzen in der rechten Weiche, seit 7 Wochen im rechten Knie.

Fall 55. Güldner, Dissert. Rostock 1895. Alter: 6o Jahre. Trauma: Nachdem schon 2 Jahre Schmerzen bestanden hatten, Sturz von einem Wagen, unbedeutende Verletzung der rechten Hüfte. 14 Tage später nach einer Anstrengung Schmerzen im Kreuz, in der rechten Hüfte und im ganzen rechten Bein. - Ausgangspunkt: Os ilium dextr. - Periostal oder myelogen: Wahrscheinlich myelogen. - Operation: Exstirpation des Tumors; Auskratzung des Knochcndefektes mit schartem Löffel. - Erfolg: Entlassung mit kleinen Wundtrichter. Nach ${ }_{4} 4$ Tagen Anschwellung der rechten Darmbeinschaufel, besonders nach dem Sacrum zu. Tod. - Metastasen: Wahrscheinlich Rezidiv mit Metastasen in inneren Organen. - Art des Sarkoms: Alveoläres großzelliges Rundzellensarkom; undeutliche Fluktuation. - Gesamtzeit des Verlaufs: ca. 21/2-3 Jahre. - Falsche Diagnose: Wegen Lumbago Bäder und Faradisation; subjektive Besserung. Später Wahrscheinlichkeitsdiagnose: AbszeB vom Sacrum ausgehend. Aufklärung durch Operation.

F a 1156 wie 55. 1895. Alter: 25 Jahre. - Trauma: Vor $\mathbf{I}^{1 / 2} / 2$ Jahren warf sich Pat. einmal im Bctt von eincr Seite gewaltsam auf die andere. Ausgangspunkt: Unteres Ende der Wirbelsäule, Kreuzbein und Darmbeinschaufel. - Periostal oder myelogen: Myclogen. - Operation: Es war unmöglich, bei der Operation die Knochenschale vollständig zu entfernen. Das Rezidiv wird ausgekratzt. - Erfolg: Entlassung mit Wunde. Die zurückgebliebenen Reste des Tumors hatten sich nicht vergrößert. Später Blutungen. Rezidiv. Wieder arbeitsfähig für leichtere Arbeit entlassen. - Metastasen: Inguinaldrüsen beiderseits, besonders rechts. - Zeit zwischen 
Trauma und Erkrankung: Vielleicht 1 1/2 Jahr, wahrscheinlich schon vorher bestehend. - Art des Sarkoms: Kindskopfgroßes Osteoidsarkom mit vielen Riesenzellen und myxomat. Erweichung. - Falsche Diagnose: Tumor, von der Nicre ausgehend. - Bemerkungen: Beim Herumwerfen im Bett empfand er einen intensiven stechenden Schmerz, zugleich bemerkte er einen taubeneigroßen Knoten in der Gegend der 12. Rippe, der am nächsten Tag wieder verschwunden war.

F a 1157 wie 55. 1895. Alter: 16 Jahre. - Ausgangspunkt: Os ilium dextr. - Operation: Probepunktion. 6 Injektionen von Pyoktanin $(1 / 300)$ - - Erfolg: Der Tumor wuchs dabei zusehends. - Art des Sarkoms: Rundzellensarkom, in der Tiefe fluktuierend. - Bemerkungen: Starke Auftreibung im Bereich des rechten Os ilium; der größte Teil derselben befindet sich hinten und erstreckt sich von der Crista nach unten bis zum Trochanter, nach hinten bis zur Symph. sacro-iliaca. Zusammen kindskopfgroß. Schmerzen in der rechten Hüftgegend, dann auch im rechten Bcin. Beugekontraktur von ca. 20 Grad. Leichtes ödem.

Fall 58. Löwentha 1, Arch. f. klin. Chir. 1895. Alter: 23 Jahre. -. Trauma: Fall auf das Gesäß beim Längssprung über den Kasten, ca. 2 Monate später Schmerzen beim Urinieren. - Ausgangspunkt: Kreuzbein und beide Darmbeinschaufeln sind angefressen. - Zeit zwischen Trauma und Erkrankung: Sarkom diagn. 5 Mon. p. Tr. - Art des Sarkoms: Großes Spindelzellensarkom. - Gesamtzeit des Verlaufs: 7 Monate p. Trauma Exitus. - Bomcrkungen: Später unfreiwillige Harn- und Stuhlentleerung; Verwirrtheit, Schmerzen in der Wade, mot. Parese des rechten Bcins, Halluzinationen.

Fi all 59. A lbert, Wiener klin. Rundschau I895, Nr. r, S. 2 u. 3. Alter: Alter Herr. - Vorausgegangene Knochencrkrankungen: Sternumsarkom, das fälschlich als liungus erklärt worden war. - Ausgangspunkt: Linkes Darmbein. - Art des Sarkoms: Pulsierend.

F all 60 wie 59. Alter: Mann in den sechziger Jahren. - Ausgangspunkt: Der Tumor saß am oberen Rand des linken For. ischiad. - Metastasen : Hypostatische Pneumonie (Metastasen?). - Art des Sarkoms: Pulsierend. Falsche Diagnose: Ischias.

F a 11 6r wie 59. Alter: Älterer Mann. - Trauma: Heftiges Trauma. - Ausgangspunkt: Linkes Darmbein, knapp neben der Symph. sacro-iliaca. Zeit zwischen Trauma und Erkrankung: Einige Wochen. - - Art des Sarkoms: Pulsiercnd. - Gesamtzeit des Verlaufs: Viclleicht 3-4 Monate.

F a 1162 wie 59. Alter: Alter Mann. - Ausgangspunkt: Linkes Darmbein. - Metastasen: Vorhanden. - Art des Sarkoms: Pulsierend. - Falsche Diagnose: Änlichkeit mit Aneurysma.

F a 1163 . K ü m m 1, Deutsche Chirurgie I905. I895. Alter: 47 Jahre. - Trauma : Zugestanden. - Ausgangspunkt: Kreuzbein. - Operation: Exstirpation. 2 Jahre später Entfernung der 2. Geschwulst im Wirbelkanal. Erfolg: 2 Monate nach der letzten Operation kann Pat. das Bett verlassen und nach 1/2 Jahr ohne Stock längere Zeit umhergehen. - Metastasen: 2 Jahre 
nach Exstirpation der I. Geschwulst eine extradural gelegene, ähnliche Geschwulst aus dem Wirbelkanal in der Höhe des 3. Brustwirbels. - Art des Sarkoms: Spindelzellensarkom. - Bemerkungen: Durch die Geschwulst im Wirbelkanal war vor der 2. Operation schon eine Lähmung der Beine und Sphinkteren eingetreten.

F a 11 64. H. P e ha m (1895), Deutsche Chirurgie 1905. Alter: I7 Jahre. - Ausgangspunkt: Unteres Kreuzbeinende. - Operation: Die Geschwulst mußte von der Beckenmuskulatur scharf abpräpariert werden, ließ sich aber vom Mastdarm leicht stumpf lösen. Der knöcherne Stiel wurde in der Höhe des 3. Kreuzbeinwirbels abgemeißelt. - Erfolg: Heilung ohne nervösc Ausfallserscheinungen. In der Knochenlücke bildete der Mastdarm im Bereich der Steißgegend bei der Inspiration eine blasenartige Vorwölbung. - Art des Sarkoms: Riesenzcllensarkom, fluktuierend. - Gesamtzeit des Verlaufs : Einige Monate (?). - Falsche Diagnose: Kalter AbszeB; erst bei der Operation ergab sich die Geschwulst. - Bemerkungen: Kindskopfgroß.

F a 11 65. Deutsche Chirurgic I 895. Krause, Altona I895. Alter: 33 Jahre. - Ausgangspunkt: Hinterfläche des linken horizontalen Schambcinastes. - Periostal oder myelogen: Periostal. - Operation: Die Breite des durch die Knochenresektion entstandenen Defektes im vorderen Beckenring, d. h. des linken horizontalen Schambeinastes und des oberen Abschnittes des linken absteigenden Schambeinastes, der Symphyse und der nächsten Teile des rechten Schambeinastes betrug $7,5 \mathrm{~cm}$. - Erfolg: Die Wunde heilte glatt; wieder arbeitsfähig. I Jahr später Hernie, die auch wieder geheilt wurde. - Bemerkungen: I Jahr später durch schwere Arbeit eine besondere Hernic (Fingeweide und besonders die Blase). Verschluß des Beckenringes durch einc osteoplastische Operation. Heilung.

F a 11 66. A. Gaspar, Dissert. München I896. Alter: 28 Jahre. Trauma: Angeblich im AnschluB an eine Erkältung Schmerzen ungefähr im Verlauf des N. ischiad. im linken Obcrschenkel. - Ausgangspunkt: Symphys. sacro-iliaca sinistra, - Periostal oder myelogen: Periostal. - Operation: Freilegung des Tumors. Die Geschwulst setzte sich so ticf in das For. ischiad. major fort, daß an eine weitere Exstirpation nicht mehr zu denken war. Erfolg: 3 Wochen später Wunde bis auf eine fünfmarkstückgroße Fistel geheilt, die in eine geräumige Höhle führt. Es besteht noch Arbcitsunfähigkeit. - Metastasen: Inguinaldrüsen minimal geschwellt. - Falsche Diagnose: Gegen die Schmerzen im Verlauf des $\mathrm{N}$. isch. nach der Erkältung Einreibungen, Wasserheilanstalt; ohne Erfolg. - Bemerkungen: Es bestand in der Art. sacro-iliaca über dem Darmbein ca. kindskopfgroße Gcschwulst.

F a 1167 wie 66. I896. Alter: 4I Jahre. - Vorausgegangene Knochenerkrankungen: Gonorrhöc. Inf. zugestanden; am Penis deutliche Narben. Trauma: Nach einer Durchnässung ror 13 Wochen Schmerzen, die vom rechten Sitzbein an der Hinterseite und Innenseite des Oberschenkels nach abwärts strahlten. - Ausgangspunkt: Von der Innenfläche des rechten Sitzbeins wölbt sich gegen das Mastdarmlumen eine Geschwulst vor; wach unten reicht sie fast bis zum Anus, endet in gleicher Höhe mit dem Tub. ischii. - 
Metastasen: Rechte Leistendrüsen stark geschwellt. Am Kopfe in der Mittellinie - Grenze zwischen Stirn- und Scheitelbcin - eine über haselnußgroße Geschwulst; eine ähnliche, pflaumengroße obcrhalb des Proc. mast. - Art des Sarkoms: Zum Teil hart, zum Teil fluktuierend. - Bemerkungen: Auch an der Hinterfläche der Symphyse ein Tumor. Tuber ischii etwas aufgetricben.

F all 68. Tegeler, Dissert. Groifswald I897. Alter: 15 Jahre. -Trauma: Fall mit der Steiß- und Kreuzbeingegend auf cine Waschtonne. Ausgangspunkt: Os sacrum. Es war fast halb durchwachsen und zum Teil zerstört. Der Tumor füllte fast das ganze Becken aus. Steißßbein ebcnfalls in zerklüftete Tumormasse verwandelt. - Periostal oder myelogen: Myelogen. - Metastasen: Lungen. - Art des Sarkoms: Kindskopfgroß. Rundzellensarkom, und zwar Osteoidsarkom; fluktuierend. - Gesamtzeit des Verlaufs: Etwas über I Jahr. - Falsche Diagnose: Rheumatismus. - Bemerkungen: Schmerzen im Kreuzbein, die Beine wurden schwächer. Incont. alvi, Beschwerden beim Harnlassen. Lähmung der Sphinktcren des Anus; Anästhesie der Rückseitc der unteren Extremitäten, der Fußsohle, Außenscite und Rücken des Fußes. Ficber.

Fall 69. Carl Perrenon, Disscrt. München i 898 . Alter: 74 Jahre. - Trauma : I'at. führte das Leiden auf seine Beschäftigung als Korbmacher zurück. - Ausgangspunkt: Rechtes Darmbein und Schambein. Dic ganze rechte Hüfte nach vorn und rückwärts von cincr sehr starken Schwellung cingenommen. Sic erstreckt sich über dic Inguinalgegend in die ganze rechte Beckenhälfte, erreicht fast Nabelhöhe, lateral den Rippenbogen. -Periostal oder myelogen: Myclogen. - Operation: Punktion ergibt cine geringe Menge einer bräunlichen Flüssigkeit; in der Ticfe weiche Massen zu erreichen. - Mctastasen: Multiple Metastasen in der rechten 3. bis 6. Rippe, in beiden I.ungen, in der linken Niere. - Art des Sarkoms: In der Reg. inguinal. Fluktuation. Gewicht des Tumors 28 Pfund. - Bemerkungen: Schon seit einigen Jahren heftige Schmerzen in der rechten Hüfe. Stuhlgang etwas angchalten. Schüttelfrost, Husten, Auswurf, Bronchitis, Ödem des rechten Beines und rechten Armes, Decub., Herzschwäche.

F a 11 70. E. G. Ssalitschew, Zentralbl. f. Chir. 1899. Alter: 38 Jahre. - Ausgangspunkt: Rechtes Os innominatum, durch das For. obt. auf den Schenkel gewachsen. Das Os innominatum war im \%entrum und im Schambeinteil vollständig zerstört, während das Os ilium sich unter der Geschwulst erhalten hatte. Der absteigende Ast des Schambeins und der aufsteigende des Sitzbeins waren unmittelbar mit der Geschwulstmasse verwachsen. - Periostal oder myelogen: Periostal. - Operation: Schnitt von der Spitze der 12. Rippe zur Spin. il. ant. sup., von da im Bogen obcrhalb des Lig. Poup. bis zum Tub. pub. Extrap. Ligatur der Art. iliaca comm., $3 \mathrm{~cm}$ von der Aorta. Ilicrauf Fortsetzung des Schnittes, so daB er einen hinteren Lappen bildet, dessen Form von der J a boulay s ctwas abweicht. Durchtrennung der Symphyse nach Ablösung der Wcichteile, M. psoas durchschnitten, ebenso N. fem., Vasa obtur., Bänder des Ileocöcalgelenkes, Nerven- 
plexus und damit Extremitäten mitsamt ihrer Beckenhälfte abgelöst. Mäßige Blutung. Muskel mit den Wundrändern vernäht. Hautnaht. - Erfolg: Eiterung, daher ein Teil der Wunde wieder geöffnet. Per secundam mit späterer Transplantation. Heilung nach ca. 3 Monaten. Funktion der Beckenorgane ungestört. Nach 3 Wochen konnte Pat. sitzen, nach 5 Wochen begann er an Krücken zu gehen. In ausgezeichnetem Zustand entlassen nach etwas mehr als 3 Monaten. - Metastasen: Art. und Vena iliaca comm. durchwachsen. - Art des Sarkoms: Mehr oder weniger große spindelförmige Zellen, häufig auch Rundzcllen mit bedeutenden Mengen von homogener Zwischensubstanz; seltener osteoides Gewebe. Gewicht ohne Inhalt des ro: I2 großen Erweichungsherdes $6 \mathrm{~kg}$. - Bemerkungen: Die Geschwulst war aus dem Zentrum des Os innominatum in der Richtung auf die Bauchhöhle zu und durch das For. obt. nach unten auf den Oberschenkel gewachsen; in das Oberschenkelbein war sic nur in den Kopf eingedrungen. Der Tumor reichte nach oben bis zum Nabel, nach unten griff er auf den rechten Oberschenkel über.

F all 7I. Lengnick, Zeitschr. f. Chir. I899. Alter: 30 Jahre. Trauma: Fall mit cinem schweren Baumstamm auf die rechte Hüfte gegen einen Steinhaufen. Sofort heftige Schmerzen. - Metastasen: Rechter Oberschenkel und in kleinen Becken. - Zeit zwischen Trauma und Erkrankung: Innerhalb einiger Wochen entsteht Geschwulst an der Aufschlagstelle. Sarkom diagnost. 3 Mon. p. Tr.

Fall 72. Hermauer, Deutsche Chirurgie I905. (I899). Alter: 43 Jahre. - Trauma: Fall auf das GesäB. -- Ausgangspunkt: Kreuzsteißbein. - Operation: Beim Abtragen der Geschwulst durch P a y r wurde der Kreuzbeinkanal breit exöffnet. - Erfolg: Ungestörte Ifeilung ohne Sensibilitätsund Motilitätsstörung. I $1 / 2$ Jahr nach der Operation war Pat. noch gesund und arbeitsfähig. - Art des Sarkoms: Alveolarsarkom. - Bemerkungen: Kindskopfgroß. Wahrscheinlich von der Dura mater ausgegangen.

Fall 73. Machol, Alfred, Dissert. Straßburg igoo. Alter: 81/2 Jahre. - Trauma: Fall mit der rechten Gesäßhälfte durch Stoß eines Mitschülers. Sofort nach dem Aufstehen Hinken. Am folgenden Tag Schmerzen in der rechten Scite und Behinderung beim Gehen. - Ausgangspunkt: Rechte Beckenschaufel. - Operation: Exstirpation unter Resectio ossium. - Zeit zwischen Trauma und Erkrankung: Sark. diagnostiziert 5 Wochen p. tr. - Gesamtzeit des Verlaufs: 7 Monate. - Bemerkungen: Rasch wachsende Schwcllung über dem Lig. Poup. in der rechten Unterbauchgegend.

Fall 74 wie 73 . 190o. Alter: 32 Jahre. - Trauma: Fall mit dem rechten Oberschenkel und der rechten Gesäßhälfte auf einen Baumstumpf. Sofort starke Beschwerden beim Gehen. Schmerzen bei Gehversuchen und Liegen auf der rechten Seite. -- Ausgangspunkt: Beckenwand. - Metastasen: Inguinaldrüsen geschwellt. Tumoren an der Außenseite des rechten Femur. - Zeit zwischen Trauma und Erkrankung: 14 Tage nach dem Trauma Anschwellung, die innerhalb eines Jahres rapid wuchs. Sark. diagn. I Jahr p. Tr. - Bemerkungen: Untersuchung p. rect.: An der Innenseite der rechten 
Beckenwand ein kleinapfelgroßer Tumor, an der Außenseite der Beckenwand über dem Trochanter cine kindskopfgroße Anschwellung. - Ziehende Schmerzen bald im linken, bald im rechten Bein; intermittierend. Rechtes Bein in der Hüfte flektiert und nach außen rotiert.

Fall 75 wic 73 . I90o. Alter: 4I Jahre. - Trauma: Vor 2 Jahren heftiger Stoß mit dem Kreuzbein gegen einen Mauerstein.- Ausgangspunkt: Kreuzbein. Kreuzbein und Steißßbein vollkommen zerstört. - Periostal oder myelogen: Myclogen. - Operation: Radikale Entfernung des Tumors erwies sich bei Operation unmöglich. - Metastasen: In beiden Nebenhoden Knoten füllbar. - Zeit zwischen Trauma und Erkrankung: Ca. I1/2 Jahre. - Bemerkungen: In der rechten Inguinalbeuge ist ein Tumor fühlbar, der sich ein wenig von der rechten Beckenschaufel abdrängen läßt und mehrerc Finger breit über die Medianlinie reicht. Blase etwas nach links verdrängt. Per rectum: Ein bcinahe das ganze Becken ausfüllender Tumor, der das Rectum komprimiert. Starker Tonesmus.

F all 76. Na nu, Congrès international de médecine Paris 1900. Deutsche Chirurgic 1903, Bd. 71. Alter: 50 Jahre. - Ausgangspunkt: Dic Geschwulst ging vom linken Darmbein aus und crgriff das linke Os pubis, Os ischii, Cavit. cotyloid., Kopf und Hals des Femur. - Operation: Esmarchsche Binde vom FuB bis zum Tumor hin. Ligatur der Art. il. comm. Mit Hilfe eines Schnittes vom Tuber pub. bis zur Spina il. post. sup. längs der Crista. Extraperit. Durchschneidung der Vasa iliaca comm. zwischen 2 I,ig. Exarticulatio interilio-abdomin. mit Lappen nach Jaboulay. Fast keine Blutung. Dauer 85 Minuten. - Erfolg: Am I. Tage leichter Kollaps. Harnverhaltung, kein Fieber. - Am 4. Tage Trennung der meisten Nähte wegen Infektionszeichen und Gangrän, die am 6. Tage die ganze Wundfläche einnimmt. - Feuchte, Gangrän und trockener Brand der Zehe treten auf. 'Tod nach 20 Tagen. - Art des Sarkoms: Myxosarkom. - Bemerkungen: Heftige Schmerzen in den unteren Extremitäten, die vor 16 Monaten mit Schmerzen im Knic begonnen hatten. Almählich bildete sich dann in der Leistengegend ein Tumor, der bis 2 linger vom Nabel hinaufreichte und die Medianlinie überschritt. - Für den ungünstigen Ausgang macht $\mathrm{N}$ a $\mathrm{n}$ u die Ligatur der Art. il. commun. verantwortlich, die einen Thrombus bis nach der Bifurkation der Aorta hin verursacht hatte, mit darauffolgender Embolie der A. iliaca der anderen Seite.

Fall 77. Berthomier, Revue de Chirurgic igor. Alter: ?. Ausgangspunkt: Os ischii; es war das Hüftgelenk mit crkrankt und, wie es scheint, auch das Os pub. - Opcration : Rouxscher Schnitt zur Appendektomie. Auf diese Weise Bloblegung der Art. Ligatur der Art. il. commun. als prälimin. Operation zur Exart. coxae. Diese kam sehr leicht zustande; dann Resektion eines Teiles des Os pub. und ischii. - Art des Sarkoms: Osteosarkom.

Fall 78. Otto KaBler, Dissert. Jena 19o2. Alter: io Jahre. -Ausgangspunkt: Wahrscheinlich Os ilium sinistrum. - Operation: Soweit es möglich ist, wird die Geschwulst herausgeschnitten. Auskratzung des Periostes 
sowie der erweichten Knochenmassen mittels scharfen Löffels (Prof. R i e d el). - Erfolg: Wunde heilt ziemlich gut. Auf Wunsch entlassen. - Art des Sarkoms: Klcine Rundzellen; ziemlich spärliche Bindegewebszüge, äußerst spärliche Blutgefäße; undeutliche Fluktuation. - Falsche Diagnose: Wahrscheinlichkeitsdiagnose auf Osteomyelitis. - Bemerkungen: Bei der wegen Osteomyelitis vorgenommenen Operation findet sich nur Sarkongewebe, das die gesamte Muskulatur einnimmt und diffus auf Periost und Knochen übergeht; die Neubildung reicht noch über die Sin. arcuat. ext. hinaus. Schmerzen in der linken Beckenschaufel, Fieber. Schlaffes Nachzichen des linken Beines beim Gehen.

F a 1179 wie 78 . I902. Alter: 60 Jahre. - Vorausgegangene Knochenerkrankungen: Mit 20 Jahren Gonorrhöe.-- Ausgangspunkt: Linkes Os ilium. - Periostal oder myelogen: Periostal. - Operation: Einschnitt entlang der Artic. sacro-iliaca. Man komint sofort auf diffuse graugelbe Neubildungsmasse, welche das ganze Os ilium einnimmt. Es wird die Operation wegen Aussichtslosigkeit auf radikale Entfernung der erkrankten Partien abgebrochen. - Erfolg: Am nächsten Tage Exitus. - Metastasen: Am sternalen Ende der Clavic. fällt eine harte, kolbige, nicht druckempfindliche Verdickung auf. - Art des Sarkoms: Spärliche Gefäßbildung, reichliche 13indegewebe- und Spindel- wie Rundzellen; kleinzelliges Rundzellensarkom. Falsche Diagnose: Diagnose schwankte zwischen Tuberkulose und Sarkom. - Bemerkungen: Ischiadische Schmerzen links, Abmagerung des linken Beines, Parese des rechten Rekurrens. Sektion: Linkes Darmbein unterhalb der abgemeißelten Stelle des hinteren Kammes von weißer, elastischfester Neubildung durchsetzt, welche bis zu $10 \mathrm{~cm}$ Länge in den Musc. iliac. int. übergreift. Nerv. fem. grenzt eben an die Neubildung.

F a 1180 wie 78 . 1902. Alter: 60 Jahre. - Ausgangspunkt: Wahrscheinlich linkes Tuber ischii. - Operation: Bei der Operation zeigte sich ein zum Rectus und der Harnröhre hingewachsener Tumor. Die Geschwulst wurde in einer Ausdehnung von der Symphyse bis dicht unter das Hüftgelenk exstirpiert. Das Rectum riß $2 \mathrm{~cm}$ weit ein. Naht. - Erfolg: Geheilt entlassen. - Bemerkungen: Vor der Afteröffnung befand sich etwas links von der Medianlinic eine harte apfelgroße Geschwulst, die vom Tub. isch. ausging und sich in das Rectum vorwölbte; hinter ihr noch eine 2. Geschwulst fühlbar. In letzter Zeit Sitzen unmöglich. Kachektisches Aussehen.

Fall 81. Herm. Meyer-de Ruyter, Dissert. Leipzig 1902. Alter: 45 Jahre. -- Operation: Probeincision ergibt Spindelzellensarkom. Der rauhe Schenkelhals bricht bei passiven Bewegungen durch. Operation: Schnitt unter der linken Crista ilei und dem Poupartschen Band bis zur Symphysengegend. Art. und Vena iliac. commun. werden unterbunden. Hautmuskellappen mit der Basis hinten und seitliche Durchmeißelung bzw. Durchsägung des $O s$ ilium in der Mitte zwischen Lin. glut. ant, und post. Dann Schambein und aufsteigenden Sitzbeinast durchtrennt, Muskel abgelöst, Bein mit Becken entfernt. Mäßige Blutung. Kollaps. - Erfolg: I Stunde nach der Operation Exitus. - Art des Sarkoms: Spindelzellensarkom. - 
Falsche Diagnose: Zuerst Gehstörungen im linken Hüftgelenk, damals wegen cines prallen, runden Tumors exspektativ behandelt. Später wurde die Geschwulst weich, dann spontane Schmerzen in der linken Hüfte.- Bemerkungen: Bei Aufnahme in der Nähe des Trochanter kleine Fistel; an der Außenseite der linken Hüfte große runde Vorwölbung, die sich unterhalb der Weiche bis zur Innenseite des Oberschenkels fortsetzt. Die Geschwulst hat dic Größe cines Kindskopfes, zeigt mäßige Fluktuation. Große Schmerzen. Gewichtsabnahme etwa 40 Pfund.

Fall 82. Deutsche Chirurgie 1905. A. Martina 1903. Alter: 52 Jahre. - Vorausgegangene Knochenerkrankungen: 2 Jahre vorher war eine kleine pigment. Warze der Vorhaut entfernt worden. - Ausgangspunkt: Rechte Darmbeinschaufel. - Operation: Exstirpation des Tumors unter Rückstreifung des Bauchfells und Resektion eines dreicckigen, die ganze Darmbeinschaufel einnehmenden Knochenstückes. Stillung der ziemlich starken Blutung durch Thermokauter. - Erfolg: Rasche Heilung. Tod 21/2 Monate nach der Operation, wahrscheinlich infolge von Metastasen. Unter Lungenblutung nach vorheriger reichlicher Expektoration von Gewebsstücken. - Metastasen: Wahrscheinlich vorhanden. - Art des Sarkoms: Melanosarkom. - Falsche I) jagnose: Es wurde P'unktion und Incision gemacht, dadurch kaum stillbare Blutung. - Bemerkungen: Faustgroße Geschwulst an der rechten 1)armbeinschaufel dicht oberhalb der Hüftpfanne.

Fall 83. Kurt Krüger, Dissert. Greifswald 1903. Alter: Io Jahre. - Vorausgegangene Knochenerkrankungen: Mit 9 Jahren angeblich wegen vereiterter: Lymphdrüsen in der Regio submandib. sin. oper. Rhachitisch verdickte Epiphysenenden der langen Röhrenknochen. - Ausgangspunkt: Os ilium sinistr. Die Geschwulst liegt gewissermaßen inncrhalb der linken Beckenschaufel, denn während diese nach außen eine erhebliche Vorbuckelung trïgt, die von einer Knochenschale umgeben ist, geht nach außen der Tumor in große retroperitoneale Knollen über. - Periostal oder myclogen: Wahrscheinlich myclogen. -- Operation (P'rof. Tillmann): Schnitt längs der Beckenschaufel. Es findet sich ein Abszeß, blutig gefärbter Eiter entleert sich. 2. Operation: Schnitt in der Narbe, in der Tiefe mehr auf die Darmbeinschaufel zu. Mit dem scharfen Löffel Entfernung rauher Knochenteilchen: starke Blutung. -- Erfolg: Nach der Operation fast ununterbrochen Fieber. Ret. urinac, Incont. alvi, getrübtes Sensorium. Nackenstarre, Krämpfe, Cheync-Stockessches Atmen. Exitus. Ca. 4 Wochen nach der I. Operation: Die ganze linke Beckenschaufel von einer genau abgrenzbaren Geschwulstmasse ausgefüllt. In der linken Beckengegend ein praller Tumor, der das Rectum etwas nach rechts verdrängt. - Metastasen: Necrosis partialis pelvis. Encephalitis metastatica praecunii dextri. - Art des Sarkoms: Rundzellensarkom. Später Fluktuation. - Gesamtzeit des Verlaufs: ca. 61/2 Monate. Falsche Diagnose: Ischias, 4 Injektionen einer 3 proz. Karbollösung I mal täglich. Später: Senkungsabszeß oder Beckenosteomyelitis. Dann AbszeB, der vielleicht ron der Symplı. sacro-iliaca ausging. - Bemerkungen: 3 Wochen vor Aufnahme Schmerzen im linken Kniegelenk, besonders beim 
Gehen. Kontraktur im Knic- und Hüftgelenk; starke Druckempfindlichkeit im Verlauf des N. isch., besonders an seiner Austrittsstelle. Staung in den Venen des Oberschenkels.

Fall 84. Jos. Deilmann, Dissert. Halle igo3. Alter: 59 Jahre. - Trauma: Bei dem vorher völlig gesunden Mann stellten sich nach einer längeren Wagenfahrt, wo Patient auf dem Wagensitz hin und her geschleudert wurde, Schmerzen im linken Hüftgelenk und in der Darmbeingegend ein. Ausgangspunkt: Es war eine Anschwellung im linken Darmbein entstanden. - Operation: Auf die Punktion hin entleerten sich $400 \mathrm{ccm}$ blutig gefärbten Exsudats, in dem sich Gewebsfetzen fanden. - Art des Sarkoms: Die Untersuchung der bei der Punktion gewonnenen Gewebsfetzen ergab kleinzelliges Rundzellensarkom. - Bemerkungen: Es war eine Anschwellung im linken Darmbein entstanden. Die Schmerzen waren anfangs nicht sehr intensiv, Patient hinkte aber seit jener Wagenfahrt mit dem linken Bein und mußte sich dann eines Stockes bedienen. Später 2 Stöcke und schließlich konnte er sich auch damit nicht mehr fortbewegen.

F all 85. Löw enstein, Beirtäge z. klin. Chirurgie Igo6. Alter: 26 Jahre. - Trauma: Stoß in die Gegend der rechten Beckenschaufel. Sofort Schmerzen und Schwellung. - Operation: Verweigert. - Zeit zwischen Trauma und Erkrankung: Nach 3 Wochen apfelgroßer Tumor iber dem Lig. Poup. rechts. Sarkom diagn. 3 Wochen p. Trauma.

F all 86. H e in r. W e i B, Dissert. 1905. Alter: 52 Jahre. - Vorausgegangene Knochenerkrankungen: Früher wegen einer bösartigen Neubildung im Gesicht 2mal operiert. Immer schwächlich und blaß. Herzbeschwerden, häufige Katarrhe. Vor einigen Jahren Schlaganfall. Am Haise zahlreiche gestielte Papillome, ebenso auf der Brust und in der Leistengegend. -Trauma: Vor ca. 2 Jahren (Umfallen eines Stellwagens) leichte Gehirnerschütterung, dabei auch Bruch des linken Oberarms. Einige Zeit später Schmerzen in linken Oberschenkel. Diese vergingen wieder. I3ergpartie. Hernach angeblich infolge von Überanstrengung und Durchnässung wieder Schmerzen im linken Oberschenkel. -- Ausgangspunkt: Os ilium sinistr. (post. Exstirp. sacromatis genac). Die Masse ist verwachsen mit Os pub., hinteren Lenden - und Sacralwirbeln. Das Acetabulum ist von oben her völlig freigelegt. - Periostal oder myelogen: Myelogen. - Operation: Bäder. Injektion von Coleys Fluid. - Erfolg: Tod. - Metastasen: Leber. Diffuse Pneumonie. In der Lunge jauchende Zerfallshöhle im rechten Unterlappen. - Zeit zwischen Trauma und Erkrankung: Zwischen vorausgegangener Operation und dem Unfall liegt ein Zeitraum von 8 Jahren. - Art des Sarkoms: Hauptsächlich gleichmäßige Rundzellen. An einzelnen Stellen spärliche Züge von Spindelzellen. - Falsche Diagnose: Ischias; eine in Hüftgelenk sitzende Entzündung. Pfuscherin: Hüftgelenkverrenkung (Einrichtungsversuch). Bemcrkungen: In der linken Bauchgegend und in der linken Lendenweiche eine über kindskopfgroße Geschwulst. In der linken seitlichen Gesäßgegend eine kindskopfgroße fluktuierende Geschwulst. Bewegungen im linken Hüftgelenk behindert. Im Urin Spuren von Eiweiß und einige hyaline Zylinder, 
heftige Schmerzen in der rechten Bauchgegend. - Die entfernten l'apillome waren Spindelzellensarkome.

Fall 87. Joh. Gottschick, Dissert. Tübingen 1906. Alter: 23 Jahre. - Ausgangspunkt: Wahrscheinlich das rechte Darmbein, was nicht mit Sicherheit festzustellen war. Das Hüftgelenk vollständig zerstört, dagegen Kopf und Schaft des Femur crhalten. Es wird das ganze Darmbein, Sitzbein und Schambein, mit Ausnahme des Ram. inf. pub. cingenommen. Coll. fem., Troch. major und minor teilweise zerstört. -- Periostal oder myelogen: Myelogen. - Operation: Probepunktion ergibt kleine Gewebsfetzen, in denen Rundzellen ohne charakteristische Anordnung aufzufinden sind. Metastasen: Lungen; Geschwulstthrombose der rechten Vena iliaca und Vena cava. Thrombose der rechten Vena femoral. - Art des Sarkoms: Kleinzelliges Rundzellensarkom mit maschigem, zur Knochenbildung neigendem Stroma. Gewicht: $9 \mathrm{~kg} 900 \mathrm{~g}$. - Gesamtzeit des Verlaufs: Vermutlich ca. $3 / 4$ Jahr. - Falsche Diagnose: Rheumatische Erkrankung. Aspirin, Einreibung. - Bemerkungen: Zuerst Schmerzen in beiden Knie- und FuBgelenken und Iaumengelenk der rechten Hand. Fieber. Später Schmerzen im rechten Hüftgelenk. Seit 5-6 Wochen rasches Wachstum einer Anschwellung der rechten Hütgelenksgegend: Gehunfähigkcit. Stuhlverstopfung, erschwertes Urinlassen. Ödeme. Unregelmäßige Temperatursteigerungen. 'Tod. Sektion: Kleine Beckenhöhle durch den Tumor eingenommen. Blise und Rectum nach links verdrängt und mit dem Tumor verwachsen. Nach oben reicht der Tumor bis zum unteren $P$ ol der rechten Niere.

Fall 88. A ug. Plesser, Jissert. Kiel 1906. Alter: 26 Jahre. Ausgangspunkt: Rechte Beckenschautel; Aubentläche derselben, dic Innenfläche scheint nach dem Röntgenbild frei zu scin. - Periostal oder myelogen: Walurscheinlich myelogen. - Operation (Helferich): Freilegung der Geschwulst von einem Winkelschnitt aus. Teils Ausmeißelung des Tumors aus dem Knochen, teils Heraushebelung desselben. Dic Beckenschaufel wird in der Mitte in etwa Tellerausdehnung durchbrochen. Später Excision der sich bildenden Fistel. Wunde verheilt nahezu. Wegen Rezidiv nochmals operiert: UmmeiBelung der ganzen Schwellung, Abtragung der Spina ant. sup. Radikale Entfernung von allem zugänglichen kranken Gewebc. - Erfolg: Reichliche Nachblutung; mit ciner granulierenden Mulde entlassen; heilte nicht ganz zu, daher wieder Aufnahme. Nach der 2. Operation: Zunehmende Kränpfe. Wiederholte Lumbalpunktion mit Injektion von $21 / 2 \mathrm{~cm}$ Kollargollösung. Meningitis, Coma. Exitus. - Metastasen: Leber. - Art des Sarkoms: Ostcochondrosarkom, in dem die Chondrombildung am meisten vorherrscht, - Ciesamtzeit des Verlaufs: 4-5 Jahre. - Falsche Diagnose: Tuberkulose der Symph. sacro-iliaca. Jodoformeinspritzungen. Später: Tuberkulöse Coxitis. - Bemerkungen: Vor 3-4 Jahren Anschwellung der rechten Beckenseite, keine Beschwerden. Später dann nach Arbcit Müdigkeitsgefüh! und leichte ziehende Schmerzen im rechten Bein. An Außenseite der rechten Beckenschaufel ein Tumor. Oberer Rand dicht unterhalb der Crista ilei, 
vorn erreicht der Tumor nicht ganz die Spina ant. sup., nach unten ist er vom Trochanter abzutrennen. Sektion: Aufsteigende Spinalmeningitis, eitrige Leptomeningitis des Gehirns.

F a 11 89. D. S. Löw e n st e in, Beitr. z. klin. Chir. I906, H. 3. Alter: 4I Jahre. - Trauma: Ziemlich derber Fall vom Rad auf die linke Gesäß. partie. Am nächsten Tag glaubte Pat. nicht mehr aufstehen zu können. 4 Wochen später wieder Beschwerden, die auf schlechtes Wetter zurückgeführt wurden. - Ausgangspunkt: Hintere Hälfte der linken Beckenschaufel. - Periostal oder myelogen: Periostal. - Operation: Probelaparotomie und Punktion des vermeintlichen tuberkulösen Abszesses hinten an der linken Hüfte. - Erfolg: Wunde heilte gut. Rascher Verfall der Kräfte. Ascites, Odeme, Exitus. - Metastasen: Subpleural beiderseits einzelne, kleine, derbe Tumormetastasen; in beiden Lungen, in den Bronchialdrüsen, in der Leber, in den portalen Lymphdrüsen, Nieren. - Zeit zwischen Trauma und Erkrankung: Ca. 6 Wochen nach dem Trauma. Abmagerung, an der linken Hüfte hinten in der Gegend des Ischiadicusaustrittes starke Druckschmerzen und an derselben Stelle zirkumskripte kleine Schwellung. - Art des Sarkoms: Polymorphzelliges Sarkom mit zahlreichen Mitosen. - Gesamtzeit des Verlaufs: Ca. 4 Monate. - Falsche Diagnose: Gallensteine. (Gallenblase war druckempfindlich, die Gegend prominierend.) Verdacht auf akute Cholecystitis oder tuberkulösen Drüsentumor. Tuberkulöser AbszeB. - Bemerkungen: Tumor reicht einerseits bis an das Kreuzbein, andererseits bis an den N. isch., der bei seinem Austritt nach oben gedrückt wird. Schmerzen nach längerem Sitzen; starke Ermüdung beim Gehen und Schmerzen im linken Bein. Hinken und Nachschleppen des linken Beines. Stechen in Lebergegend, Atembeschwerden, kont. subfebr. Temperatur.

F all 9o. Jahresbericht über die Fortschritte in der Chirurgie 1907, II. Teil. Alter: ? - Ausgangspunkt: Darmbein. - Operation : Exartic. interilio-abdominalis. - Erfolg: I'at., dessen Allgemeinzustand ein sehr schwerer war, starb an Chok gerade in dem Moment, als man nach beendigter Operation zur Naht der Haut schritt. - Art des Sarkoms: Myxochondrosarkom.

F all 9I. Jahresbericht über die Fortschritte in der Chirurgie Iglo. Riese, r9o9. Alter: 59 Jahre. - Ausgangspunkt: Rechte Beckenschaufel. - Periostal oder myelogen: Periostal. - Operation: Resektion der rechten Beckenhälfte nach Koch cr mit vorausgehender Unterbindung der Vasa hypogastr. Blutung war zwar beschränkt, aber doch noch beträchtlich. Schnitt von der Spin. il. post. inf. bis zur Symphyse. Nach Ausräumung der an den großen Beckengefäßen vorhandenen Drüsen, die rechte Beckenhälfte in der Art. sacro-iliaca durchtrennt und medianwärts vom Acetab. reseziert, so daß von der rechten Beckenhälfte nur der größte Teil des Schambeins und ein Teil des aufsteigenden Sitzbeinastes erhalten blieb. - Erfolg: Bis nach Entfernung der Nähte reaktionslos. Dann Exitus an eitrigen Lungenmetastasen nach $1_{4}$ Tagen. Lungentuberkulose. - Art des Sarkoms: Polymorphzellig. - Falsche Diagnose: Ischias. - Bemerkungen: I2 Wochen vor seiner Aufnahme Schmerzen in der rechten Hüfte. 
F all 92. Deutsche med. Wochenschr., Nr. 49. I9o9. Alter: 25 Jahre. - Opcration (St a m m): Rescktion der linken Beckenhälfte. -- Erfolg: Tod 5 Stunden nach der Resektion. Nach $\mathrm{Sta} \mathrm{m}$ durch Chok, der durch das Meißelı am Kreuzbein verursacht worden war. - Art des Sarkoms: Osteosarkom.

I a 11 93. Sus. Nabatianz, Dissert. Berin 1910. Alter: 57 Jahre. -- Trauma: 2mal Fall auf den Rücken und die Kreuzgegend. - Ausgangspunkt: Kreuzbein. - Periostal oder myelogen: Myelogen. - Art des Sarkoms: Rundzellensarkom. - Gesamtzeit des Verlaufs: Wenig über 4 Monate. - Falsche Diagnose: Ischias. Behandlunng mit Morphium, Bäder, Umschläge, Salicyl. Später: Spondylitis der unteren Lendenwirbel. Pachymeningitis spinal, vielleicht Tuberkulose des untersten Teiles der Wirbelsäule. - Bemerkungen : Linker $N$. isch. sehr druckempfindlich; Abmagerung des linken Oberschenkels. Herabsetzung des linken Patellarreflexes, geringe Verstopfung. Füße beim Gehen nur wentg über den Boden erhoben; geringe Odeme. Später: Sensibilitätsstörungen, Anästhesie des linken Obcrschenkels und der Analgegend. Lähmung des Sphinkter ani und des Detrus. vesicac. Cystitis. Unter cercbr. Erscheinungen Tod. Sektion: An Stelle der 3 letzten Kreuzbeinwirbel Geschwulst, ähnlich einer fluktuierenden Cyste.

\section{Frauen.}

Fall I. Burns Handb. d. Geburtsh.; übersetzt v. Kilian, Bonn 1834 . Alter: ?. - Ausgangspunkt: Geschwulst im Becken, die von der Symphyse an bis zum Os sacrum fest mit dem rechten Becken verwachsen war. - Bcmerkungen: Dic Geschwulst war mit der Harnröhre und mit dem Mastdarm verlötet.

Fall 2. Güldner, Dissert. Rostock I895. Braunstein, Bonn 1888. Société anat. 18+1. Alter: 43 Jahre. - Ausgangspunkt: Rechtes Os ilium. - Metastasen: Thrombose der Vena iliaca ext. und Vena saphena. - Gesamtzeit des Verlaufs: 3 Jahre. - Falsche Diagnose: Wegen Ischias 3 Jahre lang behandelt. - Bemerkungen: Ölem des rechten Beines, Diarrhöen; Arterien und Nerven des Plex, lumb. komprimiert.

It all 3 wie 2. Stanley, Medico-chirurgical Transactions I845. Alter: ?. -- Ausgangspunkt: Rechtes Os ilium. - Operation: Ligatur der Art. iliaca externa. - Erfolg: Tod 5 Minuten post operationem. - Art des Sarkoms: Pulsicrend. - Falsche Diagnose: Aneurysma.

Fall 4. Elkington, Brit. Rec. I, I848. Alter: ? - Ausgangs. punkt: Os sacrum. -- Bemerkungen: Beckenorgane aus der normalen Lage herausgcdrängt. Perforation am lebenden Kinde.

F all 5 wie 2. 3850. Alter: 24 Jahre. - Trauma: Erschien kurz nach dem Wochenbett. - Ausgangspunkt: Os sacrum, beide Ossa il. ergriffen. Metastasen: Linker Femur. - Gesamtzeit des Verlaufs: Io Monate.

Fal16. Huguie $\mathbf{r}$ in Bulletin de la Suciété de Chirurgie 1852 , A. IV. Alter: 35 Jahre. - Para: III. - Trauma: Während der 3. Schwangerschaft Schmerzen in der rechten Hüfte und dort ein Tumor von Hühnereigröße; 
rasches Wachstum nach dem Wochenbett. - Ausgangspunkt: Rechtes Os ilium. - Operation: Punktion ergibt nur Blut. - Art des Sarkoms. Osteosarkom. - Bemerkungen: Keine Pulsation, sondern Tumor wird synchron mit der arteriellen Pulsation emporgehoben.

Fall 7. E. Martin 1855. Deutsche Chirurgie 1906, Lief. 62 a. Alter: 3I Jahre. - Para: III. - Trauma: Wahrscheinlich im AnschluB an einen Sturz von einer Treppe. - Ausgangspunkt: Äste des rechten Schambeins. Eine kleinere Geschwulst am linken Seitenflügel des Kreuzbeins innen; apfelgroße Geschwulst auf der Außenfläche jeder Darmbeinschaufel; kleine an einzelnen Stellen des Darmbeinkammes, an der rechten Spin. isch., an den Körpern des 1., 2. und 8. Brust- und des 2. Lendenwirbels. - Erfolg: Tod 4 Tage p. partum unter Kollaps. - Metastasen: Hinterhaupt; Dura mat., rechte Augenhöhle, rechte I. Rippe, Lungen, Nieren. - Zeit zwischen Trauma und Erkrankung: Ca. 3 Jahre. - Gesamtzeit des Verlaufs: Ca. 3 Jahre. -Bemerkungen: Hochgradiges Geburtshindernis. Es wurde in Fußlage ein 4 Pfund schweres faultotes Kind geboren, Rumpf und Kopf ganz platt gedrückt.

F a 11 8. Langenbecks Arch., Bd. I. Senftleben i860. Alter: I 5 Jahre. - Ausgangspunkt: Fest mit Os sacrum, Os isch. und Os ilium verbunden. Os ilium zum Teil zerstört. - Mctastasen: Vena iliaca und cava; Art. pulmon. Auch in Organen. - Art des Sarkoms: Osteoidsarkom. - Gesamtzeit des Verlaufs: $3^{1 / 2}$ Monate.

Fall 9. Société anatomique de Paris i860. Alter: 49 Jahre. Ausgangspunkt: Rechtes Os ilium. - Metastasen: Knoten in Lumbal- und Sacralwirbeln. - Gesantzeit des Verlaufs: 4 Jahre. - Falsche Diagnose: Ischias. - Bemerkungen: Schwund der Gelenkpfanne und Perforation des Femurkopfes in das Beckeninnere!

Fall Io. Billroth, v. Langenbecks Arch., Bd. IO. 186I. Alter: 46 Jahre. - Trauma: Durch Fall heftige Erschütterung des rechten Hüftgelenks. Später nochmals Fall auf diese Seite. - Ausgangspunkt: Rechtes Os ilium. - Zeit zwischen Trauma und Erkrankung: 4 Monate. - Art des Sarkoms: Sarcoma teleangiectodes; pulsierend; ancurysmatische Geräusche. - Gesamtzeit des Verlaufs: I Jahr und 8 Monate.

F́a 11 II. Gwa g gmann, Schmidts Jahrbücher, Bd. 120. 1863. Alter: 43 Jahre. - Para: IV. - Trauma: Geschwulst in der letzten Zeit (Schwangerschaft) sehr rasch gewachsen. - Ausgangspunkt: Im Bereich des ganzen linken horizontalen Schambeinastes und des For. obtur. - Erfolg: Tod 48 Stunden nach der schweren Geburt eines toten Kindes, - Art des Sarkoms: Fibrosarkom; teilweise Verkalkung. - Bemerkungen: Geburtshindernis. Gelenkverbindungen der Beckenknochen sehr locker.

Fall 12. V. $Z$ a charia e, Dissert. Würzburg 1865. Alter: 24 Jahre. - Ausgangspunkt: Rechter Sitzknorren. Die Geschwulst licf nach oben und innen und endigte in der rechten g. Schamlippe. Ein mit diesem Tumor zusammenhängender Tumor verlegte den Intr. vaginac; er ging von der rechten Nymphe aus. - Operation: Ausgeführt. - Erfolg: Kleines Lokal- 
rezidiv. Bei späterer Vorstellung keine Symptome eines neuen Rezidivs. Art des Sarkoms: Rundzellensarkom. - Bemerkungen: Schmerzen in der Aftergegend.

F all I3. Société anat. de Paris 1866. Alter: Io Jahre. - Ausgangspunkt: Rechtes Os ilium. Die Geschwulst erstreckte sich auf den Oberschenkel, das Sitrum und die Beckenwirbelsäule. - Metastasen: Thrombus in der Vena cav. inf., Leber, Lunge. - Gesamtzeit des Verlaufs: 6 Monate. - Falsche Diagnose: Beginn unter Zeichen der Coxalgie. -- Bemerkungen: Später Geschwulst, Ödem, Kachexie, Gangrän im Sacrum.

I all i 4. Lü cke, Lehre v. d. Geschw. Pitha-Billroth, Chirurgie, Bd. 2. I869 (?). Alter: ?. - Para: XI. - Trauma: Während der 9. Gravid. 8 Tage vor der Entbindung entstanden, nach derselben kleiner. Während der 10. Gravid. rasches Warhstum. Nach Entbindung bis kleiner Rest zurückgebildet. Nach II. Gravid. ging der wieder größer gewordene Tumor nicht mehr zurück. - Operation: Exstirpation. - Art des Sarkons: Medullarsatkom.

F a 11 I 5. Lancet I87I, A. II. Alter: 40 Jahre. - Ausgangspunkt: Innenfläche des linken Os ilium. - Gesamtzeit des Verlaufs: Ca. 6 Monate. - Bemerkungen: Odem, Ischias, Kompression der Vasa il, der Nerven; Vasa iliac. und linker Ureter waren in den Tumor eingeschlossen; linker Ureter vollständig undurchgängig.

Fall i6. Société anatom. de Paris I873. Alter: 67 Jahre. -- Ausgangspunkt: Rechtes Os ilium, auch Sacrum ist befallen, Synchondr. sacroiliaca zerstort, obcres Drittel des Femur affiziert. - Metastasen: Algemeine Sarkomatose. - Gesamtzeit des Verlaufs: 6 Monate. - Bemerkungen: Spontanfraktur des rechten Femurhalses.

If all 17 wic 16. 1874. Alter: ? - Ausgangspunkt: Rechtes Os ilium. -- Metastasen: Knoten in den Nieren. Metastasen im 3. Lendenwirbel und in einer Rippe. - Art des Sarkoms: Tiefe Fluktuation. -- Gesamtzeit des Verlaufs: 8 Monate. - Bemerkungen: Symptome einer Arthritis der Hüfte.

F a 11 i 8 . E p pinger, Prager Vierteljahrsschrift f. Heilkunde 1875, 13d. 2. Alter: 45 Jahre. - Ausgangspunkt: Rechtes Darmbein, auf den Femur übcrgcgriffen. - Periostal oder myelogen: Periostal. - Metastasen: Leber. - Art des Sarkoms: Grobspindelig.

liall 19. r. Langenbecks Arch., Bd. 21. Krönle in-Langenbeck r875. Alter: 34 Jahre. - Trauma: Im 6. Monat gravid, nach der Entbinclung rasches Wachstum. - Ausgangspunkt: Ram. ascend. ossis ischii (?). - Operation: Versucht. Linke Ram. ascend. ossis ischii und Ram. desc. oss. pub. waren bereits vollständig zerstört, daher aufgegeben. - Erfolg: Nach ca. 7 Wochen auf Wunsch entlassen. Sic wird der profusen Jauchung der großen Wundhöhle voraussichtlich bald erlegen sein. - Art des Sarkoms: Medulläres Myxosarkom.

F a 11 20. Thise de Soyre 1875, p. 113. Alter: 29 Jahre. - Trauma: Nach der I. Geburt Schmerzen im Becken und in der Sacralgegend. 
Ausgangspunkt: Kreuzbein. - Operation: Punktion. - Erfolg: Der Tumor schien sich nach der Punktion zu vergrößern. - Art des Sarkoms: Elastisch weich, fast fluktuierend. - Gesamtzeit des Verlaufs: $3^{1 / 2}$ Jahre. - Bemerkungen: Fieber.

F a 11 2г. Volkmann, Deutsche med. Wochenschr. 1876, Nr. 24. Alter: 23 Jahre. - Para: III. - Ausgangspunkt: Os sacrum. - Periostal oder myelogen: Myelogen (von der Spongiosa aus). - Operation: Erheblicher Teil des Kreuzbeins entfernt; es blieb von der rechten Hälfte des Kreuzbeins nur eine $2 \mathrm{~cm}$ breite Spange übrig. Sacralkanal wird dabei eröffnet. - Erfolg: Nach 6 Wochen Treppensteigen möglich. Urinbeschwerden und Schmerzen nach der Defäkation blieben noch lange bestehen. - Art des Sarkoms: Riesenzellensarkom. - Bemerkungen: Beim Gehen, Stehen und Sitzen heftige Schmerzen.

F all 22. Revue mensuelle de médecine et de chir. 1878, p. Io2. Alter: 28 Jahre. - Trauma: Während einer Schwangerschaft rasch gewachsen. Nach der Geburt immer heftige Schmerzen. - Ausgangspunkt: Rechtes Os ilium. - Metastasen: Lungen und Nieren. - Gesamtzeit des Verlaufs: 6 Monate. - Bemerkungen: Gegen Ende der Schwangerschaft Schmerzen im rechten Bein.

Fall 23. Lancet 1878, A. II. Alter: 35 Jahre. - Para: X. - Trauma : Während der I0. Schwangerschaft Schmerzen in den Nieren und im rechten Unterschenkel. Nach der Geburt Schmerzen stärker. - Ausgangspunkt: Rechtes Os ilium. Sacrum und I. Lendenwirbel waren auch erkrankt. -Gesamtzeit des Verlaufs: 6 Monate. - Falsche Diagnose: Symptome einer Caries der Symph. sacro-iliaca. - Bemerkungen: Fieber; später Ödem des rechten Beins und Paralyse.

Fall 24. Rieder, Dissert. Dorpat 1878. Alter: 50 Jahre. - Para: V. - Ausgangspunkt: I. bis 3. oberer Kreuzbeinwirbel. - Periostal oder myelogen: Periostal. - Metastasen: In Beckenvenen und Beckenarterien; ferner im rechten Herzen und in der Lungenarterie. - Art des Sarkoms: Spindelzellensarkom. - Bemerkungen: Seit ro Wochen Schmerzen in der Kreuzgegend. Defäkationsbeschwerden. Ascites, Fieber, Dyspnoë, plötzlicher Tod.

F' a 11 25. Los s e n, Berliner klin. Wochenschr. I879. Alter: 28 Jahre. - Trauma: Vor 6 Jahren Fall von einem Treppenstuhl auf die linke Hüfte. - Ausgangspunkt: Fossa iliaca sin. - Periostal oder myelogen: Periostal. Operation: Handgroßes Stück Bauchfell und ein Stück Knochen an der Insertionsstelle an der Spina ant. sup. mit entfernt. - Erfolg: Nach ca. 2 Monaten mit einem eigens gearbeiteten Bruchband geheilt entlassen. Dic Heilung wurde ca. 4 Monate p. operationem noch konstatiert. - Zeit zwischen Trauma und Erkrankung: Vermutlich 3/2 Jahre. - Art des Sarkoms: Fibrosarkom. - Gesamtzeit des Verlaufs: 6 Jahre. - Bemerkungen: Kindskopfgroß.

F all 26. Li ebe, Dissert. Straßburg I88I. Alter: 17 Jahre. Para: Nulli. - Trauma: Sturz auf der Straße auf die linke Hüftseite. Sofort 
anhaltende Schmerzen. Innerhalb 6 Wochen Anschwellung der Gegend der Crista oss. il. sin. - Ausgangspunkt: Wahrscheinlich Os il. sin. - Zeit zwischen Trauma und Erkrankung: Anschwellung nach 6 Wochen. Sark. diagn. 5 Mon. p. Trauma. - Art des Sarkoms: Osteosarkom. - Bemerkungen: Wuchs zu großem, ins Abdomen reichenden Tumor an.

Fi 11 27. II avage I882. Alter: 54 Jahre. - Ausgangspunkt: Fossa iliaca sin. - Gesamtzeit des Verlaufs: 5 Monate. - Falsche Diagnose: Luetische Periostitis, antiluetische Behandlung ohne Erfolg. - Bemerkungen: Schmerzen in der Nierengegend, Müdigkeit, Ödem am linken Bein, Fieber, Verstopfung.

I a 1128 wic 27. Alter: 37 Jahre. - Trauma: Nach einem längeren Spazicrgang in der rechten Hüfte dumpfer Schmerz. - Ausgangspunkt: Fossa iliaca externa dextr. Tumor sitzt an der Spina pub. und steigt nach der Crista ilei hinan. - Metastasen: Vermutlich vorhanden. - Bemerkungen: Verstopfung, ITrinbeschwerden; heftige Fieberanfälle, Coma, Aphonic, Hemiplegie rechts, bald 'Tod.

F a Il 29 wie 27. Alter: 6 Monate. - Ausgangspunkt: Fossa iliaca sin. und Sacrococcygealgegend. - Metastasen: Ähnliche Geschwulst am Kopfe. - Gesamtzeit des Verlaufs: 4 Monate. - Bemerkungen: Großvater starb 2 Jahre später an einem Unterschenkelsarkom. - Stuhlverstopfung, Ret. urinae; Marasmus.

F a 11 zo we 27. Alter: I I Jahre - Ausgangspunkt : Fossa iliaca ext. Operation: Punktion des vermeintlichen Abszesses. - Metastasen: Knochen und innere Organe, - Gesamtzeit des Verlaufs: Ca. 7 Monate. - Falsche Diagnose: Seit 7 Monaten wegen Ischias mit Hyperästhesie und Muskelkontrakturen behandelt. Abszeß: Punktion crgibt sarkomatöse Zellen. Bemerkungen: Ödem.

Ii all 3 I wie 27. Alter: 50 Jahre. - Ausgangspunkt: Vordere Sacralfläche; auf das rechte Os ilium übergegangen. - Art des Sarkoms: Cystosarkom, - Bemerkungen: Kreuzbein durchwachsen, Nerven der Cauda equina komprimiert - Seit mehreren Monaten neuralgische Schmerzen, Stuhlverstopfung, Magen- und Urinbeschwerden, Schwäche in den Beinen; Diarrhöen, Incont. urinae, Marasmus.

Fall 32. Toporski, Dissert. Breslau i884. Alter: 25 Jahre. Trauma: Letzte Periode vor 6 Monaten. - Operation: Enukleation des Tumors. Kolossale Blutung. - Erfolg: Tod nach 6 Tagen. - Art des Sarkoms: Myxosarkom. - Bemerkungen: Subperitoneal.

If all 33. Kolaczek, v. Iangenbecks Arch., Bd. I8. 1884 (?). Alter: 35 Jahre. - Trauma: Anstrengung: Treten der Nähmaschine. Ausgangspunkt: Kreuzbein; auf die rechte Darmbeinschaufel, linken horizontalen und absteigenden Schambeinast und linkes Sitzbein übergegriffen. - Metastasen: Vorhanden. - Art des Sarkoms: Alveolarsarkom.

l'all 34. Theilhaber, Münchn. med. Wochenschr. 1886, 33. Alter: 34 Jahre. - Para: IV. - Ausgangspunkt: Os sacrum, I. bis 3. Wirbel des Kreuzbeins. - Art des Sarkoms: Spindelzellensarkom. - Bemerkungen: 
2mal spontan geboren; bei der 3. Geburt Verzögerung, aber noch spontan; 4. Geburt: Schädellage, Perforation, Uterusruptur.

F a 11 35. Doll, v. Langenbccks Arch., Bd. 37 u. Arch. f. klin. Chir., Bd. 37. I888. Alter: 22 Jahre. - Para: Nulli. - Ausgangspunkt: Rechtes Os ilium, Außen- und Innenfläche. - Periostal oder myelogen: Periostal. - Operation (Czerny): Exstirpation der Geschwulst mit entsprechender Resektion der Darmbeinschaufel unter 4 proz. Karbolspray. Auch vom Kreuzbein Teile abgetragen. Unterbindung der Art. circumfl. ilei. - Erfolg: Nach Operation starker Kollaps. Tod am 2. Tage post operationem an Sepsis. Metastasen: Rechte Lunge. - Art des Sarkoms: Gefäßarmes, teilweise crweichtes Chondrosarkom. - Gesamtzeit des Verlaufs: Rasch gcwachsen, scit einigen Wochen erst bemerkt.

Fall 36. Braunstein, Dissert. I888. Alter: 40 Jahre. - Vorausgegangene Knochenerkrankungen: Aufnahme wegen Humcrussarkom. Ausgangspunkt: Bei der Sektion fand sich ein Sarkom des Darmbeins.

F a 11 37. H avage i888. Alter: I6 Jahre. - Para: Nulli. - Aus. gangspunkt: Außenfläche der Art. sacro-iliaca dextr. - Operation: Punktion ergab nur Blut. - Metastasen: Lymphdrüsen geschwellt. - Art des Sarkoms: Fluktuierend. - Falsche Diagnose: Es wurde rechtseitige Sacrocoxalgie mit Ostitis des Os il. dextr., tief. Abszeß und sympt. Ischias diagnost. - Bemerkungen: N. ischiad. in das Sarkom eingeschlossen. Die Geschwulst war durch die Inc. ischiad. in das Beckeninnere gewachsen.

F a 11 38. Eugen Rüg e, Dissert. Greifswald I888. Alter: I9 Jahre. - Ausgangspunkt: Rechte Darmbeingrube zu beiden Seiten; Sitzknorren und Kreuzbein sind ergriffen. - Operation: Ligatur der Art. epigastr. superfic. und prof., Abmeißelung der Art. sacro-iliaca, ebenso des absteigenden Sitzbeinastes. Dicht uber dem Tub. ischii Durchtrennung des horizontalen Schambeinastes. Hierauf Durchtrennung der noch sitzenden leichten Verbindungen der rechten Beckenhälfte. Am Sitzknorren und Kreuzbein Auskratzung mit scharfem Löffel. Thermokauter. - Erfolg: Tod nach 2 Stunden durch Anämie. Art des Sarkoms: Rundzellen, vercinzelte spindelige Elemente; fluktuierend. - Bemerkungen: Reicht bis zur Höhe des Nabels. Seit 5 Wochen stets zunehmende Schmerzen, die vom rechten Oberschenkel ausgingen und sich auf den ganzen Fuß verbreiteten. Rechtes Hüftgelenk in mäßiger Abduktion und starker Flexion. Bewegungen schmerzhaft, frei.

F a 1139 wie 38 . Alter: I9 Jahre. - Trauma: War ziemlich heftig rücklings auf das Gesäß gefallen. - Ausgangspunkt: Vorderfläche des Sacrums. Durch das Kreuzbein hindurch und das For. isch. major setzt sich die Geschwulst auch in die Weichteile der Regio glut. fort. - Periostal oder myelogen: Myelogen. - Art des Sarkoms: Riesenzcllensarkom. -- Gesamtzeit des Verlaufs: Ca. I Jahr. - Bemerkungen: Intermitticrende Schmerzen im Verlaufe des N. ischiad. Später: Exulceration in der Sacralgegend mit Blutungen. Kompression der Beckenorgane. Tod an bilateraler croup. Pneumonie. Sektion: Kleine Beckenhöhle fast völlig ausgefüllt. Die Geschwulst reichte auch noch etwas in die große Beckenhöhle. 
F a 11 40. Otto Roth, Dissert. 1888 (?). Alter: 55 Jahre. - Vorausgegangene Knochenerkrankungen: Hatte einmal das Gallenfieber. Ausgangspunkt: Os sacrum. - Periostal oder myelogen: Periostal. - Falsche Diagnose: Wegen Ischias mit dem galvanischen Strom behandelt; später: Blutegel, Nachblutung kaum zu stillen. - Bemerkungen: Seit Jahren Obstipation; Kreuzschmerzen, dann auch im rechten Bein, auch im FuB, Bewegungen schmerzhaft. Schließlich häufige Blutungen aus Mund und Nase, am ganzen Körper Petechien. Der rechte Plex. isch. war vollkommen umschlossen.

F a 11 41. N i e rle, Dissert. München 1889. Alter: 6 Jahre. - Aus. gangspunkt: Linke Crista ilei. - Art des Sarkoms: Alveolär, kleine Rundzellen. - Gesamtzeit des Verlaufs: Tod, nachdem 7 Wochen bemerkt.

F a ll 42 wie 4I. 1889. Alter: 6I Jahre. - Vorausgegangene Knochen. erkrankungen: 3 ähnliche Tumoren an den Rippen. - Ausgangspunkt : Linkes Darmbein. Auch die Wirbelsäule zeigte überall rauhe Knoten und die Lendenwirbelsäule war links fast in ihrer ganzen Ausdehnung usuriert. - Metastasen: Rippen (?). - Art des Sarkoms: Kleinzelliges Rundzellensarkom mit stark entwickeltem Stroma, Riesenzellen. - Gesamtzeit des Verlaufs: Ca. 5 bis 7 Monate.

I all 43. Gussenba uer, Prager Zcitschr. f. Heilkunde i 890 , Nr. 5-6. Alter: 45 Jahre. - Para: VII. - Trauma: Nach einem längeren Marsch traten zuerst die Schmerzen auf. - Ausgangspunkt: Innenfläche der rechten Darmbeinschaufel. Hatte den absteigenden Sitzbein- und den horizontalen Schambeinast bis zur Wand des Hüftgelenks ergriffen. - P'eriostal oder myelogen: Myelogen. - Operation: Exstirpation. Radikale Entfernung wegen hochgradiger Blutung unmöglich. - Erfolg: Lokalrezidiv, Verjauchung, nach 2 Monaten Tod. - Metastasen: Inguinale, iliacale und retroperitoneale Drüsen. - Art des Sarkoms: Zerfallenes melanot. Sarkom. - Gesamtzeit des Verlaufs: I Jahr 8 Monate. - Falsche Diagnose: (Differentialdiagnose) îuberkulöser Senkungsabszeß. -- Temerkungen: Nach dem Knie ausstrahlende Schmerzen.

Fall 44. Gussenbauer, Prager Zeitschr. f. Heilk. i8gr. Alter: 33 Jahre. - Para: VII. - 'Trauma: Vor 2 Jahren fieberloses 7. Wochenbett, manuelle Lösung der Plac.; hernach kont. Kreuzschmerzen. - Ausgangspunkt: Os sacrum; war bis in den 5. Lendenwirbel und in den Wirbelkanal gewachsen. - Periostal oder myelogen: Myelogen. - Operation: Freilegung der hinteren Kreuzbeinfläche und des Tumors; Ausmeißelung des I. Kreuzbeinwirbels. Wiederholte prof. Blutung. Exstirpation des Kreuzbeins versucht. - Erfolg: Tod während der Operation. - Zeit zwischen Trauma und Erkrankung: 2 Jahre. - Art des Sarkoms: Riesenzellensarkom. - Bemerkungen: Wiederholte Perforation in Rect.; Scheide, Uterus, Blase, Mastdarm und Adnexe verdrängt. Stuhlverstopfung und Harnverhaltung.

I all 45 wie 44. Alter: 24 Jahre. - Para: Nulli; Mädchen. Ausgangspunkt: Rechtes Os ilium; herdweise Nekrose des rechten Darmbeins. Ein 2. Tumor am rechten Oberschenkel, der Insertion des Musc. sart. und des Tensor fasciae lat. folgend; ein 3. Tumor entsprechend der Iage der 
iliacalen Lymphdrüsen. - Periostal oder myelogen: Periostal. - Operation: Isolierung der Geschwulst von den Oberschenkelmuskeln; Freilcgung der Darmbeingeschwulst unter Ausmeißelung eines Dreiecks. Exstirpation der Lymphdrüsen. - Erfolg: Wegen inoperablen Sarkoms der zurückgebliebenen iliacalen und inguinalen Lymphdrüsen ungeheilt entlassen. Rezidiv. - Metastasen: Sekundäre Sarkomknoten. - Art des Sarkoms: Medulläres, alveoläres Rundzellensarkom, weich, elastisch. - Falsche Diagnose: Ischias. Bemerkungen: Schmerzen in der rechten Hüfte und im rechten Oberschenkel.

F a 11 46. B r a u n, Zentralbl. f. Gynäk. 1892, S. 887. Alter: 25 Jahre. - Operation: Wegen drohender Berstung machte Bra un in der Nähe der Crista eine $61 / 2 \mathrm{~cm}$ lange Probeincision. - Erfolg: Exitus nach 6 Wochen. Art des Sarkoms: Osteosarkom. - Falsche Diagnose: Früher wurde eine im Lig. lat. sin. befindliche Geschwulst ats Beckenexsudat diagnostiziert. - Durch Probeincision Osteosarkom diagnostiziert. - Bemerkungen: Anschwellung des linken Oberschenkels und Unterschenkels. Die Geschwulst reichte zuletzt bis zum Rippenbogen.

Fall 47. Tillmanns, Lehrb. d. spez. Chir. 1892 . Alter: 48 Jahre. - Ausgangspunkt: Darmbein. - Art des Sarkoms: Melanosarkom. - Bemerkungen: Mannskopfgroß.

Fall 48. Tillmanns, Deutsche Chirurgic I905. Körte I893. Alter: ?. - Trauma: Zugegeben. - Ausgangspunkt: Kreuzbein. - Operation: Die von einer Kapsel umschlossene Geschwulst ließ sich nach Resektion des Kreuzbeins und Durchtrennung des Levat. ani und der Becken. fascic gut auslösen. Das crkrankte Kreuzbein wurde $4 \mathrm{~cm}$ unter der Verbindungslinie der Spin. il. post sup. durchgemeißelt, die Wundfläche ausgekratzt und verschorft. - Erfolg: Heilung; ein Rezidiv wurde wieder entfernt. - Art des Sarkoms: Myxosarkom; beim Rezidiv war Faserknorpel eingelagert. - Bemerkungen: Mastdarm war plattgedrückt.

Fall 49. Karl Deininger, Dissert. Würzburg 1893. Alter: I8 Jahre. - Para: Nulli. - Trauma: Stoß. - Ausgangspunkt: Rechtes Darmbein. - Periostal oder myelogen: Myelogen. - Zeit zwischen Trauma und Erkrankung: Einige Jahre. - Art des Sarkoms: Alveoläres Osteosarkom, vorwicgend Rundzellen, daneben Riesenzellen. - Bemerkungen: Ca. kindskopfgroß.

F a 11 5o. Bericht über die Verhandlungen der Deutschen Gesellschatt für Chirurgie, XXII. Kongreß 1893. Beilage z. Zentralbl. f. Chir., C.z e rny. Alter: ?. - Operation: Resektion des Kreuzbcins bis zum 2. Sacralwirbel hinauf und der rechten Tuberos. os. ilii. Es ließ sich die 3. Wurzel des Plex. sacr. nicht schonen. - Erfolg: Es blieb dauernde Lähmung der Blase und des Mastdarms, Schwäche der unteren Extremitäten zurück. Tod I 1/2 Jahr später an Rezidiv. - Art des Sarkoms: Chondrosarkom.

F a 1 5 I. Zentralbl. f. Chir. 1895, Nr. 7. Piqué. Alter: ?. - Ausgangspunkt: Schambein. - Operation: Exstirpation unter Resektion der Symphyse und einer Partie des absteigenden Schambeinastes. -- Erfolg: Günstig. 
Patientin konnte trotz des Defektes im vorderen Beckenring gut gehen. Bemerkungen: Versuch, eine Prothese anzubringen, mißlang.

Fall 52. Schoppig, Dissert. Monatsschr. f. Geburtsk., Bd. 7I. Bartscher i 895. Alter: ?. - Para: I. - Ausgangspunkt: Rechte Articul. sacro-iliaca. - Art des Sarkoms: Chondrosarkom (oder Chondrom). - Bemerkungen: Tumor reicht bis zu den falschen Sacralwirbeln, bis zum Iliat. sacr. nach links und zum Os coccyg. nach unten. - I. Geburt war Zangengeburt, Mutter und Kind leben.

F a 11 53. Güldner, Dissert. Rostock 1895. Alter: 27 Jahre. Ausgangspunkt: Innere und äußere Fläche des Os ilium dextr. - Operation: P'robepunktion. Operation: Das Os ilium, das vollständig ergriffen war, völlig entfernt. - Erfolg: Ca. 1/4 Stunde p. op. Kollaps, Exitus, keine Sektion. Art des Sarkoms: Fluktuierend und pulsierend, Pergamentknistern. - Bemerkungen: Schmerz in der Lumbalgegend; leichte Kyphose der Lendenwirbelsäule.

F a 1154 wic 53. Alter: I7 Jahre, - Trauma: Fall auf dem Eise ohne unmittclbare Folgen. Seit dieser Zeit aber Gefühl von Schmerz in der rechten IIüfte und Nachziehen des rechten Beines. - Ausgangspunkt: Rechte Darm. beinschaufel. - Pcriostal oder myelogen: Wahrschcinlich periostal. - Operation: Probepunktion. Operation: Freilegung des Tumors, AbmeiBelung der äußeren Corticalis im Bereich des hinteren Drittels der Schaufel. - Erfolg: Heilung per primam. - Zeit zwischen Trauma und Erkrankung: Seit dem Trauma Gefühl von Schmerzen und Nachziehen des rechten Beines. - Art des Sarkoms: Alveoläres Gefäßsarkom, bestehend aus großen Rundzellen. Bemerkungen: Tumor reicht vom Darmbcinkamm bis $20 \mathrm{~cm}$ unterhalb desselben und von der Spina bis hinter den Trochanter.

Fa 1155 wie 53. Alter: 34 Jahre. - Para: V. - Ausgangspunkt: Untere Begrenzung der linken Beckenhälfte - Schambeinast, Tuber ischii und aufsteigender Sitzbeinast von dem Tumor eingenommen. Dieser ist auch im Innern des Beckens zu fühlen. - Metastasen: Beiderseits geschwollene Leistendrüsen. - Bemerkungen: Schmerzen in der linken Hüfte; Nachziehen des linken Beines; Stellung des linken Beines wie bei Luxat. perin. Vollständige Gehunfähigkeit.

F a 1156 wie 53. Alter: 18 Jahre. - Trauma: Vor 8 Jahren Gelenkrheumatismus. Es rötcte sich die linke Hüfte und das ganze Bein und schwoll an; scitdem soll das Bein in der Stellung geblieben sein. - Ausgangspunkt: I) linke seitliche und hintere Hüftgelenk- und Darmbeingegend ist von dem Tumor eingenommen. - Operation: Injektion von Pyoktanin. - Metastasen: Beiderseitige Inguinaldrüsen geschwellt. - Zeit zwischen Trauma und Erkrankung: Vielleicht 8 Jahre. Einc Geschwulst im Bereiche des Bauches rührt angeblich von der Krankheit vor 8 Jahren her. - Art des Sarkoms: Pseudofluktuation. - Bemerkungen: Der Tumor erstreckt sich in der Reg. inguin. und lumb. der linken Bauchseite fort nach oben bis zum Rippenbogen, nach rechts bis zur Mittellinic. Stellung des linken Beines ähnlich wic bei Lux. iliaca. 
F a 1157 wie 53. Alter: 50 Jahre. - Para: 6 Geb., I Abort. - Ausgangspunkt: Rechts, wahrscheinlich Os ilium. - Operation: Bloßlegung und Entfernung der Geschwulst. - Erfolg: Ca. 4 Wochen nach der Operation Coma und Exitus. - Gesamtzeit des Verlaufs: Ca. I Jahr. - Falsche Diagnose: Ischias. Abszeß, ausgehend von Beckenknochen. - Bemerkungen: In der rechten Beckenhälfte ein über faustgroßer Tumor, undeutlich fluktuierend. Schmerzen in der rechten Hüftgegend, Gehunfähigkeit. Rechtes Bein stark auswärts rotiert, etwas abduziert. Ödem an der AuBenseite der rechten Hüfte.

Fall 58. Fergusson, Lees 1895. Alter: ?. - Ausgangspunkt: Kreuzbein. - Bemerkungen: Geburtshindernis.

F all 59. A. Gastpar, Dissert. München 1896. Alter: 45 Jahre. Para: Nulli. - Trauma: Vor 1/4 Jahr traten die Schmerzen angeblich nach einer Anstrengung, als Patientin einem Wagen nachlaufen wollte, im Oberschenkel nach außen von der Inguinalseite und an der Hinterseite verstärkt auf. - Ausgangspunkt: Linkes Os ilium. - Periostal oder myelogen: Myelogen. - Operation: Freilegung des Tumors, Durchmeißelung des ca. 2 Finger breiten normalen Randes des oberen Darmbeinkammes. Durchtrennung der noch restierenden Brücke zwischen Darmbeinschaufel und Pfannengegend. Erfolg: Gangrän des Fußes, eines Teiles des Oberschenkels. Amputation des Oberschenkels. Nach 2 Tagen oberhalb des Lig. Poup. abnorme Resistenz zu fühlen. Rezidiv? - Metastasen: Vene vollständig thrombosiert. - Art des Sarkoms: Hämorrhagisches Rundzellensarkom, größtenteils von knöcherner Schale umgeben. - Gesamtzeit des Verlaufs: Vermutlich ca. I 1/4 Jahr. Bemerkungen: Oberhalb des Trochanter die Beckenschaufel durch einen Tumor aufgetrieben, der bis an den Beckenkamm hinaufreicht. Spin. ant. sup. nicht scharf abgrenzbar, hier ebenfalls ein Tumor, Schmerzen in der Vorderseite des linken Oberschenkels. Bewegungen des Oberschenkels schmerzhaft.

Fiall 6o. Schoppig, Dissert. Zentralbl. f. Gynäk. I896. Alter: 23 Jahre. - Para: I. - Ausgangspunkt: Rechter Schambeinast und Darmbeinschaufel. - Operation: Sectio caesarea. - Erfolg: Einige Monate nach der Sectio caesarea Tod an Kachexie; keine Sektion. Kind lebt. -- Art des Sarkoms: Chondrosarkom (oder Chondrom). - Bemerkungen: Hier und da Schmerzen im Becken.

Fall 6r. Hans Hen rici, Dissert. München i897. Alter: I 5 Jahre. - Ausgangspunkt: Rechter Schambeinast, Knochen durchsetzt und Muskulatur durchwuchert. - Operation: Freilegung des Tumors längs dem Poup. Band. Verzicht auf Totalexstirpation. - Erfolg: Nach I4 Tagen Gangrän etwas unterhalb der Mitte des Unterschenkels. 4 Wochen nach der teilweisen Exstirpation perforiert oberhalb des Leistenbandes ein Abszeß. Wiederholt starke Blutung. - Metastasen: Lymphdrüsen der Fossa ovalis zu einem derben Paket vergrößerter Inguinaldrüsen, beide Lungen, Anämie aller Organe. Venen der ganzen rechten Extremität thrombosiert. - Art des Sar. koms: Schr zellreiches Fibrosarkom. - Gesamtzeit der Verlaufs: Vermutlich 
ca. $1^{1 / 3}$ Jahr. - Falsche Diagnose: Wegen cines Geschwürs, das von Blutegelbiß, dic wegen Schwcllung des Fußes am Untcrschenkel gesetzt worden waren, herrührte, Verdacht auf Lues. Jodkali und graue Salbe. Heilung. Bemerkungen: Kindskopfgroß. Schmerzen im rechten Bein und in der Fossa ovalis; jauchige Cystitis.

I a 11 62. Revuc de gynécologie 1899. Alter: 16 Jahre. - Ausgangspunkt: Os ilium. - Operation: Mediane Laparotomie und temporäre Ligatur der Aorta und Art. iliaca com., dabei heftige venöse Blutung aus Unterhautund Peritoncalvenen. Der Crista ilei paralleler Schnitt bis in die Gegend der Vasa femor. Blutung so abundant, daß Operation niclit fortyesetzt werden kann. F a u r e beabsichtigte, die Exart. interil. abdom. auszuführen. - Erfolg: Tod bei der Operation. - Art des Sarkoms: Osteosarkom. - Bemerkungen: Ödem cler unteren Extremität.

Iia 11 63. Löwenstein, Beiträge z. klin. Chir. 19o6. Aus der Heidelb. Klinik I899. Alter: I 5 Jahre. - Trauma: Sturz auf den Boden mit der linken Hüftgegend. Sofort starke intermittierende Schmerzon, in den lib ausstrahlend. - Ausgangspunkt: Os ilium sinistr. - Periostal oder myelogen: Periostal. - Zeit zwischen Trauma und Erkrankung: Etwa 7 Monate post trauma Schwellung der linken Unterbauchgegend. Sarkom diagn. io Mon. p. tr. Bemerkungen: Gehen und Stehen schr erschwert; $N$. ischiad. sehr druckempfindlich bis zum Kinie.

Fall 64. K. Würz, Beitr. z. klin. Chir. I9oo. Alter: 52 Jahre. Trauma: Fall mit dem Steiß auf einen Stein. Sofort Schmerzen, 6 Wochen lang. - Ausgangspunkt: Os coccyg. -- Periostal oder myclogen: Periostal. Operation: Exstirpation. - Zeit zwischen Trauma und Erkrankung: Nach I Jahr wurden die Schmerzen wieder stärker und seit 2 Jahren bilden sich 2 Tumoren am Steißbein. Sarkom diagn. 3 Jahre p. tr.

Fiall 65. Fr. Schnitzler, München Igoo. Alter: 40 Jahre. Ausgangspunkt: Die (reschwulst sitzt bei der Sektion der Lendenwirbelsäule fest auf, Lendenwirbelkörper teils zerstört, teils erweicht. - Metastasen: Multiple Metastasen im Mesenterium, Leber, Lungen, Herz usw. - Gesamtzeit des Verlaufs: Vermutlich ca. I Jahr. - Bemerkungen: Von der Gegend der untersten Rippe in die Fossa il. sich erstreckender, zum Teil auch dem I'romont. aufliegender Tumor. - Fieber, Appetitlosigkeit, Schmerzen im Rücken, Ilüfte und Oberschenkel. Ödem des Oberschenkels.

I. a 1166 wie 65 . Alter: $\mathrm{I}^{3} / 4$ Jahre. -- Vorausgegangene Knochenerkrankungen: Wahrscheinlich angeboren (?). - Trauma: Vor $1 / 2$ Jahr Fall über die Sticge herunter, später über einen Wassertrog, ohne daß jedoch dabei die Kreuz-Steißbeingegend betroffen wurde. - Ausgangspunkt: Unterer 'Teil des Kreuzbeins und das nur noch teilweise vorhandene Steißbein eingebettet in eine mit Knochenbälkchen durchsetzte Masse. - Periostal oder myelogen: Wahrscheinlich periostal. - Operation: I. Probepunktion: Dunkles Blut. 2. Probepunktion: Blutig gemischte flockige Massen. Incision klärte auf. SchluB der Wunde. - Erfolg: Ca. 4 Wochen nach Incision Tod. - Metastasen: Rectum, Scheide, Urethra von den Geschwulstmassen umgeben und 
teilweise infiltriert. Die Geschwulst ist auch in den Wirbelkanal vorgedrungen. - Zeit zwischen Trauma und Erkrankung: Ca. ${ }^{1} \frac{1}{1 / 2}$ Jahr. - Art des Sarkoms: Alveoläres Rundzellensarkom. - Falsche Diagnose: Tief liegender chronischer Lymphknotenabszc 3 im Cav. ischio-rectale. - BCmerkungen: Nicht genau abgrenzbare Geschwulst der Kreuz- und Steißbeingegend. Verstopfung, teilweise quälcnder Stuhldrang, geringe Urinentleerung. Ficber. Blutabgang aus der Analöffnung (Perforation).

Fall 67. Dr. O. Zeller I90I. Deutsche Zeitschr. f. Chir. r9o4, Bd. 7I. Alter: 38 Jahre. - Para: II. - Ausgangspunkt: Gegend der rechten Synchondr. sacro-iliaca. - Periostal oder myelogen: Periostal. - Operation: Mit Meißel wird der Fuß der Geschwulst aus der Beckenwand ausgegraben. - Erfolg: 49 Tage nach der Operation geheilt entlassen; fast 2 Jahre rezidivfrei. - Art des Sarkoms: Fibrosarkoma myxomatodes cysticum. - Bemerkungen: Kleines Becken fast ganz ausgefüllt. 2mal durch Kaiserschnitt entbunden wegen der Geschwulst. Das 2. Kind lebte.

F a 1168 . Rev, de Chir. 1902. Deutsche Zeitschr. f. Chir. 1904. S a va riand. Alter: 7 Jahre. - Ausgangspunkt: Incisura ischiad. major. Periostal oder myelogen: Periostal. - Operation: Exart. interilio-abdomin., Art. il. int. u. ext. unterbunden. Innerer Lappen mit den Adduktoren, Durchschneidung des Schambein- und Sitzbeinastes. Ablösung des Peritoneums mit dem Musc. obtur. int. Vertikale AbmeiBelung des linken Kreuzbeinflügels. Ausfluß von Cercbrospinalflüssigkeit. Mäßige Blutung. -- Erfolg: Tod wenige Stunden nach der Operation. - Metastasen: Fehlen. - Art des Sarkoms: Kleinzellig. -- Gesamtzeit des Verlaufs: 3 Monate von Beginn der Schmerzen bis zur Operation. - Bemerkungen: Dic Geschwulst reichte oben bis zur Crista ilei, vorn bis zum Trochanter major. Innen greift sie auf das Os sacrum über. Sanduhrform: Vom For. isch. maj. zur Hälfte nach innen, zur Hälfte in der hinteren Beckenmuskulatur entwickelt. Schmerzen im Bereiche des N. isch. Gehen und Stehen fast unmöglich.

F a 1169 . Jahresber. f. Chir. 1902, III. Teil. Morest in 1902. Alter: 30 Jahre. - Operation: Exart. interil.-abdom. Rakettschnitt nach $\mathrm{S}$ a 1 is t $\mathrm{sch}$ eft, dessen geschlossencr 'Teil am Beckenrand außen begann und vor dem Trochanter sich in einen den Oberschenkel umfassenden Zirkulärschnitt teilte. Zucrst Unterbindung der Il. ext., dann Spaltung der Symphyse. -Erfolg: Tod einige Stunden nach der Operation an zunehmendem Kollaps. Bemerkungen: In den hinteren Lappen wurde der Muse glut. max. genommen und nach Entfernung des Beckens mit der Muskulatur der Bauch. wand vercinigt.

F a Il 70. Jos. Deilmann, Dissert. Halle I903. Alter: I I Jahre. - Trauma: Fall rücklings. - Metastasen: In beiden Inguinalbeugen zahlreiche harte Lymphdrüsen. - Zeit zwischen Trauma und Erkrankung: Durch den Fall entstand unterhalb des Kreuzbeins eine walnußgroße derbe Anschwellung. - Falsche Diagnose: Ein Arzt schnitt 4 mal in dic Geschwulst, wobei sich nur I3lut entleert haben soll. - Bemerkungen: Die Gegend der unteren IIälftc des Kreuzbeins zeigt eine ca. kindskopfgroße Geschwulst. 
Geschwulstmassen drängten sich gegen den Mastdarm vor. Analöffnung nicht zu sehen, I Jahr nach dem Fall bildete sich allmählich oberhalb des Gesäßes eine große Guschwulst, druckempfindlich. - Links reichte die Geschwulst bis nach vorn zur Mitte des horizontalen Schambeinastes, rechts beinahe bis zum Tub. pub., nach oben bis zum 2. Lendenwirbel.

F a 1 I 7 r wie 63. Alter: I I Jahre. - Trauma: Fall auf der Eisbahn auf dic rechte Gesälsseite. Sofort geringe Schmerzen. - Zeit zwischen Trauma und Lrkrankung: Nach $;$ Wochen setzen tagelang dauernde Schmerzen in der rechten Hüftgegend ein. Dann Schwellung in der rechten Leistengegend. Sark. diagn. 9 Mon. p. Tr. - Falsche Diagnose: Coxitis. Röntgenbild zeigte großen Tumor. - Bemerkungen: Schmerzen und Gehstörungen nehmen zu. Gehunfähigkeit.

I a 11 72. Jahresber. über die Fortschritte in der Chirurgie 1904. K e e n und a c Costa, Intem. clinics, vol. IV. Alter: ?. - Ausgangspunkt: Ilium. - Operation: Amputat. interilio-abdomin. - Erfolg: Tod 33 Stunden nach der Operation.

F a 11 73. Prof. Dr. Ricse, Deutsche med. Wochenschr. 1909. Alter: I 3 Jahre. - Vorausgegangene Knochenerkrankungen: Vater luetisch. Selbst als kleincs Kind Ceschwüre am ganzen Körper. - Ausgangspunkt: Röntgenbild: Vom Knochen ausgehender Tumor, der vorn bis zum Schambein ging und das Kreuz- und Steißbein zur Hälfte einnahm. Der Tumor mußte von der Beckenschaufel in der Gegend der Art. sacro-iliaca ausgegangen sein. Operation: Zucrst Bein nach Vorschrift Momburgs eingewickelt, dann Schlauch um den Bauch. Schnitt parallel dem Poup. Bande und der Crista il. bis zur Spin. post. inf. Ohne jeden Blutverlust vor sich gehende Ablösung der vom Becken ausgehenden Muskulatur, schwierige Trennung des Tumors vom Bauchfell, Abschicbung der lliac. Gefäbe und des $N$. fem. Eröffnung des Itüftgelenks, Durchschneidung der Kapsel und der Bänder, Abtrennung der vom Tub, oss. ischii entspringenden Muskeln, Isolierung des $N$. isch., Durchschneidung des Schambeins dicht neben der Symphyse und Durchmeißelung des Sacrums dicht neben den For. sacr. Heraushebung des Beckens. Tamponade der Knochenfläche des Sacrums. Naht, Entfernung der Schläuche. Extensionsverband. Gipshanfschiene. Kochsalzinfusion. Erfolg: Puls während der Operation 95 Schläge, nach der Operation 150. lieilung per primam. Nach der Opcration 8 Tage lang schwere Durchfälle, wahrscheinlich durch Storung im Bereich des Splanchnic-Gebictes infolge des I) ruckes von sciten des Schlauches, der fast 2 Stunden gelegen hatle. Der starke Fluor albus gleich nach der Operation hattc vielleicht diesclbe Ursache. - 5 Wochen post operationem Aufstehen; später Gehfähigkeit bei geringer Unterstüzung. Scheinbare Verkürzung des Beines durch dic Ifinaufschiebung am I'romont. beträgt $5 \mathrm{~cm}$. Femurkopf findet seinen Halt an der linken Scita des Promont. - Metastasen: Nicht nachweisbar. - Art des Sarkoms: Chondro-Chondroid-Osteoid-Sarkom. Das Wachstum des Tumors geht in doppelter Weise vor sich: Hauptsächlich außen in der periostalen Iage, indem hier das wuchernde Periost die fibrös knorpeligen Massen licfert; 
im Innern des Tumors nur ein beschränktes Wachstum; dieses geht hier von schleimig-knorpcligen Elementen aus, die relativ breite Mäntel um die Gefäße bilden. - Bemerkungen: Zuerst Schmerzen in der linken Hüfte, die in die Wade ausstrahiten; das Kind konnte später nicht mehr auftreten. Linke Beckenhälfte von einer vom Knochen nicht abgrenzbaren Geschwulst ausgefüllt, die breit in die Bauchhöhle hineinragte; druckempfindlich. Bewegungen im Hüftgelenk nach allen Richtungen cingeschränkt. Oberschenkel in Flexionskontraktur.

F a 11 74. Jahresbericht über die Fortschritte auf dem Gebiete der Geburtshilfe und Gynäkologie I907. Ray, Brit. med. journ. Alter: ?. Ausgangspunkt: Vorderscite des Kreuzbeins. - Operation: R a y arbeitete sich zwischen Anus und Steißbein in die Tiefe, um den Tumor zu entleeren. Starke Blutung. - Erfolg: 2 Stunden post operationem erneute Blutung und plötzlicher Verfall der Patientin. - Falsche Diagnose: R a y hielt es für eine Cyste oder für einen Abszeß. - Bemerkungen: Geburtshindernis. Zur Rettung des Kindes zunächst ein vergeblicher Zangenversuch; dann durch Wendung und Extraktion Geburt eines toten Kindes. Die schon vorher sehr elende Mutter starb.

F a 11 75. Berliner klin. Wochenschr. 1908, Nr. 20. Dr. Ko hs a k u N unokawa. Alter: 33 Jahre. - Ausgangspunkt: Os coxae sinistr., progrediens ad Os sacrum et vertebras lumbales inferiores (3). Die rechte Beckenhälfte zeigte nur sehr wenig Aftermasse im Bereich des rechten Darmbeins, reichlicher im Bereich des Scham- und Sitzbeins. - Periostal oder myelogen: Periostal. - Metastasen: Sarcoma secundarium ossium multiplex et Glandulae thyreoid. Cystitis suppurat. Decub. sacral., auch in den Lungen, und zwar fast ausschließlich in den Lungenarterien. - Art des Sarkoms: Teils rundliche, teils spindelige Zellen mit einem dichten, vielfach ganz homogenen Reticulum: Fibrosarkom mit Tendenz zur Verkalkung. - Gesamtzeit des Verlaufs: Etwas über 1/2 Jahr. - Bemerkungen: Vor 1/2 Jahr Schmerzen im linken Bein, nach 4 Wochen auch im rechten, später im Unterleib und in der Kreuzbeingegend. Fast vollständige Unempfindlichkeit für Nadelstiche in der Gegend um After und Scheide. Herabsetzung der Empfindung auf der Beugescite beider Ober- und Unterschenkel. Öfter unwillkürliche Urin- und Stuhlentleerung. - Sektion: In der Gegend des For. obt. sin. eine in das Becken vorspringende, ca. hühnereigroße Protuberanz. Linkes Hüftbein außen und innen eingenommen. Kompression des aus dem For. sacr. austretenden Nerven.

F a 11 76. Fischer, Münchn. med. Wochenschr. 1909, Nr. 37. Alter: 56 Jahre. - Metastasen: Multiple. - Art des Sarkoms: Rundzellensarkom mit Riesenzellen.

III. Geschlecht nicht angegeben.

F a ll I. Arch. f. klin. Chir. I869, Bd. Ir. Bill roth, H e inc. Alter: ?. - Ausgangspunkt: Beckenknochen. - Art des Sarkoms: Pulsierend.

Fall 2. Tillmanns, Deutsche Chirurgie 1905, Liefg. 62 a. G. 
Oppizzi. I870 (?). Alter: ?. - Ausgangspunkt: Darm- und Kreuzbein im Bercich der Art. sacro-iliaca und des Tuber ischii. - Operation: Unterbindung der Art. iliaca interna. - Art des Sarkoms: Pulsierend, gefäßreich. - Falsche Diagnose: Aneurysma.

Fall 3. Estlander, Virchow-Hirsch, Jahrg. 73, II. 1873. Alter: ?. - Trauma: Fall auf den Steiß (187I), nach welchem starker, brennender Schmerz zurückblieb und allmählich eine langsam zunehmende Anschwellung auftrat. - Ausgangspunkt: Vom Os sacrum ging cine Cystc aus und rom 4. und 5. Lendenwirbel ein Myxosarkom. - Art des Sarkons: Myxosarkom. -- Bemerkungen: Tod am 30. IX. I872 an interstitieller Nephritis.

F all 4. Deutsche Chirurgic 1905 . The Lancet 1874 . Guthric. Alter: ?.-- Ausgangspunkt: Beckenknochen. - Operation: Unterbindung der Art. iliaca commun., das Peritoneum wurde dabei an zwei Stellen verletzt. - Erfolg: Pulsation in der Geschwulst hörte auf und ihr Wachstum nahm temporär ab. Nach 6 Wochen wieder rapides Wachstum. Tod 7 Monate post operationem. — Art des Sarkoms: Pulsierend, gefäßreich, Gefäßgeräusche. - Falsche Diagnose: Ancurysma.

Fall 5. Deutsche Chirurgie 1905. The Lancet 1874. Porta. Ausgangspunkt: Beckenknochen. - Operation: Unterbindung der Art. hypogastrica. - Erfolg: 'Tod innerhalb 40 Stunden an Peritonitis. - Art des Sarkoms: Pulsierend, gefäßrcich, Gefäßgeräusche. - Falsche Diagnose: Glutäal-Ancurysma.

Fa 11 6. König, Lehrb. d. spez. Chir. I885. Alter: ?. - Ausgangspunkt: Darmbcinschaufel unterhalb des Musc. iliac. - Periostal oder myclogen: Periostal. - Art des Sarkoms: Rasch wachsend. - Falsche Diagnose: Es täuschte einen Echinococcus vor.

F a 117 wie 6. Alter: ?. - Trauma: Die Geschwulst war nach einem Fall auf das Darmbein gewachsen. -... Art des Sarkoms: Myeloidsarkom. -Falsche Diagnose: Entzündliche Geschwulst, welche zunaichst das ganze Darmbein als durch knöcherne Periostschwellung vergrößert erscheinen ließ3.

F all 8. Deutsche Zeitschr. f. Chir. I903, Bd. 7I. Jaboulay, Congr. de chirurg. I 808. Alter: ?. - Ausgangspunkt: Os ilium. - Operation: Exarticulatio interilio-abdom. mit prïventiver Ligatur der Art. iliaca commun. - Erfolg: Gangrän im Bercich der Art. iliaca int. und nach 5 Tagen Tod an Sepsis. - Art des Sarkoms: Osteosarkoma.

If a $11 \%$. Deutsche Chirurgie 1905, Liefg. 62 a. Tillmanns. Dewa n d re. Alter: ?. .... Ausgangspunkt: Becken. -- Periostal oder myelogen: Myelogen. - Art des Sarkoms: Gefäßreiches Myeloidsarkom.

\section{Eigener Fall.}

K. II. gynäkologische Klinik und gynäkologische Abtcilung des allgemeinen Krankenhauses 1. d. I. in München: Journal Nr. I64; Hauptb.-Nr. 3229. B., Vilitoria, 59 Jahre alt, Toilettenfrau, in München geboren und beheimatet, wurde am 2I. VII. I9I in die Klinik aufgenommen. 
An a mese: Mutter an Lungenleiden, Vater angeblich an Milzentzündung gestorben. 3 Brüder gestorben im Alter von 12, 18 und 21 Jahren an unbekannten Krankheiten, einer war angeblich ausgewachsen (Tuberkulose). 5 Schwangerschaften, 5 Geburten ohne Kunsthilfe. Wochenbetten fieberfrei. I Kind lebt, ist gesund; die anderen in frühen Jahren gestorben. Keine Fehlgeburt. Die I. Periode hatte Patientin mit 13 Jahren. Menopause besteht seit dem 53 . Lebensjahr.

Patientin war gesund bis vor $1 \frac{1 / 2}{2}$ Jahren. Damals stürzte sie, während sie etwas Schweres in den Händen hielt, mit der Unterbauchseite gegen eine Tischecke. 1/2 Jahr nach diesem Unfall trat eine kleine Geschwulst in der Gegend der linken Leistenbeuge auf. Die Geschwulst machte anfangs nur hier und da blitzartige Schmerzen von geringer Ausdehnung. Späterhin wuchs die Geschwulst sehr rasch, besonders in der letzten Zcit. Es stellten sich auch mehr Schmerzen und Bewegungsbehinderung am linken Bein ein. Seit dem Bestehen des Tumors magerte dic Kranke allmählich sehr stark ab. Paticntin war in Arbeit bis 20. VII. 19I I. Keine Urin- und Stublbeschwerden.

Status praesens: Mäßig kräftige, in ihrem Ernährungszustand deutlich reduzierte Frau; keine sichtbare Anämie, keinc deutliche Kachexic. Temperatur: $3^{8}$ Grad.

Motilität ungestört bis auf entsprechende Bewegungsbehinderung des linken Beines. Patellarreflex beiderseits gleich, keine Sensibilitätsstörungen. Lungengrenzen an normaler Stelle, verschieblich, überall Vesikuläratmen. Herzdämpfung nicht verbreitert, über dem linken Herzen systolisches Geräusch. Aktion regclmäßig, Puls etwas bcschlcunigt, mäßig kräftig. Brüste atrophisch, hängend, ohnc Sekretion.

In der linken Unterbauchgegend findet sich, noch in die linke Leistengegend sich erstreckend, eine die ganze Gegend vollständig einnehmende, weit hervorragende Geschwulst. Dieselbe sitzt der Gegend des linken Schambeines sehr fest auf. Die Haut ist darüber verschieblich. Die Venen des Unterhaut\%ellgewebes sind stark ektasicrt. An der oberen Peripherie der Geschwulst werden die Bauchclecken durch diese so hervorgewölbt, daß sie ganz steil, fast einen rechten Winkel mit der Umgebung bildend, aufsteigen. Bei der Palpation zeigt sich, daß dic Geschwulst, welche anscheinend den Bauchdecken angehört, sich auch in die rechte Unterbauchgegend erstreckt und hier und da mehr nach innen zu hineintagt. Über den in der rechten Bauchseite gelegenen Teilen der Geschwulst ist tympanitischer Schall nach. weisbar. I)ie Geschwulst zeigt teils solide Partien, teils solche, in denen prallelastische Fluktuation vorhanden ist. Der linke Musculus rectus fühlt sich stark gespannt an und geht in den Tumor über. Am linken Bein sind keine Zirkulationsstörungen nachzuweisen. Der Puls der Arteria femoralis ist unter dem Leistenbande deutlich fühlbar.

Vulva geschlossen; Damm erhalten; Portio klein, atrophisch, ganz frei bewcglich. Das Corpus uteri ist infolge Verhinderung an der bimanuellen Untersuchung durch den Tumor nicht zu fühlen. Nach der ausgedehnten Beweglichkeit der Portio ist jedoch ein Zusammenhang desselben mit der 
Geschwulst ausgeschlossen. Die Aclnexe sind nicht zu fühlen, die Parametrien sind frei.

Im Harn licin Eiwciß, kein Zucker. Herr Dr. Grashey (chirurg. Klinik) fertigte ein Röntgenbild an, auf dem jedoch wenig l)etails zu erkennen sind, da die mächtige Geschwulst einen starken Schatten gibt. Der obere Rand des linken oberen Schambeinastes ist unscharf.

I)iarium (vor der Operation): 22 . VII. Temp), morgens 36,3 Grad, abends 37,4 Grad. Rizinusöl. 23. VII. 36, I Grad; 37,6 Grad. Brustpulver. 24. VII. 3 5,3 Grad; 37,2 Grad. 25. VII. 36,4 Grad; 37,8 Grad. 26. VII 36,8 (irad; 37,3 Crad. Latwerge.

Operation (Prof. $A$ maru) am 27. VII. I9I : Chloroformäthemarkose. Querer Schnitt über die Geschwulst hinweg in der Höhe der Spinae iliacae. Auslösung der oberflächlichen Partien ohne besondere Schwierig. keiten. Iierbei reißen mehrere mit verändertem Blutfarbstoff gefülte cystische Partien des Tumors ein. Jei tieferem Vordringen zeigt sich, daß die Coschwulst mit dem Peritoneum parietale der vorderen Batuchwand breit verwachsen ist und hier mehrere in das Abdomen vorragende knollige, teils solide, teils $\mathrm{cy}$ stische Partien aufweist. Ferner besteht ein inniger Zusinmenhang mit der Blasenwand, welche bei dem Versuch der Loslösung breit einreibt. 1)ie lilase kinn nur mit einem fast kleinhandtellergroßen Defekt der Blasenwand am Fundus von der Geschwulst gelöst werden. Hierbei findet eine breite Eröfnung des Cavum Retzil. Jetzt zeigt sich, daß der Tumor seinen Ausgang won einer zirkumskripten Stclle des linken horizontalen Schambeinastes nimmt und auch noch mit der Fascia jleopectinea in innigem Zusammenhang steht. Die Ablösung ron der Fascie kann anscheinend im Gesunden erfolgen, dagegen zeigt sich bei der Ablösung rom Schambein, daB auch clas Knochenmark in IIaschußgröße von Tumorgewebe durcliset ist. Scharfe Abtragung der verdächtigen Knochen- und Knochenmarkspartien mit nachfolgender Verschorfung. IJann Naht der Blase in zwei Etagen mit Katgut, wobei die Schleimhat nicht mit grefaßt wird. Dic Blase ist dadurch in ihrem Breitendurchmesser stark verkleinert, kaum dagegen in ihrem Langsdurchmesser. Der grobe Peritonealdefekt läl3t sich nur bis auf Kleinhandtellergröße durch Katgutnähte verkleinern. In den Peritoncaldefekt wird Vetz cingelagert und am Rande durch Katgutnähte fixiert. Die Vereinigung der Muskulatur und der Fascien der vorderen Jauchwand kann nur in Ganz greringen Maße erfolgen, so daß die wiederangelegte IIaut dicht auf das Jeritoneum und das in die Peritonealwunde implanticrte Netz zu licgen kommt. Cazedrainage des Cavum Retzii und der Abtragungsstelle des Tumors. VerschluB der Bauchwunde durch Zwirnnähte bis auf die Drainagestelle. Daucrkatheter.

Diarium (nach der Operation!: 27. VII. Am Abend des Operationstages kollapsähnlicher Zustand. Kampfer subkutan. Zweimal Kochsalzinfusion von $11 / 2$ bzw. I l subkutan mit Coffein. 1/2 Spr. Norphium, + Spr. Kampfer. Temp. 36,3 Grad; 1'. 9o. 28. V'll. T'omp. 37,5 Gr.; 37,9 Gr. L'uls: 103; frinmeng(': 600 cem. 1/2 Spr. Morphium, 3 Spr. Kampfer. 29. Vil. 
Temp. 38 Gr.; 37,4 Gr.; P. I04; Urin $800 \mathrm{ccm}$. Einlauf. 30. VII. Temp. 37,3 Gr.; 36,8 Gr.; P. 100; Urin 1000 ccm. Einlauf. 3I. VII. Temp. 36,5 Gr.; 37,I Gr.; P. I02; Urin I000 ccm. Allgemeinzustand ordentlich, P. regelmäßig, kräftig. Appetit vorhanden. I'eritoneum frei. Darntätigkeit im Gange. Jeden Tag Verbandwechsel notwendig infolge starker wässeriger Durchtränkung der Verbandstoffe von der Verbandstelle her. Anscheinend seröse Durchtränkung aus den breiten Wundflächen, keine Urinbeimengung. Datuerkatheter liegt noch. I. VIII. Temp. 37.4 Gr.; 38 Gr.; P. I06; Urin $1600 \mathrm{ccm}$. Schmerzhafter Husten. Mixt. Ipccac.; Einlauf. 2. VIII. Temp. 37 Gr.; 37,6 Gr.; P. II6; Urin I $500 \mathrm{ccm}$. Mixt. Ipec. 3. VIII. Temp. 36,5 Gr.; 38, I Gr.; P. I Io; Urin I $600 \mathrm{ccm}$. 3mal Brustwickel; Mixt. Ipec. Einlauf. Der Verband zeigte ziemlich urinösen Geruch. Jodoformgazeverband und Drainage erneuert. 4. VIII. Temp. 36,I Gr.; 37,7 Gr.; P. II2; Urin I700 ccm. 5. VIII. Temp. 37,7 Gr.; 38, I Gr.; P. I20; Urin $1500 \mathrm{ccm}$. Einlauf. 6. VIII. Temp. 37 Gr.; 38,3 Gr.; P. II2; Urin I $700 \mathrm{ccm}$. Brustwickel und Mixt. Ipecac. von 4.-6. 7. VIII. Temp. 37,7 Gr.; 37,8 Gr.; P. Ioo; Urin $\mathrm{I} 600 \mathrm{ccm}$. Daucrkatheter wird entfernt. Einlauf. Trional und Veronal. 8. VIII. Temp. 37,8 Gr.; 38,4 Gr.; P. I I6. 9. VIII. Temp. 37,7 Gr.; 37,5 Gr.; P. 96. Jodoformgazeverband und Drainage erneuert. Dauerkatheter wieder eingelegt. Io. VIII. Temp. 37,3 Gr.; 37,9 Gr.; P. Ioo. I ccm Digalen; Bitterwasser. II. VIII. Temp. 36,8 Gr.; 38,4 Gr.; I ccm Digalen; Bitterwasser. I2. VIII. Temp. 37,3 Gr.; 37,4 Gr.; P. Ioo. Bei diesmaligem Verbandwechsel wird der Dauerkatheter fortgelassen. Es hat sich auf beiden Nates, besonders rechts, ein tiefgehender Decubitus ausgebildet, der mit Jodtinktur und Borvaseline behandelt wird. I $\mathrm{ccm}$ Digalen. I4. VIII. Temp. 36,5 Gr.; 36,8 Gr.; P. 96. Pat. steht seit heute etwas auf und geht mit Unterstützung im Zimmer herum. Außerdem bleilt sic eine Zeitlang außcrhalb des Bettes auf. Auf $1 / 2$ Stunde kommt sie in ein warmes Bad, worauf der Verband wie sonst erneuert wird. I8. VIII. Temp. 36,3 Gr.; 37, I Gr.; P. II2. Der Decubitus hat sich ziemlich gut gercinigt. Fin nekrotisches Stück im rechtseitigen Decubitus wird mit der Schere entfernt. Sonst wird die bisherige Bchandlung fortgesetzt. 2I. VIII. Temp. 36,6 Gr.; 36,8 Gr.; P. Ioo. Allgemeinbefinden den Unständen gemäß gut. Pat. bleibt einige Stunden des Tages auBer Bett, um den Decubitus zu entlasten. Letzterer wird weiterhin wie bisher behandelt. Brustpulver. 27. VIII. Temp. 36,9 Gr.; 36,6 Gr.; P. Ioo. Die Besserung dauert subjektiv und objektiv an. Der Decubitus ist in Ileilung begriffen und sieht gut granulierend aus. Appetit und Stuhlgang werden besser. Brustpulver. Eisen-Arsen. 3I. VIII. Temp. 36,6 Gr.; 37,3 Gr.; P. 107. Pat, klagt über Beschwerden nach dem Wasserlassen. Blasentee; Urotropin; Eisen-Arsen. 4. IX. Temp. 36,8 Gr.; 37, I Gr.; P. I03. Im Befinden der Pat. ist keine Andcrung cingetreten. In Urin ist kcin Eiwciß nachweisbar, im Sediment aber viele Leukocytcn, Kolibakterien und vereinzelte geschwänzte Epithelicn. Die Operationswunde ist noch nicht ganz geschlossen. Der Decubitus granuliert gut. Blasentee, Urotropin. EisenArsen. 12. IX. Temp. 36,6 Gr.; 36,9 Gr.; P. ıоo. Da die Pat. über Brennen 
beim Wasserlassen klagt, wird eine Blasenspülung gemacht. Jedoch empfindet die Pat. schon bei der Einführung des Katheters, der übrigens nur ca. 8- Io cm vorgeschoben werden kann, derartige Schmerzen, daß von dem Lingriff abgesehen wird. In dem Katheterurin vereinzelte Erythrocyten, viele Leukocyten, Kolibazillen und kubische Epithelien. Phenazonklysma; Morphium-Belladonna-Suppositorien. I9. IX. Temp. 36,9 Gr.; 37 Gr.; P. 96. Pat. klagt viel über Brennen beim Urinieren. Die Leibwunde ist noch immer nicht ganz geschlossen. Der Decubitus ist auf etwa $\mathbf{I}$ qcm reduziert, gut granulicrend. Seine Umgebung in etwa Handtcllergröße infiltriert. $16 . \mathrm{X}$. Temp. 36,8 Gr.; P. I03. Keine Beschwerden. Erhcbliche Gewichtszunahme. Leib in den linken unteren Partien etwas vorgewölbt. Keine Hernie. Opcrationswunde und Decubitus vollständig geheilt. Mit fester Bandage entlassen.

Am I3. III. I912, also ca. 5 Monate nach der Entlassung aus der chirurgischen Klinik in München, wurde die Pat. auf eigenes Verlangen wegen Rheumatismus in das Krankenhaus München-Schwabing aufgenommen.

Krankheitsgeschichte (Hauptbuch-Nr. I5II):

Anamnese: Seit 21. X. Schmerzen in beiden Schultergelenken, Ellenbogengelenken und Knic- und FuBgelenken; Ziehen in den Gliedern. Schmerzen im Kreuz. Appetit gut. Schlaf schlecht. Stuhlgang in Ordnung. Schmerzen an der Narbe. Pat. kann sich nicht bücken. Häufiges Wasserlassen.

St a tus pracsens: Mittelgroß, mittclkräftig gcbaut, mäßig gut ernährt, frisch aussehend. Schlcimhäutc blaß. Rachen: Tonsillen leicht gerötet und geschwollen. Hals o. B. Thorax: Brcit, gut gebaut, gut und gleichmäßis beweglich. Lungen: Grenzen normal, gut verschicblich; Schall hell, gleich; Atmung vesikulär. Herz: Grenzen normal; Töne rein. Abdomen: Stark vorgewölbt, derb. Suprasymphysär eine ca. $20 \mathrm{~cm}$ lange, schmale Narbe, darunter eine etwas längere, an einer Stclle tief eingezogene und hier noch leicht sezernierend. Über dem Kreuzbein unregelmäßige Narbe. In der Bauchdecke sowic in der Tiefe rechts einige Knoten von Walnußgröße. Leber und Milz nicht vergrößert nachweisbar. Extremitäten: Hebung beider Arme im Schultergelenk wird stark gchemmt, angeblich wegen Schmerzen. Schulterknochen sowie Oberarme druckempfindlich. Nervensystem: l'upillen glejch weit, rcagieren gut. Übrige Reflexc in Ordnung. Urin: Albumen in Spur vorhanden; kein Zucker. Im Scdiment Leukocyten. Temperatur normal.

16. III. Temp. 36,2 Gr.; 38,8 Gr. Übungstherapie. Pyramidon. 20. III. Temp. 36,9 Gr.; 37,2 Gr. Schmerzen im Nacken; Glicderschmerzen etwas geringer. Körpergewicht $57 \mathrm{~kg}$. Rheumasan. Glühlicht. Pyramidon. 23. III. Temp. 36,2 Gr.; 36, I Gr. Befinden im ganzen leidlich. Pat. ist den ganzen 'lag auf. Hebung der Arme unmöglich. Glüllichtkasten; Aspirin. 25. III. Temp. 36 Gr.; 38 Gr. Temperatursteigerung bei subjektivem Wohlbefinden. Lungen o. B. Abdomen: Gespannt, in der Nabelgegend leicht druckempfindlich. Gliblichtkasten; Aspirin. 27. III. Blutbefund; Hämoglobingelalt: 7o Proz.; Erythrocyten: 3200000 ; Leukocyten: 6000; polynukl. Leukocyten: 
54 Proz.; Lymphocyten: 38 Proz.; große mononukleäre Leukocyten: 5 Proz.: eosinophile Leukocyten: 3 Proz.; Körpergewicht: $57,9 \mathrm{~kg}$. 30. III. Temp). 36,6 Gr.; 37, I Gr. Immer starke Schmerzen in den Armen. Hebung der Arme stark gehemmt. Moorumschlag. 3I. III. Temp. 36,7 Gr.; 36,9 Gr. Körpergewicht: 58,4 kg. Pyramidon. 4. IV. Temp. 36,6 Gr.; 37,2 Gr. Röntgenphotographie der Schultergelenke: Kein Befund. Moorumschlag. 9. IV. Temp. 36,6 Gr.; 37,5 Gr. Körpergewicht: 58,9 kg. Stuhlgang stets in Ordnung. Lindenblütentee; Rheumasan; Pyramidon. I3. IV. Temp. 37,4 Gr.; 38,3 Gr. Körpergewicht: $59,4 \mathrm{~kg}$. Röntgenbestrahlung der Tumoren in der rechten Bauchseite. Unterhalb der Symphyse links derber, harter Tumor (Knochen?). 18. IV. Temp. 36,5 Gr.; 36,9 Gr. Nochmals Röntgenbestrahlung. Sternanistee. 25. IV. Temp. 37,6 Gr.; 39,3 Gr. Schmerzen in der rechten Bauchseite; keine wesentliche Allgemeinstörung. Gestern 20 Tropfen Morphium; heute Veronal. Rheumasan. Thermophor. 5. V. Temp. $3^{6,4}$ Gr.; 36,5 Gr. Körpergewicht: 58,9 kg. Sehr häufiges Wasserlassen; Urin 2800; spez. Gew. 1004. Polydypsie. Appetitlosigkeit; Fieber. Sehr vicle Schmerzen in der rechten Bauchseite. Die Tumoren sind etwas kleincr geworden. Lindenblütentee; Pyramidon. 20. V. Temp. 36,9 Gr.; 36,6 Gr. Körpergewicht: $58,7 \mathrm{~kg}$. Urin $2400-2900 \mathrm{ccm}$; spez. Gew. I004-ioo6. Keine Veränderung. Morphium. 2. VI. Temp. 36,6 Gr.; 37,6 Gr. Körpergewicht: 58,7 kg. Stuhl stets in Ordnung. Spitalantrag. 9. VII. Temp. 36,9 Gr.; 37,8 Gr. Körpergewicht: $59,6 \mathrm{~kg}$. Immer Fieber und Schmerzen. Abdomen sehr clerb, gespannt. Der 'Tumor unterhalb der Symphyse nimmt zu. Lungen o. B. 22. VII. Temp. 37 Gr.; 37,9 Gr. Körpergewicht: $60 \mathrm{~kg}$. Gewichtszunahme trotz Fiebers; Appetitlosigkeit. Lungen, Herz o. B. Stuhlgang in Ordnung. 24. VII. Ins Gasteigspital aufgenommen. Krankheit: Hauptdiagnose: Sarkomatose; Rheumatismus. Nebendiagnose: Anämie; Cystitis chronica (Cystis resecta). Auf ärztliche Veranlassung ungeheilt und arbeitsunfähig ins Gasteig. spital entlassen am 24. VII. I9I2. Weitere ärtliche Bchandlung wird noch benötigt.

Am 4. IX. I9I2, also nach etwas mehr als I Monat, wird die Pat. abermals auf eigenes Verlangen wegen Leibschmerzen in das Krankenhaus München-Schwabing aufgenommen.

Krankheitsgeschichte (Krankenhauptbuch-Nr. 4290):

Anamnese: cf. Krankengeschichte 15I//2. Pat. hat seit einigen Wochen das Spital verlassen. Sic kommt ins Krankenhaus, da sie sich sehr elend fühlt. Insbesondere sind die Schmerzen in der rechten Bauchseite andaucrnd, als ob ein Geschwür da sci, Toben und Stechen. Die Geschwulst am rechten Oberschenkel hindert bejm Gehen. Appetitlosigkeit; Müdigkeit; häufiges Wasserlassen.

B ef und: Die Kranke sieht sehr elend, blaß, abgemagert aus. Dic Tumoren in der rechten Bauchseite haben zugenommen; der derbe, mit der Symphyse im Zusammenhang stchende Tumor des linken Oberschenkels ist fast doppelt so groß wic beim Austritt der Pat. aus dem Krankenhaus. Lungen o. B. Herz: I. Ton unrein; Aktion regelmäBig. Keine Verbreiterung. 
Leber: Nicht vergrößert nachweisbar. Temperatur bis 38 Grad. Urin: Eiweißhaltig. Im Sediment: Leukocyten; keine Zylinder. I'olyurie: $3000 \mathrm{ccm}$; spez. Gew. nieder. Therapie: Morphiumtropfen; Wärme; Inf. Sennae. 12. IX. Temp. 36,I Gr.; 38 Gr. Morphium; Natr. bic.; Einlauf. I7. IX. Temp. 36,1 Gr.; 37 Gr. Körpergew. $56,5 \mathrm{~kg}$. Morphium; Vinum Condurango. 2. X. Temp. 36,3 Gr.; 36,6 Gr. Körpergew. 57,3 kg. Vinum Condurango; Sternanistec. 20. X. Temp. 36,4 Gr.; 36,5 Gr. Körpergew. $53 \mathrm{~kg}$. Immer Brechneigung. Alypintropfen helfen leidlich. Es wurde bis jetzt stets Morphium gercicht, ebenso Vinum Condur.; Coc. hydrochl. 25. X. Temp. $3^{6,3}$ Gr.; 36,5 Gr. Immer zunehmende Kachexic. 2. XI. Exitus. Krankheit: Hauptdiagnose: Sarkomatose; Nebendiagnose: Anämie; Cystitis chronica.

Sektionsbericht: B., Victoria, Stcinmetzwitwc, 60 Jahre alt. Zcit der Sektion: 3. XI. I9I2 (Dr. B org greve).

Kleine, senile, weibliche Leiche in mäßigem Ernährungszustande. Totenstarre vorhanden. In der linken Regio inguinalis findet sich ein derber, halb. faustgroßer, nicht beweglicher Tumor unter der Haut; ferner dicht oberhalb der Symphyse füllt man einen harten, apfelgroßen, etwas beweglichen Tumor unter den Bauchdecken. Schmale, querverlaufende Narbe oberhalb der Symphyse.

I. Allgremeine Besichtigung der Körperhöhlen: Subkutanes I'ett goldgelb, gut entwickelt; Muskulatur von rotbratuner Farbe, etwas trocken.

Bei Eröffnung des Abdomens zeigen sich zahlreiche Verwachsungen des großen Netzes mit der Bauchwand und in unteren Teil eine Verwachsung der zuletzt beschriebenen Tumormassen mit aler Bauchelecke. Das Peritoneum ist reichlich schwarz pigmentiert. Das kleine Becken ist zienlich ausgefüllt von cincr kindskopfgroßen, derben Tumormasse, der rechts hinten der weiche Vterus aufgelagert ist; links hinten sind dic linken Adnexe aufgelagert, während die rechten Adnexe nach hinten geschlagen sind und der scitlichen Bauchwand anliegen. Das Cöcum hat cin etwa $15 \mathrm{~cm}$ langes Mesenterium und ist frei beweglich. Die $\Lambda$ ppendix ist $10 \mathrm{~cm}$ lang, ist durchgängig und mit der hinteren Cöcumwand verwachsen. In den in einen schmalen Spalt verwandelten Douglas kann man mit der Hand kaum cindringen. Beim Ablösen der Haut in der linken Inguinalgegend stöBt man auf derbe, knotige Tumormassen, die sich bis handbreit unterhalb des l'oupartschen Bandes erstrecken und a. d. S. teils zienlich homogen weißlich, teils bräunlich verfärbt sind. Rippenknorpel sind teilweise verknöchert. Die linke Lunge ist frei, in der Pleurahöhle 2 EBlöfel klarer, seröser Flüssigkeit. Die rechte Lunge ist an der Spitze spangenförmig verwachsen. Pleurahöhle leer. Der Herzbeutel licgt in Halbhandtellergröße vor, ist sehr fettreich und enthält einige Tropfen seroser Flüssigkeit. Zwerchfellstand entspricht rechts wie links dem oberen Rand der 5. Rippe.

II. Organe der Bauchoöhle: Milz 9:3:4, hat eine glatte Kapsel. A. d. S. ist das Organ von rotbrauner Farbc, Pulpa etwas abstreifbar, Follikel deutlich crkennbar, trabckuläres Gerüst und Konsistenz etwas vermehrt. Bei Herausnahme des Dünndarms finclen sich stellenweise leichte Verwachsungen, 
die im ganzen lösbar sind. Ductus choledochus ist durchgängig. Die Leber ist von normaler Größe, mit glatter glänzender Oberfläche. A. d. S. ist das Organ von rotbrauner Farbe, die Zeichnung ist deutlich. Blutgehalt normal, Konsistenz nicht vermehrt. Die Gallenblase enthält schwärzliche, fadenziehende Galle; Schleimhaut ist intakt. Mesenterium sehr fettreich. Drüsen und Gefäße sind unverändert. Der Magen enthält bräunliche Flüssigkeit, ist von mittlerer Größe. In der Fundusgegend finden sich zahlrciche kleinste Blutaustritte. Schleimhaut ist im ganzen von graugrüner Farbe, ohne Narben oder Substanzverluste. Pankreas ist von normaler Größe, a. d. S. blaßbraun, von normaler Läppchenzeichnung. Dic Genitalien lassen sich zusammen mit dem kindskopfgroßen Tumor Ieicht aus dem kleinen Becken herausschälen. Der Tumor ist im ganzen glatt auf seiner Oberfläche, auf der Rückseite von Peritoneum überzogen. Nebennieren beiderseits etwas kleiner wie gewöhnlich, Mark schmal, Rinde gelb, schmal. Ureteren sind links doppelt, sehr stark erweitert und im Bogen von links nach rechts hinter den Tumor verzogen. Der rechte Ureter ist ebenfalls erweitert. Linke Niere mit reichlicher Fettkapsel, Fibrosa abziehbar, Oberfläche glatt, von graugelber Farbe. Beim Aufschneiden quillt aus dem stark erweiterten Nierenbecken, dessen Schleimhaut injiziert ist, grauweise trübe Flüssigkeit. Die Rinde quillt etwas über, Markkegel sind stark abgeflacht und sind von trüber, graugelber Farbe. An zahlreichen Stellen finden sich grauweiße Knötchen. Die Zeichnung ist nicht mehr erkennbar. Die rechte Niere hat ebenfalls stark entwickelte Fettkapsel, Fibrosa abzichbar. Die Niere hat glatte Oberfläche. A. d. S. ist die Rinde von graugelber Farbe, Markkegel rötlich, abgeflacht; Nierenbecken über hühnereigroß, abgeflacht, stark injiziert.

III. Organe der Brusthöhle: Das Herz ist fast so groß als die Leichenfaust, rechter Ventrikel ist schlaff, von normaler Weitc und Dicke der Wandung. Muskelfettgrenze ist deutlich. Klappenapparat des rechten Herzens intakt. Foramen ovale ist geschlossen. Linker Ventrikel von normaler Weite und Dicke der Wandung. Klappenapparat intakt. Aorta zeigt geringe gelbliche Fleckung. Coronarien o. B. Linke Lunge: Pleura überall glatt und glänzend. Das Organ ist überall gut saft- und lufthaltig. Der Blutgehalt ist im Unterlappen vermehrt. Die rechte Junge zeigt dasselbe Bild wie die linke, nur findet sich hier an der Spitze eine markstückgroße Verdickung der Pleura.

Aus dem kleinen Becken läßt sich leicht ein über kindskopfgroßer Tumor mit Blase und Genitalien herausschälen, er ist nur am Beckenboden fest verwachsen. Rechts oben vorn sitzt die Blase auf, die nach Eröffnung eine intakte, lcicht gerötete Schleimhaut vorblicken läßt, die in der Mitte der verwachsenen Fläche durch einen markstückgroßen Knoten etwas vorgewölbt wird. Die beiden linken Ureteren münden vorn unten nebeneinander, von einer Schleimhautfalte halbmondförmig etwas gedeckt, ein, nachdem sie den ganzen Tumor von hinten umzogen haben. Ca. $\mathrm{I}_{1 / 2} \mathrm{~cm}$ davon entfernt mündet der rechte Ureter in den freien Teil der Blasenwand ein. Alle Öffnungen sind gut sondierbar. Von ciner Operationsnarbe ist an der Blase nichts mehr zu erkennen, ilıre Weite entspricht der Größe einer Faust. 
Körperlänge: I6I; Körpergewicht: $44 \mathrm{~kg}$; linke Lunge: 400; Herz: 250; Leber: I 130 ; rechte Lunge: 410; linke Nicre: I 40; Milz: 100.

An a t om is che Diagn os c: Intraligamentäres Lipom (Liposarkom?); Metastasen in beiden inguinalen Lymphdrüsengruppen, be sonders links (gemischtes Sarkom). Pyelonephritis und Pyonephrose beiderseits mit multiplen AbszeBchen in der linken Nicre. Doppelter Ureter links. Coecum mobile.

Makroskopische Beschreibung des bei der Operation gewonnenen Tumors: Nahezu mannskopfgroße Geschwulst mit äußerst unregclmäßiger Oberfläche. Große Knollen wechseln mit kleinen und kleinsten Höckern ab. Nach Farbe, Konsistenz und Oberflächenbeschaffenheit kann man sofort zwei ganz verschiedene Teile an dem Tumor erkennen. Die eine Partie, mehr in der Peripherie in Form von großen Knollen, ist hellgelb gefärbt, derb, auf der Oberfläche vollkommen glatt, während der übrige, mehr die Mitte einnehmende Teil der Geschwulst im allgemeinen kleinere Höcker zeigt, dunkler, weicher und auf der rauhen Oberfläche vielfach mit kleinen, bis erbsengroßen Knötchen besetzt ist. Manche Stellen sind hier nahezu schwarz verfärbt durch Resicluen von Blutungen.

Auf dem Schnitt erkennt man cbenfalls schon makroskopisch dic zwei ganz verschiedenen Bestandteile: Der cine ist glatt, mehr homogen, glänzend, von derbelastischer, leimähnlicher Konsistenz und gelatinöscm Aussehen, während der andere Teil dunkler, weicher und mehr faserig ist. Auch hier finden sich die crwähnten, fast schwarz tingierten Partien.

Der mikroskopische Befund ergibt entsprechend dem makroskopischen Verhalten der Geschwulst zwei verschiedene Gewebsarten: Der eine auf dem Schnitt gelatinös ausschende Teil erweist sich als reines Sarkom, der übrige Teil dagegen als Liposarkom.

Es handelt sich demnach bei diesem Fall um ein fast mannskopf. großes gemischtes Sarkom (Liposarkom), das sich bei einer 59jährigen Patientin, die fünfmal geboren hatte, im Laufe cines halben Jahres im Anschluß an einen StoB entwickelt hat und, wie die Operation zcigte, vom linken horizontalen Schambeinast, und zwar wahrscheinlich vom Knochenmark ausging. Nicht ganz acht Monate nach der Operation wurde ein Rezidiv diagnostiziert und etwa $\mathrm{I}^{1 / 4}$ Jahr nach derselben starb die Patientin nach einem Gesamtverlauf von etwa $21 / 4$ Jahren.

Eine sichere Diagnose war vor der Operation sehr schwer zu stellen; man dachte vor allem an einen Bauchdeckentumor wegen der sonst für derartige Geschwülste charakteristischen Konfiguration der Bauchdecken, indem diese besonders an der oberen Peripherie der Geschwulst nahezu eine Einsenkung bildeten, um sich dann ganz steil über den Tumor emporzuwölben. Auch hielt man es für möglich, daß dic Geschwulst rom runden Mutterband ausging. 
Intcressant ist auch noch der Erfolg der Röntgenbestrahlung beim Rezidiv. Nach zweimaliger Bestrahlung wurden die Tumoren kleiner, fingen aber, als die Bestrahlung abgebrochen wurde, sofort wieder an zu wachsen.

Zum Schlusse meiner Arbeit erfülle ich eine angenehme Pflicht, wenn ich Herrn Geh. Hofrat Prof. Dr. Döderlein für die gütige Übernahme des Referates, Herrn Prof. Dr. Amann für die Überlassung der Arbeit und Herrn Dr. Hans Albrecht für die freundliche Unterstützung meinen besten Dank ausspreche.

\section{Literaturübersicht.}

I. Ascoli u. Izar, Die Serodiagnose bösartiger Geschwülste mittels der Meiostagminreaktion. Münchn. med. Wochenschr. 1910, Nr. 22.

2. B ergmann u. B runs. Handb. d. prakt. Chir.

3. Borst, Die Lehre von den Geschwülsten.

4. B ra unstein, Über Beckengeschwülste. Inaug.-Diss. Bonn I888.

5. C a a n, Uber Radiumbehandlung bösartiger Geschwülste. Münchn. med. Wochenschr. 1909, Nr. 42.

6. Czerny, Über sacrale Tumoren. Kongreßbericht. Beilage z. Zentralblatt f. Chir. 1893 , Nr. 30.

7. - Rede zur Eröffnung der II. internationalen Konferenz für Krebsforschung in Paris. Münchn. med. Wochenschr. I910, Nr. 44.

8. Deilmann, Uber den Zusammenhang von Sarkom und Trauma. Inaug.-Diss. Halle I903.

9. Deininger, Ein Beitrag zur Exstirpation von Beckengeschwülsten. Inaug.-Diss. Würzburg 1893 .

1o. Dorn, Über einen Fall von Fibrosarcoma ossis ilei mit Resektion des Darmbeins. Inaug.-Diss. Würzburg 1894.

II. Erken, Über Beckensarkome. Inaug.-Diss. München 1894 .

I2. Freimadl, über Beckensarkome. Inaug.-Diss. München 1894.

I3. Gastpar, Dic malignen Tumoren des Beckens. Inaug.-Diss. München I 896.

I4. Godert, Von den Beckenknochen ausgehende Tumoren als Geburtshindernis. Inaug.-Diss. Halle 1895 .

15. G otts chick, Ein Beckensarkom von ungewöhnlicher Größe. Inaug.Diss. Tübingen rgo6.

I6. Cr ü $1 \mathrm{dner}$, Über primäre Beckenknochensarkome. Inaug.-Diss. Rostock 1895 .

17. H enrici, Über Beckensarkome. Inaug.-Diss. München 1897.

18. Jahresbericht über die Fortschritte in der Chirurgie: 1902; 1904; 1907; I908; I910; je II. Abteilung.

19. Kaß।er, Beckengeschwülste und Echinokokken der Beckenknochen. Inaug.-Diss. Jena 1902. 
20. Ka $u f m a n n$. Lehrb. d. pathol. Anat.

21. Kocher, Chirurgische Operationslehre.

22. König. Lehrb. cł. spez. Chir.

23. Krüger, lber clas Sarkom der Darmbcinschaufel. Inaug.-Diss. Greifswald 1903 .

24. L es er, Spezielle Chirurgic.

25. L. ex e r. Lehrb. d. allgem. Chir.

26. Lö wenstein, Ier ätiologische Zusammenhang zwischen Trauma und Sarkom. Beitr. z. klin. Chir. 1906, H. 3 .

27. Machol, Die Entstehung von Geschwülsten im AnschluB an Verletzungen. Inaug.-I)iss. Straßburg I9oo.

28. Ma d elung, Über intraperitoneale Digitalkompression von Beckenblutgefäßen. Deutsche Zeitschr. f. Chir. I903, Bd. 7I, Bd. I u. 2.

2). M e r, Dystokic bei Beckentumoren. Inaug.-Diss. München 1909.

30. Micheli u. Cattoretti, Die Meiostagminreaktion bei bösartigen Geschwülsten. Münchn. med. Wochenschr. I9ro, Nr. 2 I.

31. M üller, I)ie Röntgenstrahlen im Dienste der Therapie. Münchn. med. Wochenschr. I909, Nr. 5.

32. $\mathrm{N}$ a batian $z$, Sarkom des Os sacrum. Inaug.-Diss. Berlin Igro.

33. N i e rle, I)rei Fälle von Sarkom des Darmbeins. Inaug.-Diss. München I 889 .

34. Nunokawa, Periustales Fibrosarkom des linken Hütbeins mit fast ausschließlicher Metastasierung im Knochensystem. Berliner klin. Wochenschrift 1908, Nr. 20.

35. Perrenon, Uber ein myclogenes Sarkom des Beckens von enormem Umfang. Inaug.-Diss. München 1898.

36. Plosser, Cber einen Fall von Osteochondrosarkom des Darmbeins. Inaug.-Diss. Kiel.

37. Reckermann. Inaug.-Diss. Würaburg 1885 .

38. Ribbert, Geschwulstlehre.

39. Ricse, Beckenrescktion wegen Sarkom. Deutsche med. Wochenschr. 1909, Nr. 49.

40. Schmaus, Grundriß der pathologischen Anatomie.

4r. Schmidts Jahrbücher, verschicdene Bände.

42. Schneider, Uber einen Fall von myelogenem Sarkom der oberen Tibiacpiphyse. Inaug.-Diss. Kiel 1905.

43. S chnitzler, Uber einen Fall von Sarkom der Kreuzsteißbeingegend. Inaug.-Diss. München 1900.

44. Tegeler, Ein Fall von Sarkom des Os sacrum. Inaug.-Diss. Greifswald 1897 .

45. Till ma nns. Deutsche Chirurgie 1905, Liefg. $62 \mathrm{a}$.

46. -... Spez. Chirurgie.

47. Verebélly, Über das Myclom. Beitr. z. klin. Chir. I906, H. 3 . 
304 SchmidSEDER, Über primäre Beckenknochensarkome usw.

48. Weiß, Uber cinen Fall von Myclom des Darmbeins mit Metastasenbildung. Inaug.-Diss. München 1905.

49. Werner u. Caan, Über die Wirkung von Röntgenstrahlen auf Geschwülste. Münchn. med. Wochenschr. 1910.

50. Zeller, Zur Exstirpation der Beckengeschwülste. Deutsche Zeitschr. f. Chir. 1904, Bd. 7I, H. 5-6.

5 I. Zi egler. Allgemeine und spezielle pathologische Anatomie.

Siehe ferner meine Zusammenstellung. 